\title{
Development of a Hydrodynamic Model of Puget Sound and Northwest Straits
}

Z Yang TP Khangaonkar

December 2007 


\title{
DISCLAIMER
}

This report was prepared as an account of work sponsored by an agency of the United States Government. Neither the United States Government nor any agency thereof, nor Battelle Memorial Institute, nor any of their employees, makes any warranty, express or implied, or assumes any legal liability or responsibility for the accuracy, completeness, or usefulness of any information, apparatus, product, or process disclosed, or represents that its use would not infringe privately owned rights. Reference herein to any specific commercial product, process, or service by trade name, trademark, manufacturer, or otherwise does not necessarily constitute or imply its endorsement, recommendation, or favoring by the United States Government or any agency thereof, or Battelle Memorial Institute. The views and opinions of authors expressed herein do not necessarily state or reflect those of the United States Government or any agency thereof.

\author{
PACIFIC NORTHWEST NATIONAL LABORATORY \\ operated by \\ BATTELLE \\ for the \\ UNITED STATES DEPARTMENT OF ENERGY \\ under Contract DE-AC05-76RL01830
}

Printed in the United States of America
Available to DOE and DOE contractors from the Office of Scientific and Technical Information,
P.O. Box 62, Oak Ridge, TN 37831-0062;
ph: (865) 576-8401
fax: $(865)$ 576-5728
email: reports@adonis.osti.gov

\begin{abstract}
Available to the public from the National Technical Information Service, U.S. Department of Commerce, 5285 Port Royal Rd., Springfield, VA 22161 ph: (800) 553-6847 fax: $(703) 605-6900$ email: orders@ntis.fedworld.gov online ordering: http://www.ntis.gov/ordering.htm
\end{abstract}

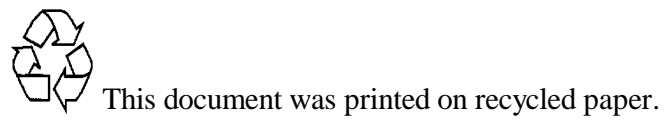




\title{
Development of a Hydrodynamic Model of Puget Sound and Northwest Straits
}

\author{
Zhaoqing Yang \\ Tarang Khangaonkar
}

December 2007

\author{
Prepared for \\ Northwest Straits Commission \\ Mt. Vernon, Washington
}

Battelle_Pacific Northwest Division

Richland, Washington 99352 


\section{Executive Summary}

The nearshore habitat in Puget Sound has been impacted due to human development. The loss of estuarine functions such as movement and mixing of salt and freshwater, and loss of sediment and nutrient supply, have degraded the tidal marshland habitat and affected salmon populations. Restoration efforts currently underway around Puget Sound focus on recovering fundamental nearshore processes such as tidal hydrodynamics, estuarine processes, and the restoration of tidal channels that provide fish access. Accurate simulation of hydrodynamics in Puget Sound including coastal circulation and transport in the nearshore areas has become an essential requirement for many projects in connection with coastal restoration and improvements to tidal marshland habitat and salmon migration.

The Marine Sciences Laboratory of Pacific Northwest National Laboratory (PNNL) has developed three-dimensional (3-D) hydrodynamic models for several estuaries and coastal basins in Puget Sound to support restoration projects, and has initiated a model development effort for the entire Puget Sound. The Northwest Straits Marine Conservation Initiative, authorized by Congress and guided by the Northwest Straits Citizen Advisory Commission (NWSC), is nationally recognized as an innovation that brings sound science and an ecosystem perspective together through the actions of seven marine resources committees. To support PNNL's effort of model development for Puget Sound and the straits, NWSC funded PNNL for the model validation and application components of the study. This report summarizes the development, validation, and application of the Puget Sound hydrodynamic model.

The hydrodynamic model used in this study is the Finite Volume Coastal Ocean Model (FVCOM) developed by the University of Massachusetts at Dartmouth. The unstructured grid and finite volume framework, as well as the capability of wetting/drying simulation and baroclinic simulation, makes FVCOM a good fit to the modeling needs for nearshore restoration in Puget Sound. The model domain covers the entire Puget Sound, Strait of Juan de Fuca, San Juan Passages, and Georgia Strait at the United States-Canada Border. The model is driven by tide, freshwater discharge, and surface wind. Preliminary model validation was conducted for tides at various locations in the straits and Puget Sound using National Oceanic and Atmospheric Administration (NOAA) tide data. The hydrodynamic model was successfully linked to the NOAA oil spill model General NOAA Operational Modeling Environment model (GNOME) to predict particle trajectories at various locations in Puget Sound. Model results demonstrated that the Puget Sound GNOME model is a useful tool to obtain first-hand information for emergency response such as oil spill and fish migration pathways. The modeling effort completed to date and model results are summarized below:

- A nearshore high-resolution 3-D hydrodynamic model was developed to simulate circulations driven by tides, winds, and density gradients in the entire Puget Sound, Strait of Juan de Fuca, San Juan Islands, and Southern Georgia Strait.

- Preliminary model validation showed that the tidal prediction matched the NOAA tide data well at various locations in the straits and Puget Sound.

- The model reproduced tidal characteristics such as phase difference, amplitude amplification, diurnal inequality, and Coriolis effect reasonably well in the entire model domain. 
- The model was able to simulate freshwater plume dispersion and transport in many estuaries and bays in Puget Sound and the straits.

- The model was successfully linked to the NOAA oil spill model GNOME for particle trajectory simulations. GNOME was applied to simulate particle trajectories in six selected locations in Puget Sound and the straits.

While the Puget Sound model was successfully developed, and preliminary model validation has been conducted, considerable effort is still needed before the model can achieve operational status and forecasting capabilities. Further improvement of the model is necessary in several areas and is being pursued as part of ongoing PNNL Puget Sound model development efforts. Specific model limitation and improvements are listed below:

- Further calibration/validation of the model is necessary at every estuary, bay and sub-basin and will be conducted as part of future site-specific studies and as sufficient measured data become available.

- In the current model setup, the northern model open boundary was specified along the United States-Canada border, and the Fraser River was not considered due to the lack of bathymetry data on the Canada side. To simulate the effect of Fraser River on Puget Sound, it is important to include the Fraser River and extend the model domain to the entire Georgia Strait.

- Wind may play an important role in circulation in some shallow water regions in Puget Sound. Spatial uniform wind stress was applied in the current model configuration. To simulate wind effect accurately, spatial varied wind force should be considered, either based on multiple meteorological observation stations around Puget Sound or on predicted wind field from the meteorological model.

- The entire model domain covering the Strait of Juan de Fuca, Puget Sound, and Georgia Strait is generally considered as a large complex estuarine system. Initial conditions of salinity and temperature fields are important for accurate simulation of long-term subtidal circulations in Puget Sound. Initial conditions can be improved based on climatology data. 


\section{Acronyms}

$\begin{array}{ll}\text { 2-D } & \text { Two-dimensional } \\ \text { 3-D } & \text { Three-dimensional } \\ \text { DEM } & \text { Digital Elevation Model } \\ \text { FVCOM } & \text { Finite Volume Coastal Ocean Model } \\ \text { LIDAR } & \text { light detection and ranging } \\ \text { NAD } & \text { North American Datum } \\ \text { NAVD 88 } & \text { North American Vertical Datum of 1988 } \\ \text { NOAA } & \text { National Oceanic and Atmospheric Administration } \\ \text { NWSC } & \text { Northwest Straits Citizen Advisory Commission } \\ \text { USGS } & \text { United States Geological Survey } \\ \text { UW } & \text { University of Washington }\end{array}$





\section{Contents}

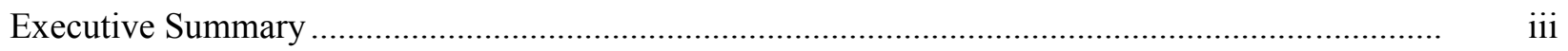

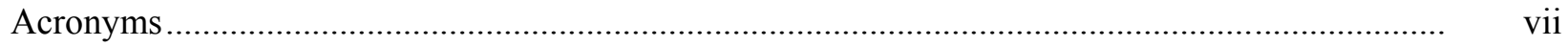

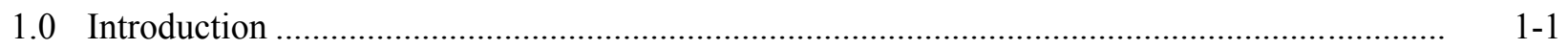

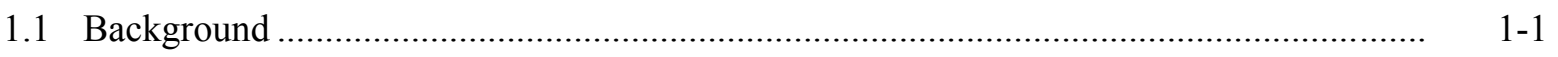

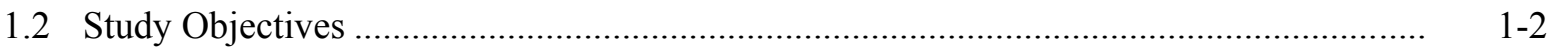

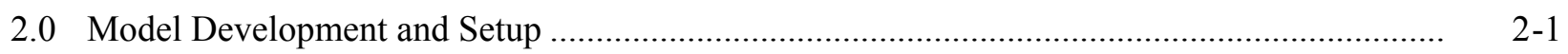

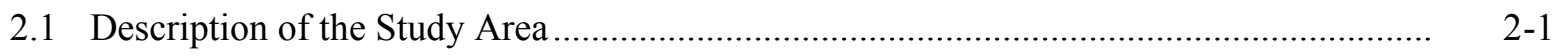

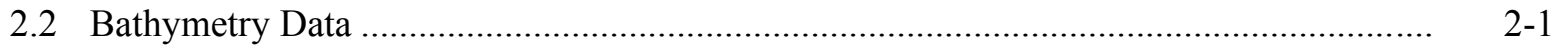

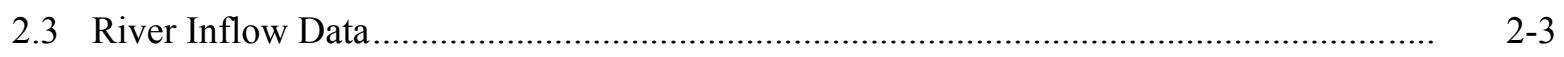

2.4 Tide Data and Wind Data.................................................................................... $2-15$

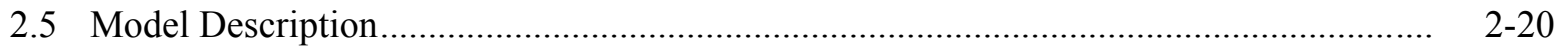

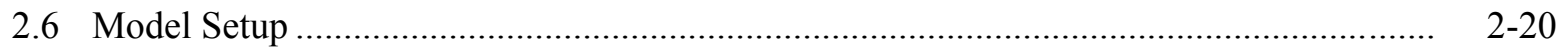

2.6.1 Model Grid .......................................................................................... $2-20$

2.6.2 Model Boundary Conditions …........................................................................... 2-20

3.0 Validation of Hydrodynamic Model of Puget Sound ............................................................ $3-1$

4.0 Model Application for Water Movement in the Straits .......................................................

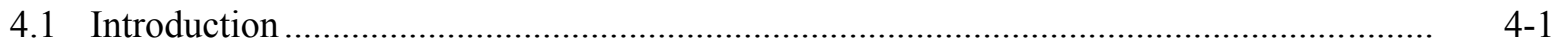

4.2 Model Application -Simulations of Particle Trajectories Using GNOME ....................... 4-1

4.2.1 Particle Trajectory Simulation in Puget Sound .................................................. 4 4-1

4.2.2 Particle Trajectory Simulation in Northwest Straits............................................... 4-9

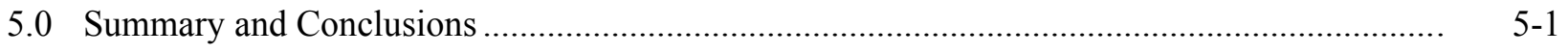

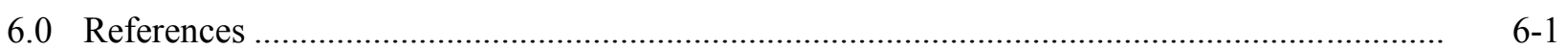




\section{Figures}

2-1 Oceanographic Regions of Puget Sound and Its Adjacent Waters ........................................ 2-2

2-2a Puget Sound DEM Bathymetry Data............................................................................... 2-4

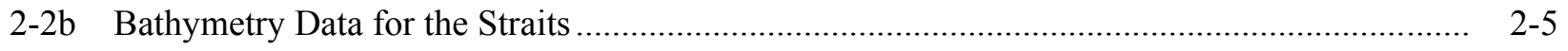

2-3 LIDAR Bathymetry Data in Skagit Bay ....................................................................... 2-6

2-4 LIDAR Bathymetry Data in Port Susan .............................................................................. 2-7

2-5 LIDAR Bathymetry Data in Snohomish River................................................................ 2-8

2-6 LIDAR Bathymetry Data in Nisqually River ................................................................ 2-9

2-7 LIDAR Bathymetry Data Skokomish River...................................................................... 2-10

2-8 LIDAR Bathymetry Data in Bellingham Bay and Lummi Bay............................................ 2-11

2-9 Skagit River Cross-Section Data .............................................................................. 2-12

2-10 Snohomish River Cross-Section Data …........................................................................ 2-13

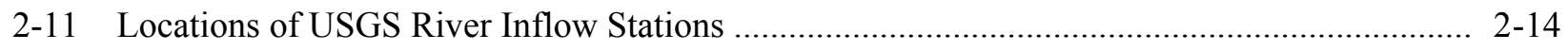

2-12 River Inflows in Whidbey Basin, North Sound, and Strait of Juan de Fuca .......................... 2-16

2-13 Tide Stations for Model Open Boundary Condition and Validation ....................................... 2-17

2-14 Predicted Tides at Model Open Boundaries ........................................................................ 2-18

2-15 Measured Wind Data at Paine Field, WA ....................................................................... 2-19

2-16 Hydrodynamic Model Grid of Puget Sound ........................................................................ 2-21

2-17 Model Grid of Southern Puget Sound …...................................................................... 2-22

2-18 Model Grid of Central Basin ....................................................................................... 2-23

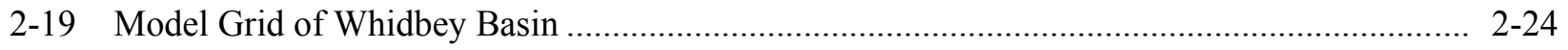

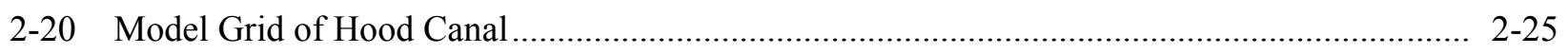

2-21 Model Grid of San Juan Passages and North Sound ........................................................ 2-26

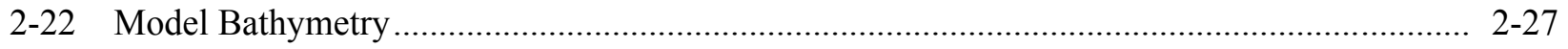

3-1 Model Validations for Water Surface Elevations in Puget Sound......................................... 3-2

3-2 Model Validation for Velocity in Strait of Juan de Fuca.................................................... 3-3

3-3a Water Surface Elevation at High Tide .............................................................................. $3-4$

3-3b Water Surface Elevation at Low Tide ........................................................................... $3-5$

3-4a Surface Velocity Magnitude during Flood Tide .................................................................... 3-6

3-4b Surface Velocity Magnitude during Ebb Tide ...................................................................... 3-7

3-5a Surface Velocity Vectors in San Juan Passages during Flood Tide ........................................ 3-8

3-5b Surface Velocity Vectors in San Juan Passages during Ebb Tide ........................................... 3-9

3-6a Surface Velocity Vectors in Southern Puget Sound during Flood Tide ................................... 3-10

3-6b Surface Velocity Vectors in Southern Puget Sound during Ebb Tide..................................... 3-11

3-7a Surface Salinity Distribution in Whidbey Basin during High Tide ........................................ 3-13

3-7b Surface Salinity Distribution in Whidbey Basin during Low Tide ........................................ 3-14 
3-8a Surface Salinity Distribution in North Sound during High Tide .......................................... 3-15

3-8b Surface Salinity Distribution in North Sound during Low Tide......................................... 3-16

4-1 GNOME for Puget Sound........................................................................................ 4-2

4-2 Particle Trajectories after 4 Hours of Initial Release in Hood Canal, Elliott Bay, and

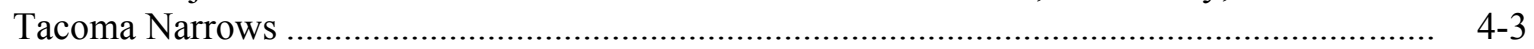

4-3 Particle Trajectories after 8 Hours of Initial Release in Hood Canal, Elliott Bay, and

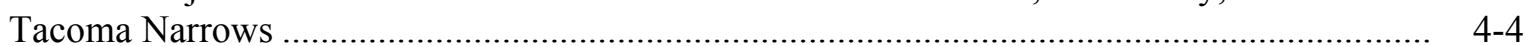

4-4 Particle Trajectories after 12 Hours of Initial Release in Hood Canal, Elliott Bay, and Tacoma Narrows

4-5 Particle Trajectories after 16 Hours of Initial Release in Hood Canal, Elliott Bay, and Tacoma Narrows

4-6 Particle Trajectories after 20 Hours of Initial Release in Hood Canal, Elliott Bay, and Tacoma Narrows

4-7 Particle Trajectories after 24 Hours of Initial Release in Hood Canal, Elliott Bay, and Tacoma Narrows

4-8 Particle Trajectories after 4 Hours of Initial Release in San Juan Passages and Strait of Juan de Fuca

4-9 Particle Trajectories after 8 Hours of Initial Release in San Juan Passages and Strait of Juan de Fuca.

4-10 Particle Trajectories after 12 Hours of Initial Release in San Juan Passages and Strait of Juan de Fuca

4-11 Particle Trajectories after 16 Hours of Initial Release in San Juan Passages and Strait of Juan de Fuca

4-12 Particle Trajectories after 20 Hours of Initial Release in San Juan Passages and Strait of Juan de Fuca.

4-13 Particle Trajectories after 44 Hours of Initial Release in San Juan Passages and Strait of Juan de Fuca 


\subsection{Introduction}

\subsection{Background}

The nearshore habitat in Puget Sound has been impacted due to human development. Changes to the nearshore include artificial structures such as tide gates, dikes, and bulkheads and pollution from various sources including failing septic systems and agricultural and industrial activities. The loss of estuarine functions such as movement and mixing of salt and freshwater, and loss of sediment and nutrient supply, have degraded the tidal marshland habit and affected salmon populations. Restoration efforts currently underway around Puget Sound focus on recovering fundamental nearshore processes such as tidal hydrodynamics, estuarine processes, and the restoration of tidal channels that provide fish access. Accurate simulation of the hydrodynamics in Puget Sound in the nearshore areas has become an essential requirement for many projects in connection with coastal restoration and improvements to tidal marshland habitat and salmon migration. The Marine Sciences Laboratory of Pacific Northwest National Laboratory (PNNL) is currently involved in a number of restoration projects in Puget Sound. Three-dimensional (3-D) hydrodynamic models have been developed for several estuaries and coastal basins in Puget Sound including the Skagit Bay, Port Susan Bay, Snohomish River Estuary, Whidbey Basin, Strait of Juan de Fuca, Nisqually Reach, Elliott Bay-Duwamish River, and the Cherry Point shoreline. To further understand circulation patterns in Puget Sound and assess the exchange and interaction between estuaries and subbasins and the cumulative effect of multiple restoration projects, a high-resolution hydrodynamic model for the entire Puget Sound is highly desirable. Ideally, the model should have the ability to predict water surface inundation, velocity and salinity distribution, and sediment and water quality variables for assessing the feasibility of planned restoration activities. The model may be used to guide restoration design, monitoring, and address the effort of proposed restoration achieved in future climatological conditions.

The Marine Sciences Laboratory of PNNL initiated the development of a Puget Sound-wide hydrodynamic modeling capability (tool) that will enable high-resolution, and accurate simulations of the transport and dispersion of contaminant plumes resulting from releases in the marine environment of Puget Sound. This initiative for Puget Sound Model development consists of the following major elements:

1. Data review and processing

2. Initial model set up and development

3. Preliminary model validation for tides in Puget Sound

4. Preliminary model application of circulation and transport in Puget Sound

5. Study report.

The scope of PNNL's Puget Sound project model development project covered the activities for the first two items listed above: 1) data review and processing, and 2) initial model development. To continue model validation and application in the entire Puget Sound, additional funding was sought.

The Northwest Straits Marine Conservation Initiative, authorized by Congress and guided by the Northwest Straits Citizen Advisory Commission (NWSC), is nationally recognized as an innovation that brings sound science and an ecosystem perspective together through the actions of seven marine resources 
committees, including Clallam, Jefferson, Whatcom, Skagit, San Juan, Island and Snohomish counties. NWSC coordinates the efforts and activities of restoration and conservation projects that protect vital marine resources in the water body of Northwest Washington, from the Strait of Juan de Fuca and northern Puget Sound to the Canadian border. Recognizing that the PNNL efforts of developing the hydrodynamic model of Puget Sound is in line with NWSC's mission of protecting and restoring marine resources in the straits, NWSC funded PNNL for the remaining tasks: 3) preliminary model validation, 4) preliminary model application of circulation and transport with focus on the Northwest Straits regions of Puget Sound, and 5) a study report.

\subsection{Study Objectives}

The overall objective of this study is to develop and validate the PNNL Puget Sound Hydrodynamic and Transport model for the entire Puget Sound and apply the model to simulate the transport processes related to release of contaminant pollution in Puget Sound and straits. Also, Puget Sound supports several major watershed basins and many estuaries that are vital to salmon habitat and migration. Understanding the overall interaction of these estuaries and their connection to the greater Puget Sound through model simulation would assist in the design of estuarine restoration and salmon migration management. The specific objectives of this study, with a focus on the Northwest Straits region of Puget Sound, are as follows:

- $\quad$ Preliminary model validation for tides in Puget Sound: Model validation for a large and complex modeling system like Puget Sound is a labor- and data-intensive task. To conduct calibration/ validation properly, synoptic data collected over the entire study domain are required. These data include a time history of water surface elevation and time histories and profiles of velocity, salinity, and temperature. However, no data collection activities are planned as part of this work. Instead we envision that model calibration/validation will be a long-term, ongoing process and will be continued as data become more available in different areas of Puget Sound in the future. Based on the review of data available in Puget Sound, a specific period corresponds to the most complete data set comprising model boundary conditions, and measured data were selected for model validation. Adjustment of the model configuration including model parameters, model grid resolution, bathymetry, and boundary conditions will be done to provide a reasonable match between observed data and predicted results, which is the primary objective of this task. The validation process will include qualitative checks to ensure that circulation in Puget Sound is reproduced correctly. As mentioned previously, this task is not intended to result in the final calibrated model but will represent the first step of the ongoing model calibration/validation effort and will be a demonstration that the predicted hydrodynamic parameters reasonably match the observed data.

- Preliminary model application of circulation and transport in the straits and Puget Sound: The objective of this task is to generate a hydrodynamic solution file with a connection to the General National Oceanic and Atmospheric Administration (NOAA) Operational Modeling Environment model (GNOME) for the entire Puget Sound covering neap and spring tidal periods. From this large data set, local model predictions will be extracted at sites of interest to NWSC. These sites may include potential sites targeted for nearshore restoration or sensitive sites of interest such as shellfish and other spawning grounds. Horizontal 2-D plots and animations of velocity vector and particle trajectory simulations at these sites are included deliverables as part of this task. 
- Study Report: This report summarizes the results of the modeling effort, which includes background, data input, and objectives and model set up, validation, and application results. The report discusses the model set up and calibration. The data input for the models is also presented in this report. The data products provided in this report include description and graphical presentation of existing data, model geometry, model grid and model boundary conditions, model validation, and application results. 


\subsection{Model Development and Setup}

\subsection{Description of the Study Area}

Puget Sound, located in the northwest corner of the United States in the state of Washington, is a large estuarine system bounded by 2,597 miles of complex shorelines and consists of several subbasins and many large estuaries with distinct properties of their own. Geographically, Puget Sound is defined by the water body that is southeast of McCurdy Point and Partridge Point at the entrance of Admiralty Inlet, east of Deception Pass and south of the Swinomish Channel (Figure 2-1). Pacific Ocean water enters the Puget Sound estuary system and the Georgia Strait through the Strait of Juan de Fuca. The Strait of Juan de Fuca is also the outlet of freshwater leaving Puget Sound and the Georgia Strait (Fraser River). Exchanges between Puget Sound water and the saline Pacific Ocean water occur mainly through Admiralty Inlet. A shallow double-sill exists in Admiralty Inlet restricting the water exchange between Puget Sound and the Strait of Juan de Fuca. Deception Pass and the Swinomish Channel are two narrow pathways that contribute very small percentage of water exchanges for the entire Puget Sound but may have significant effect on local estuarine circulation in the Skagit-Padilla Bay systems. No major rivers discharge into Admiralty Inlet. Average water depth in Admiralty Inlet is much lower than the Central Basin. The Central Basin is the largest and deepest basin in Puget Sound. It connects with Admiralty Inlet at the north, Southern Puget Sound at the south, and Whidbey Basin at the northeast. Major freshwater inflows into the Central Basin include the Puyallup River and the Duwamish River. The Sammamish and Cedar rivers flow into Lake Washington, which is regulated through the Hiram M. Chittenden Locks that discharges to the Central Basin. Southern Puget Sound consists of a number of narrow inlets and a shallow sill at the Tacoma Narrows. The Tacoma Narrows is the only passage between the Central Basin and Southern Puget Sound. Major rivers flowing into Southern Puget Sound are the Nisqually River and the Deschutes River. Hood Canal is the smallest and least complex basin in terms of geometry in Puget Sound. Another shallow sill approximate $50 \mathrm{~m}$ deep exists at the entrance of Hood Canal, which restricts water exchange between Admiralty Inlet and Hood Canal. The Skokomish is the main river that discharges into Hood Canal. Other, smaller rivers in Hood Canal include the Hamma Hamma, Duckabush, Dosewallips, Big Quilcene and Tahuya. Whidbey Basin consists of the three largest rivers that discharge into Puget Sound: the Skagit River, Snohomish River, and Stillaguamish River.

These three rivers supply about $70 \%$ of freshwater into Puget Sound. Unlike other subbasins, there are no sills in Whidbey Basin. Whidbey Basin connects to the Central Basin through Possession Sound. The Nooksack River and Samish River discharge into North Sound, while the Elwha and Dungeness rivers discharge into the Strait of Juan de Fuca.

\subsection{Bathymetry Data}

Bathymetry used for the development of the Puget Sound model primarily consists of data from the following four sources:

1 The University of Washington's (UW) Puget Sound Digital Elevation Model (DEM)

2 Bathymetry data from the Canadian Department of Fish and Ocean 


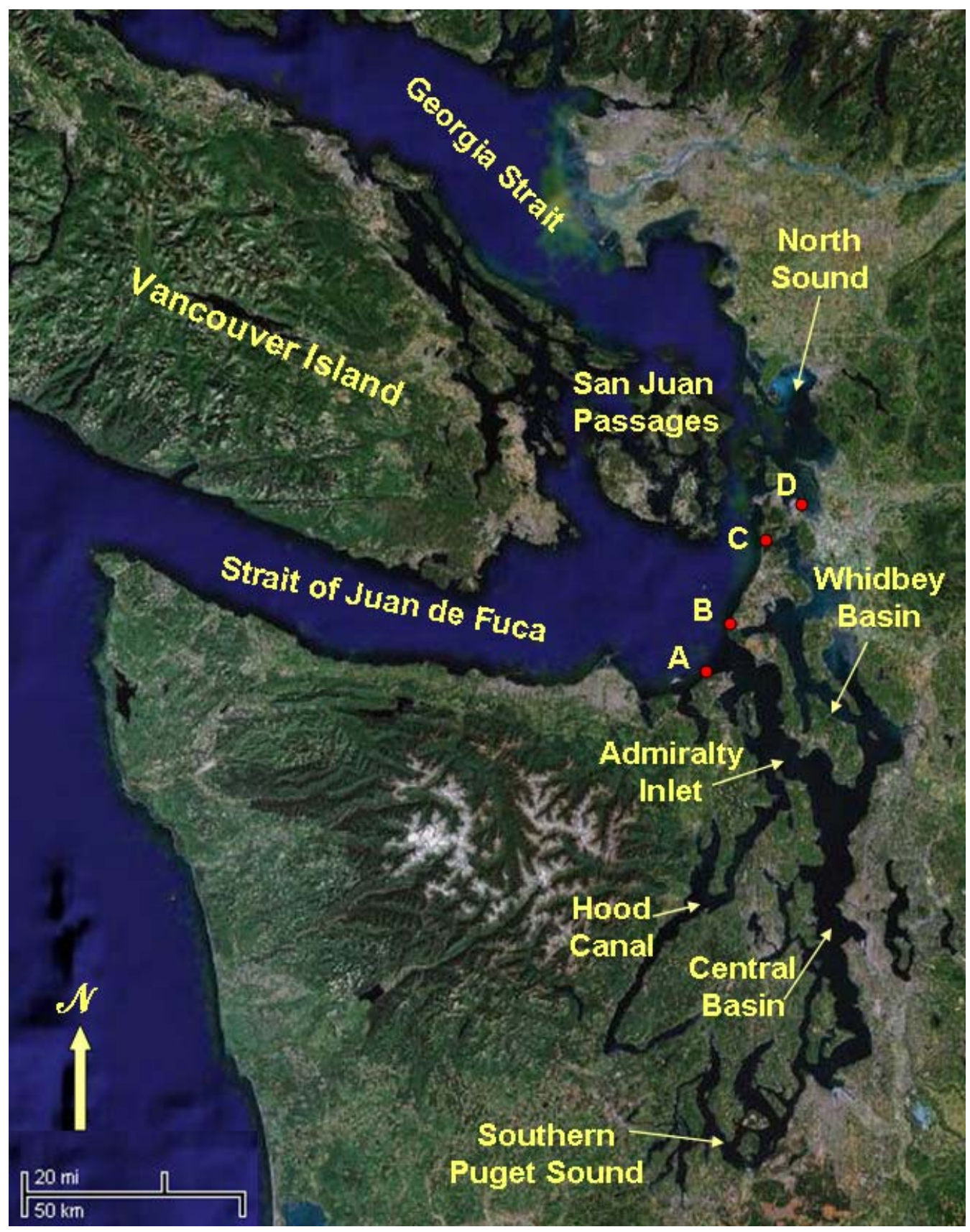

Note:

- $\quad \mathrm{A}-\mathrm{McCurdy}$ Point

- $\quad \mathrm{B}$ - Partridge Point

- $\mathrm{C}$ - Deception Pass

- D-Swinomish Channel

\section{Battelle}

The Business of Innovation

FIGURE 2-1

Oceanographic Regions of Puget Sound and Its Adjacent Waters

Northwest Straits Commission

Mt. Vernon. Washington 
3 Light detection and ranging (LIDAR) data for the nearshore intertidal zone from the Puget Sound LIDAR Consortium.

4 River cross-section data for the river channels from various counties and the U.S. Army Corps of Engineers.

The UW Puget Sound DEM bathymetry data cover the main study domain of Puget Sound (Figure 2-2a). These data are at $30-\mathrm{ft}$ by $30-\mathrm{ft}$ horizontal spatial resolution. There are some data gaps on the Canadian side of the border and near the San Juan Island Passages. Additional data for the San Juan Island Passages were obtained from NOAA. Other adjacent water bodies including a portion of the Strait of Juan de Fuca, the San Juan Island Passages, North Sound, and the Fraser River were obtained from the Canadian Department of Fish and Ocean (Figure 2-2b). These data are at coarser resolution than the UW DEM data but are considered sufficient for this phase of the Puget Sound model development effort. All bathymetry data used in the model development were referred to the North American Vertical Datum of 1988 (NAVD 88).

For the nearshore regions of interest with large areas of intertidal zones and marshland, available bathymetric LIDAR data were used. Accurate presentation of the bottom elevations in the intertidal zones is critical for modeling the estuarine circulation. The main source of LIDAR data was the Puget Sound LIDAR Consortium. Additional LIDAR data were obtained from difference sources such as counties, tribes, and local agencies. The Whidbey Basin consists of the largest intertidal zones in Puget Sound (Yang et al. 2006; Yang and Khangaonkar 2007). LIDAR bathymetric data in Skagit Bay, Port Susan Bay, and the Snohomish River Estuary used in development of the Whidbey Basin region are shown in Figures 2-3 to 2-5. The intertidal mudflat area in Admiralty Inlet and the Central Basin is relatively small. In the Southern Puget Sound Basin, a large tidal mudflat exists at the mouth of the Nisqually River (Figure 2-6). In Hood Canal, there are few large rivers, and tidal mudflats are limited. Figure 2-7 shows the tidal mudflat elevations in the Skokomish River in Hood Canal. In the North Sound region, large mudflats also exist in Bellingham Bay and Lummi Bay (Figure 2-8).

River cross-section data in general are very sparse. In the current model setup, river cross-sections or bathymetry were obtained for some major rivers including the Skagit River, Stillaguamish River, Snohomish River, Duwamish River, Nisqually River, and the Deschutes River. An example of river cross-section data for the Skagit River and Snohomish River are shown in Figures 2-9 and 2-10. For other rivers, the river widths were estimated based on U.S. Geological Survey (USGS) topographical maps, and the water depths were all assumed to be $2 \mathrm{~m}$. It is expected that in subsequent phases of model improvement, the river depth will be improved based on available cross sections, guided by specific project needs.

\subsection{River Inflow Data}

There are approximately 17 rivers that discharge into Puget Sound and its adjacent waters and are gauged by the USGS. Most of these rivers have real-time USGS stream flow gauges. Figure 2-11 shows all current USGS river stations monitoring inflows into Puget Sound. The Skagit River is the largest river to discharge into Puget Sound. Whidbey Basin consists of the three largest rivers (Skagit River, Snohomish River, and Stillaguamish River) in Puget Sound and accounts for more than $70 \%$ of the total freshwater flow into Puget Sound. No major rivers discharge into Admiralty Inlet. Two rivers discharge into the Central Basin of Puget Sound, the Duwamish River and the Puyallup River. The Sammamish and Cedar rivers flow into Lake Washington, which is regulated through the Hiram M. Chittenden Locks 


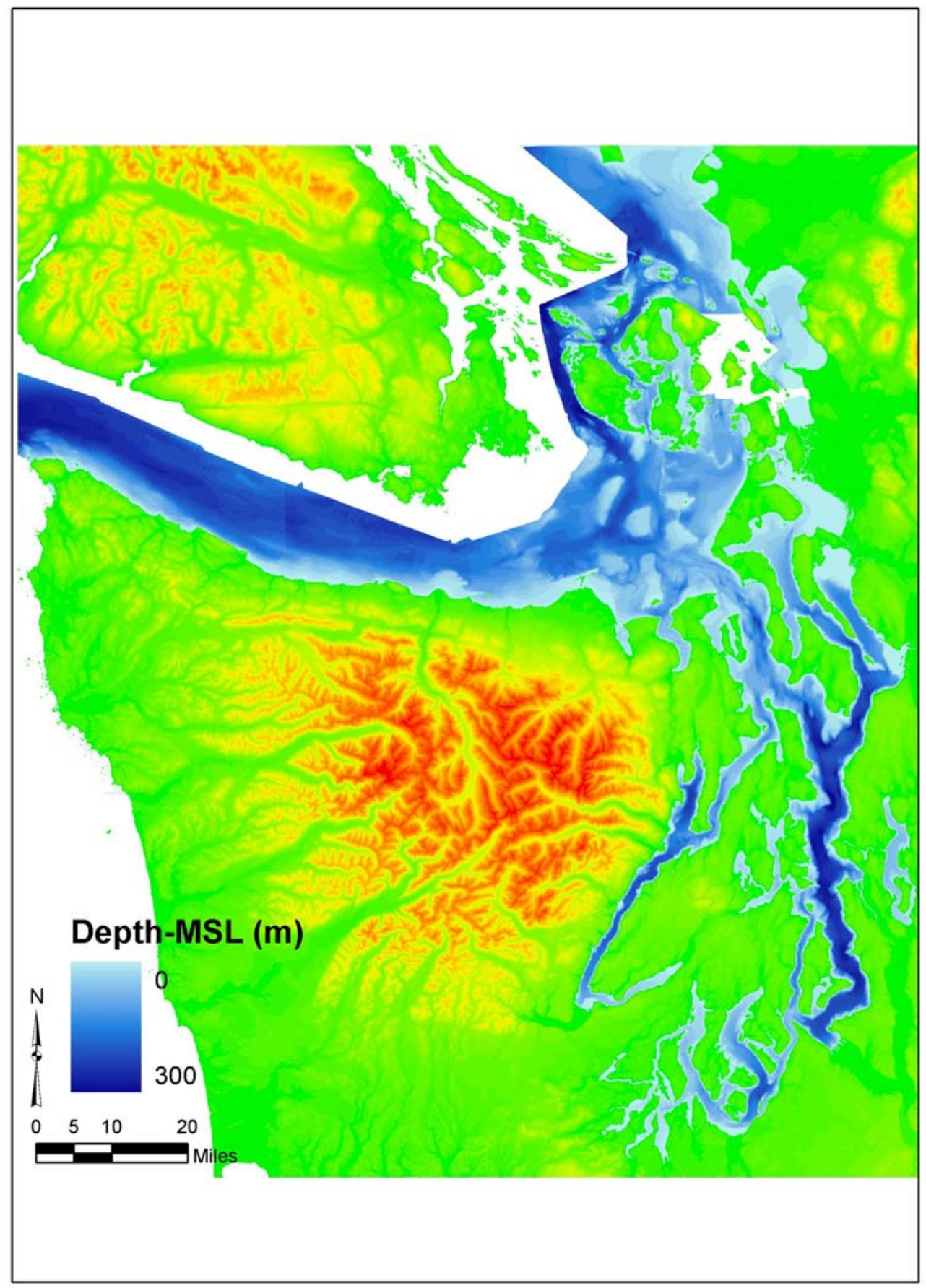

Note:

- $\quad$ Elevation is with Reference to NAVD 88.

- Source: University of Washington

\section{Battelle}

The Business of Innovation
FIGURE 2-2A

Puget Sound DEM Bathymetry Data

Northwest Straits Commission Mt. Vernon, Washington 


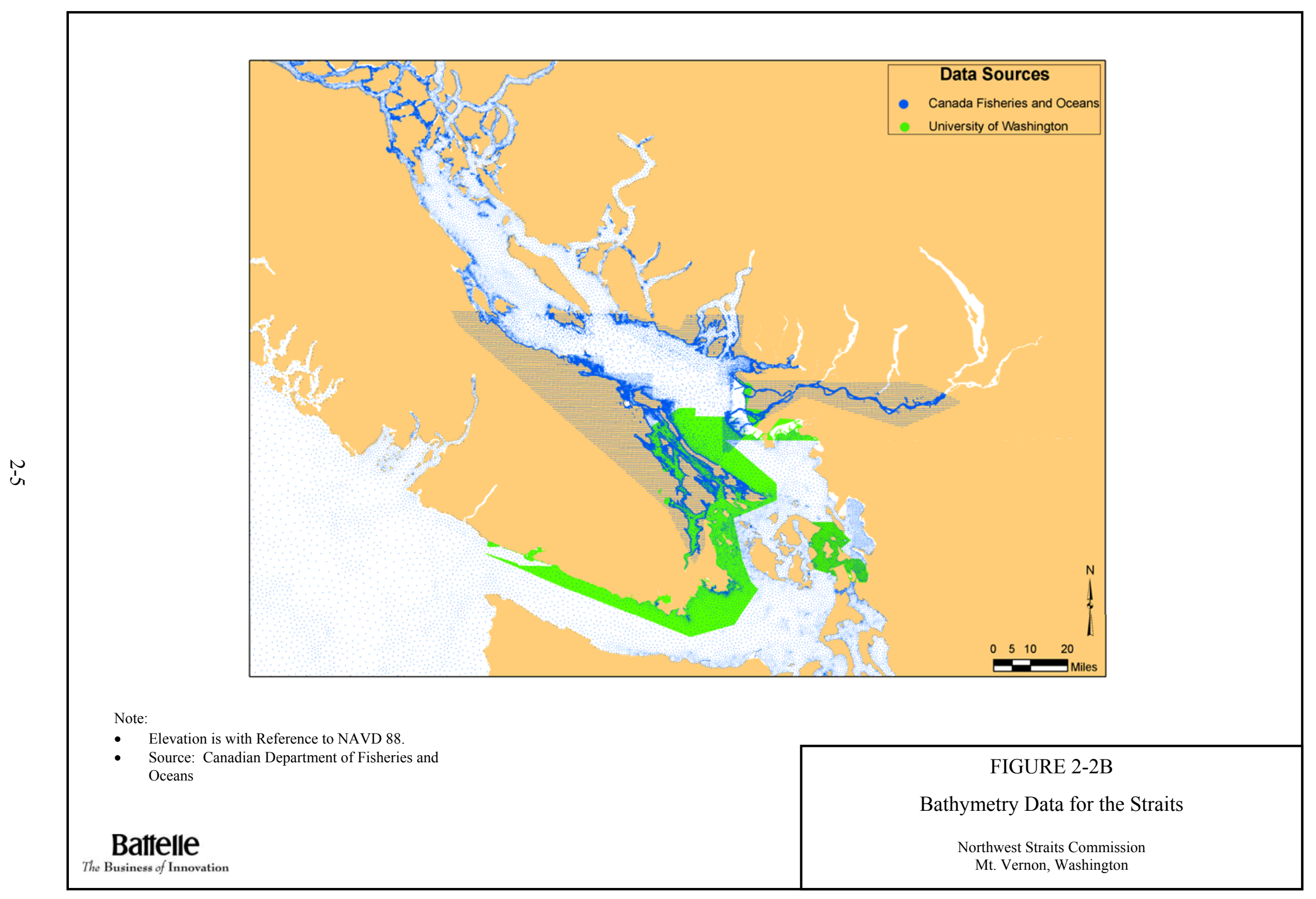




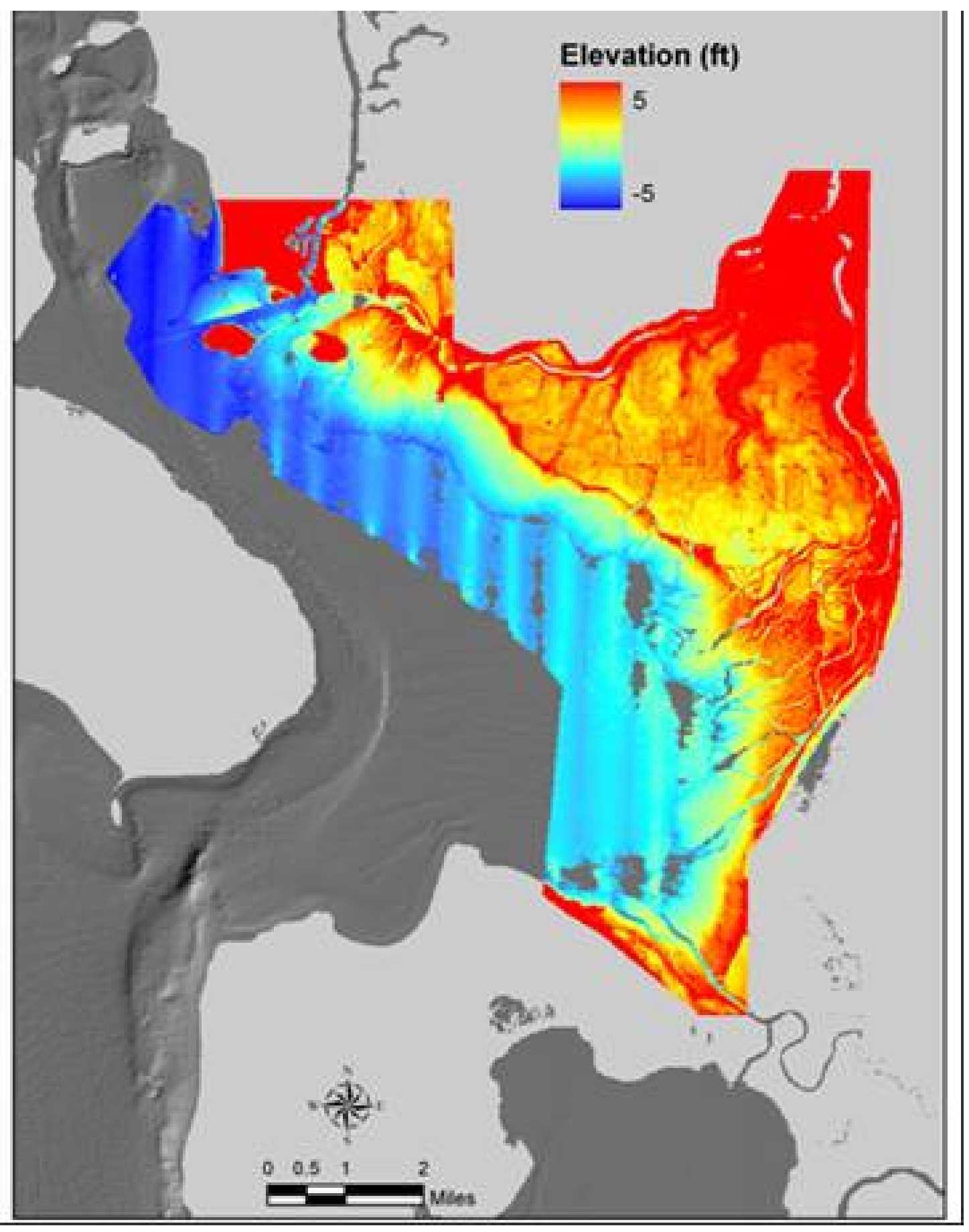

Note:

- $\quad$ Elevation is with Reference to NAVD 88.

- $\quad$ Source: Puget Sound LIDAR Consortium and SRSC

\section{Battelle}

The Business of Innovation

\begin{tabular}{|c|}
\hline FIGURE 2-3 \\
LIDAR Bathymetry Data in Skagit Bay \\
Northwest Straits Commission \\
Mt. Vernon, Washington \\
\hline
\end{tabular}




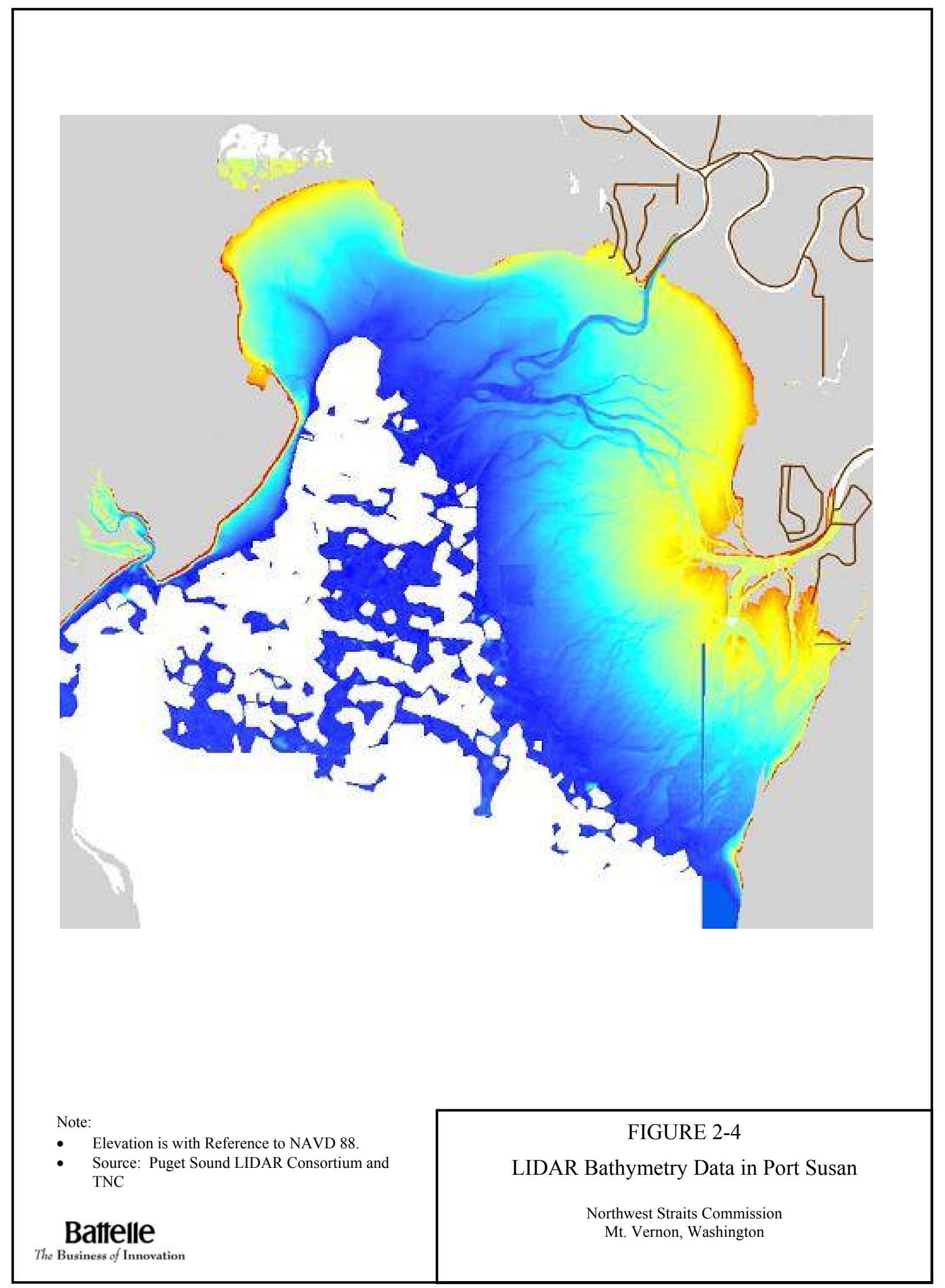




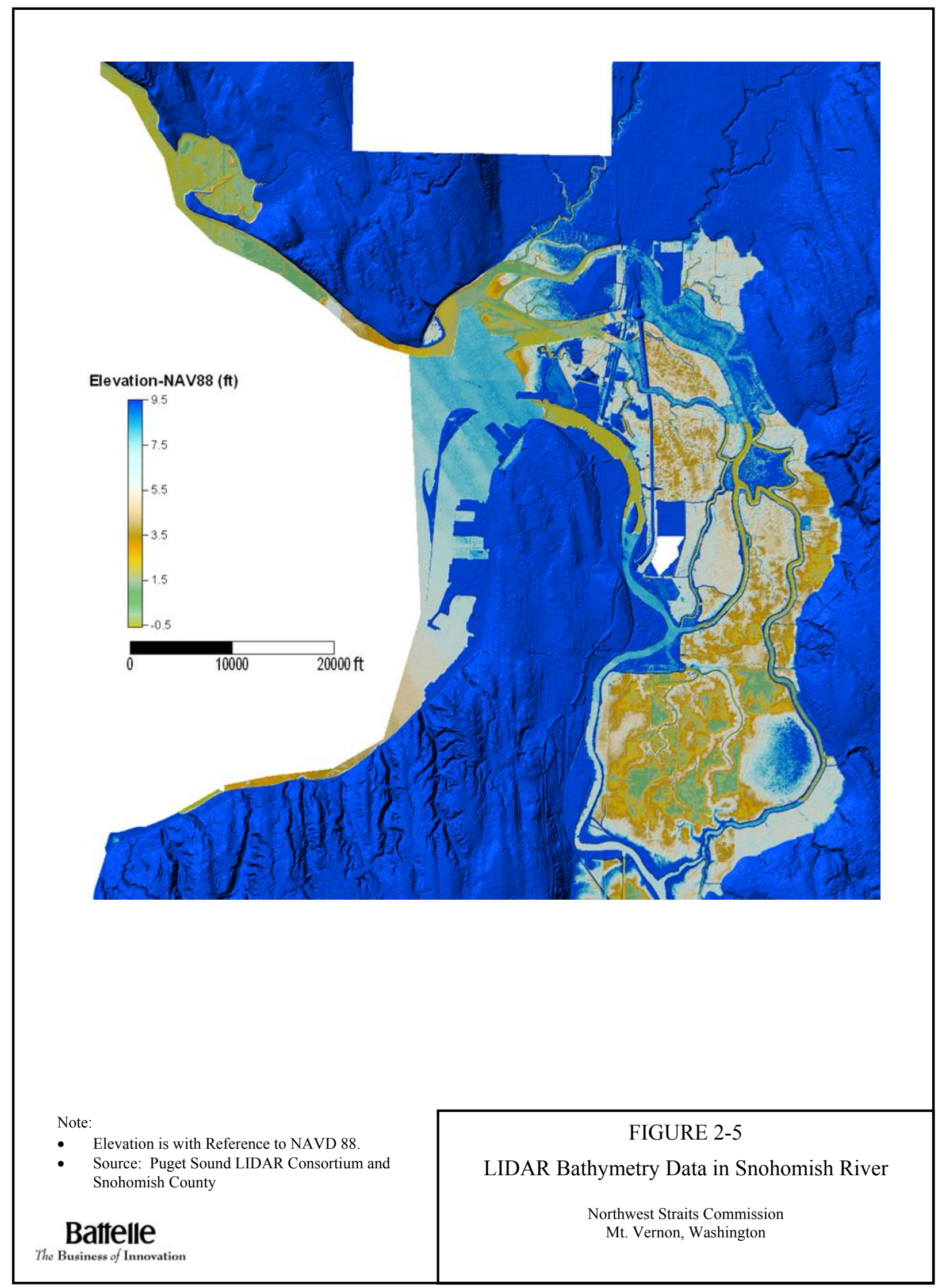




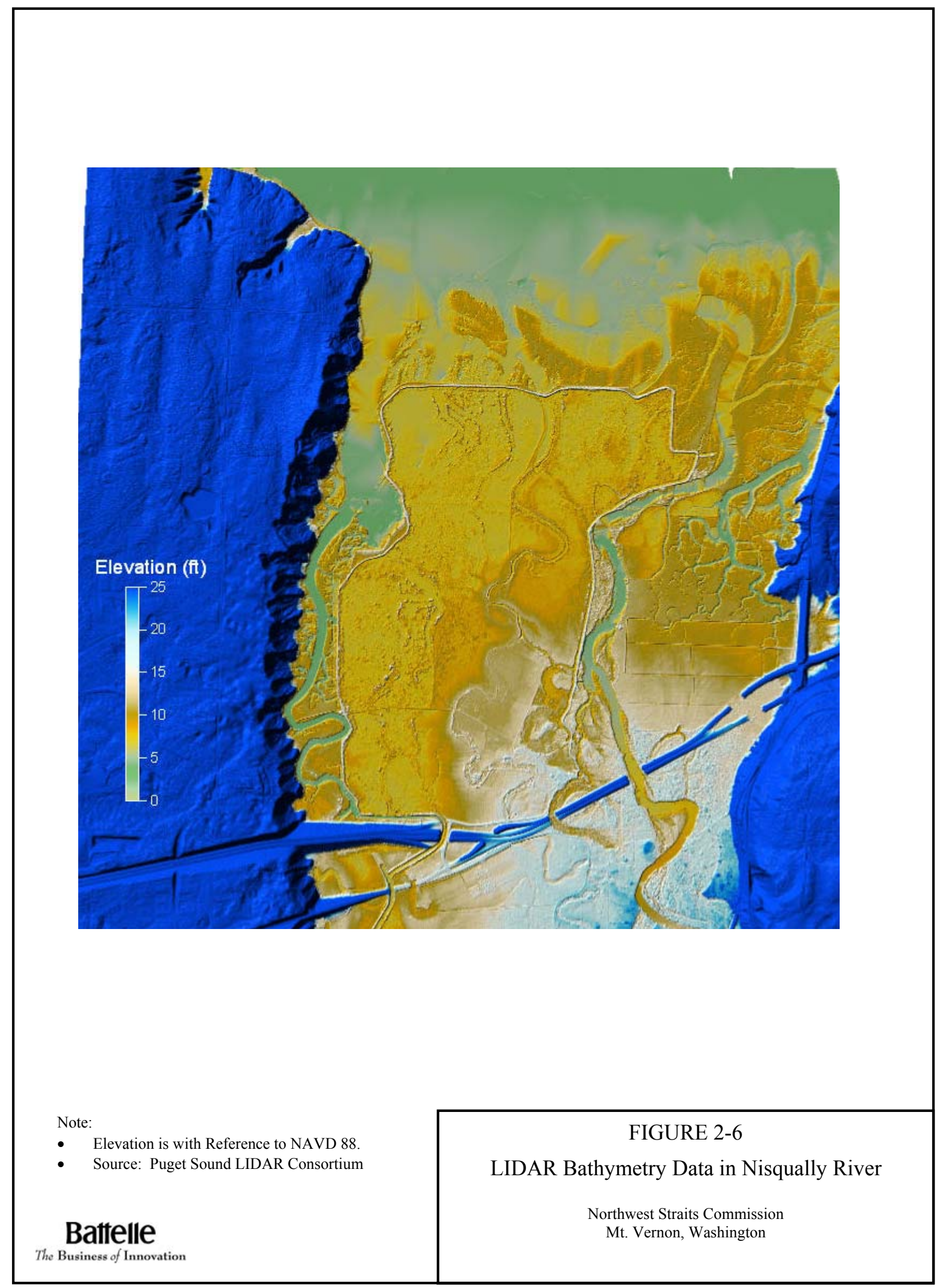




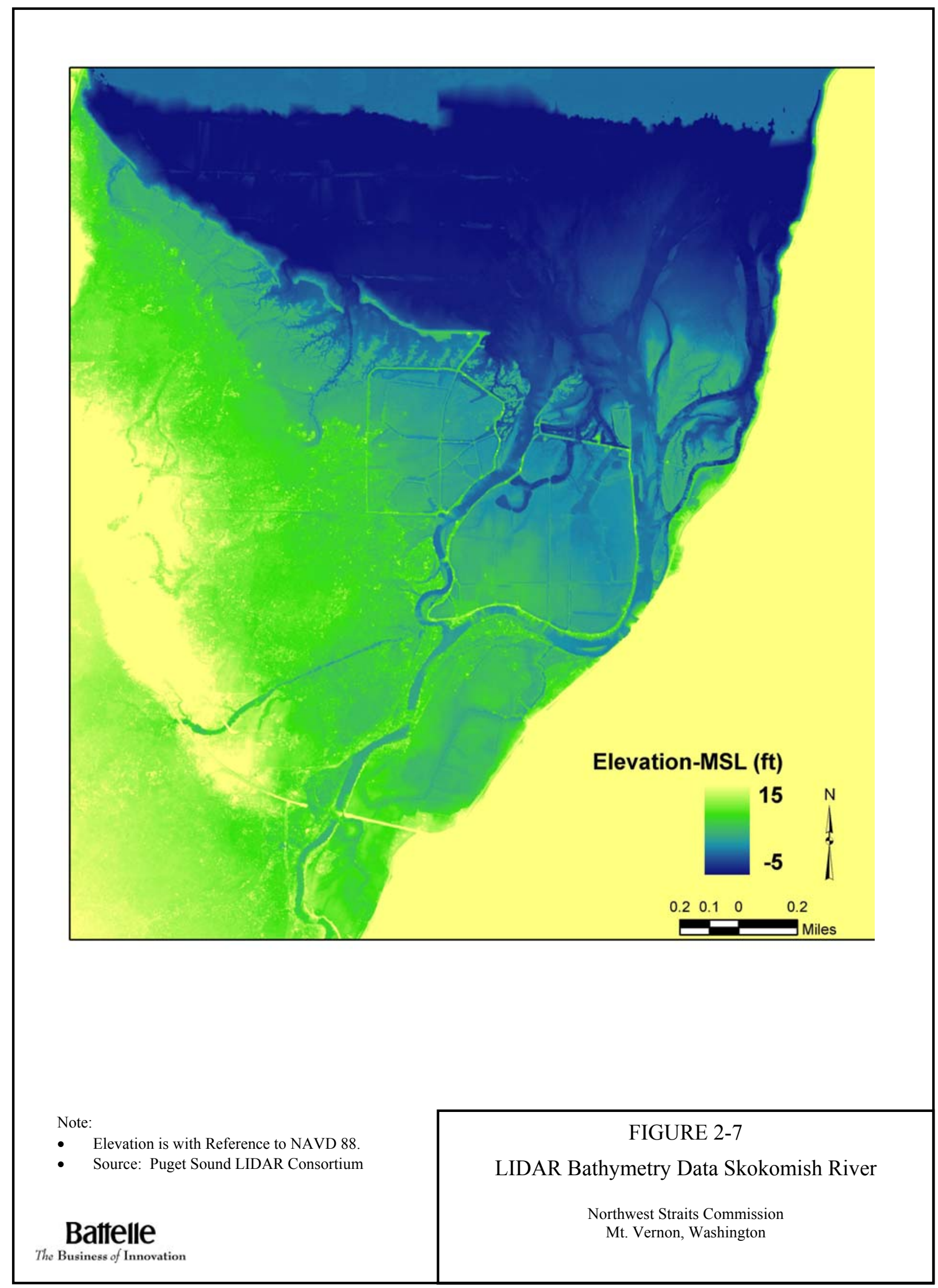




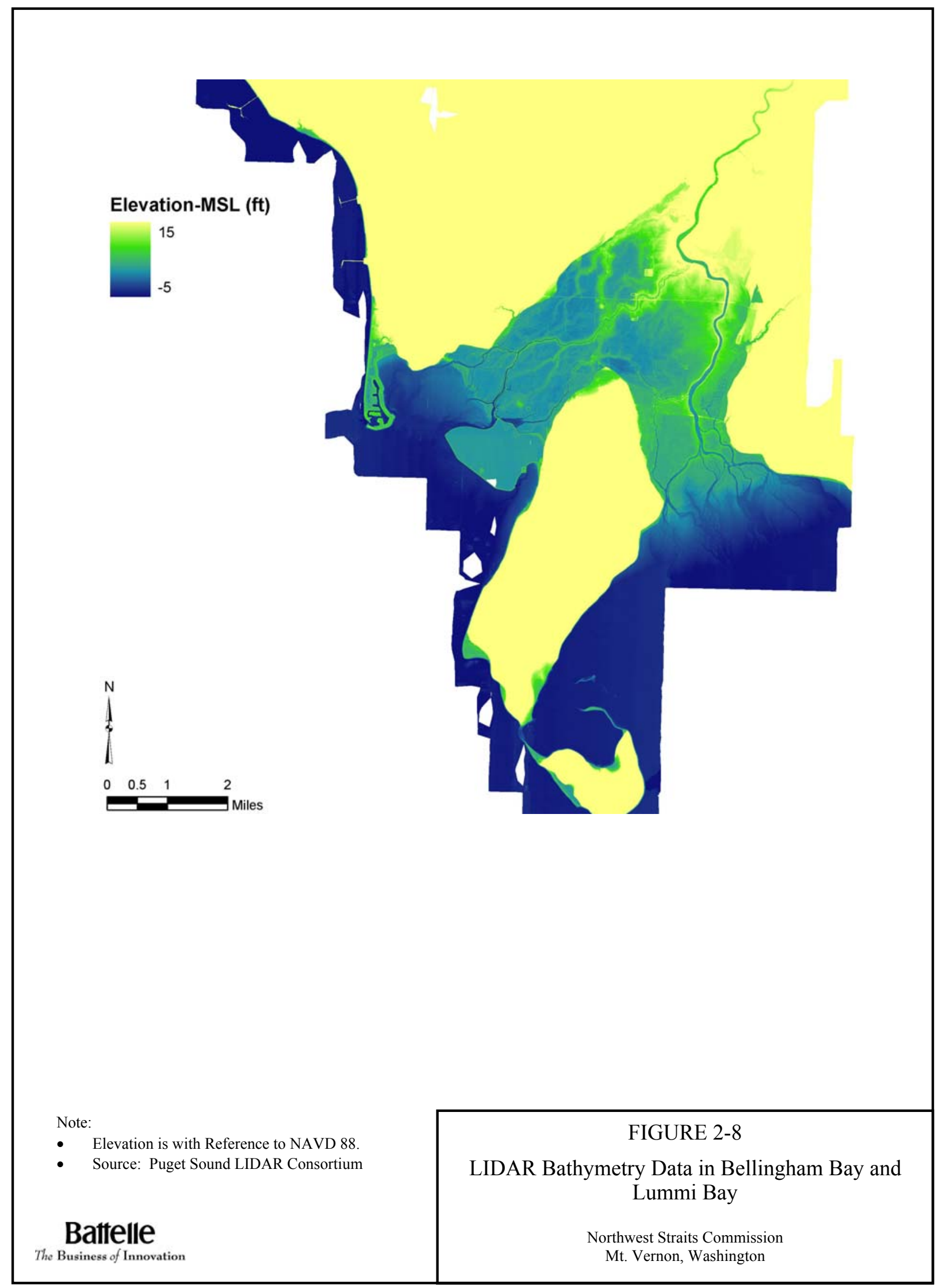




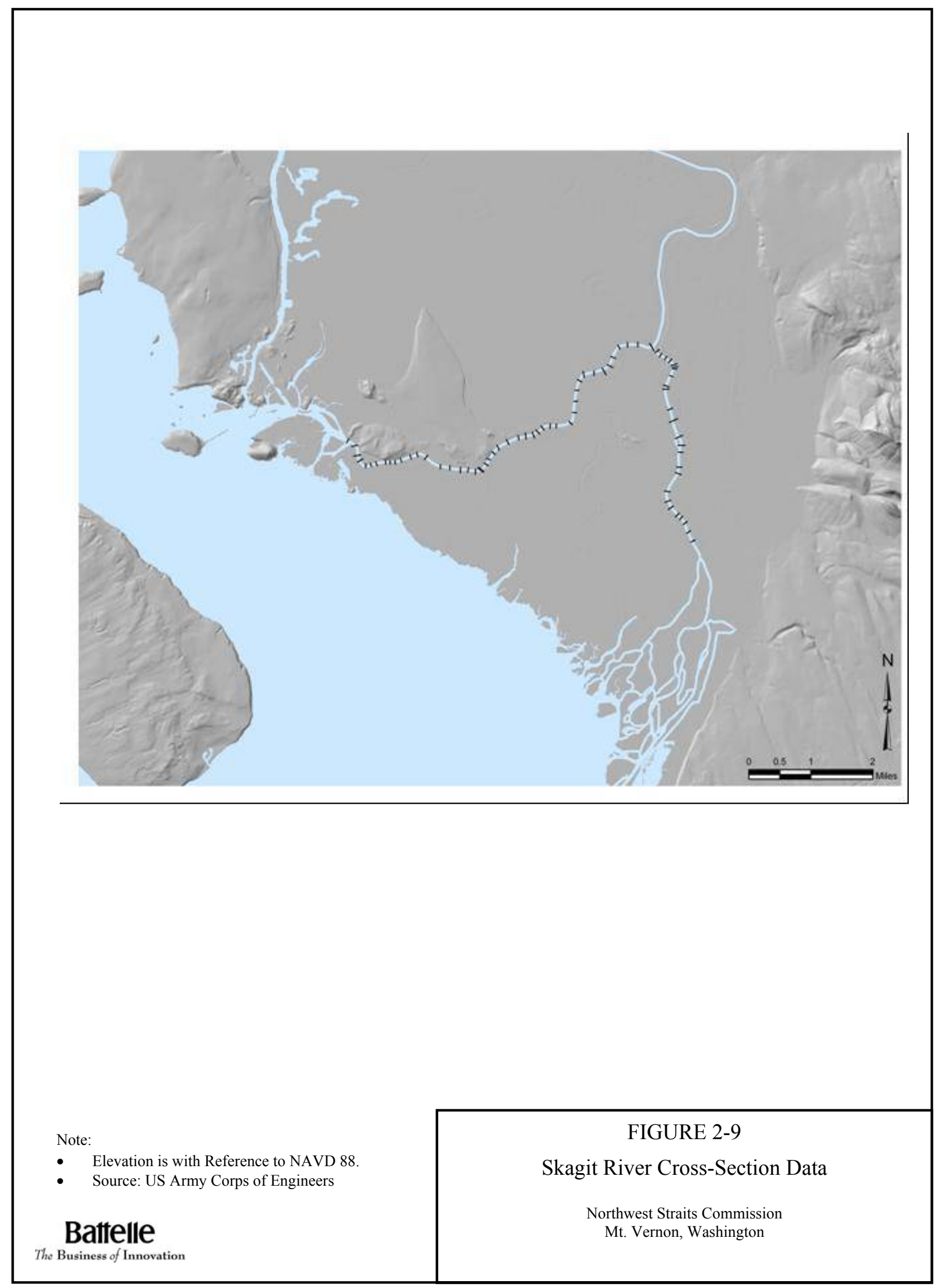




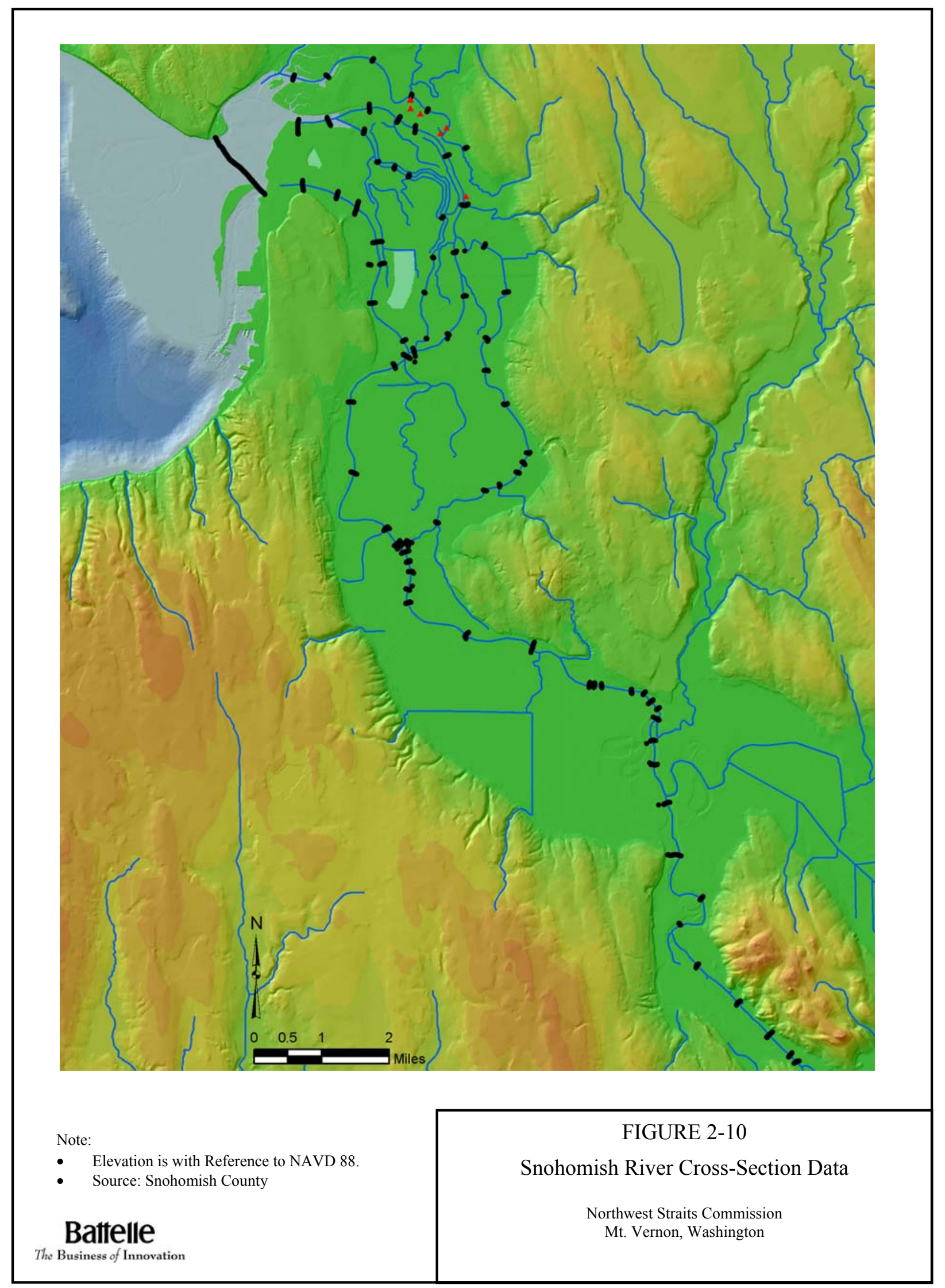




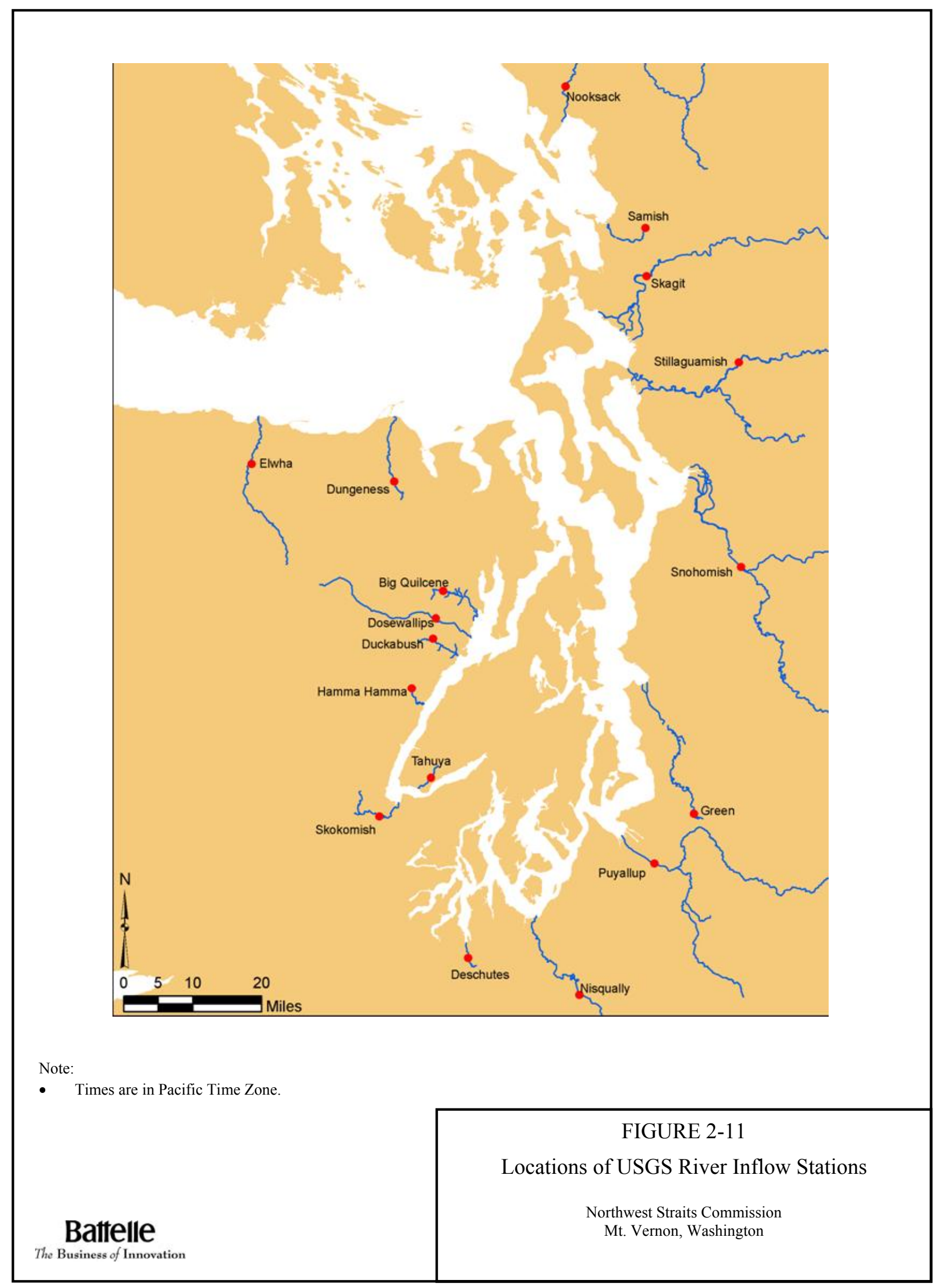


at Lake Union and discharges into the Central Basin. The river flow of the Puyallup is the fourth largest river discharge into Puget Sound. The South Puget Sound Basin consists of two major rivers, the Nisqually River and Deschutes River. A large river delta exists near the mouth of the Nisqually River. The Deschutes River runs through the Capital Lake near the city of Olympia before it discharges into Budd Inlet in south Puget Sound though a tide gate. Hood Canal is a unique water body because of its deep-narrow geometry setting and limited water exchange restricted by a shallow sill near the mouth. Small river inflows, which may not be significant in other subbasins, may affect the physical process in Hood Canal. Therefore, several small river flows are considered in the model configuration. The Skokomish River is the largest river discharge into Hood Canal. A large delta is formed in the mouth of the Skokomish River. In North Sound, which consists of Bellingham Bay and Samish Bay, the circulation is controlled by the river flows from the Nooksack River and Samish River and waters from Rosario Strait. An example of river inflows in Whidbey Basin, the Strait of Juan de Fuca, and north Puget Sound for the period of November 2001 is shown in Figure 2-12.

\subsection{Tide Data and Wind Data}

Tide is the dominant forcing mechanism for circulation and movement of water in Puget Sound and the straits. There are several real-time tidal observation stations and many predicted stations maintained by NOAA in Puget Sound and its adjacent waters. Figure 2-13 shows the tide stations that were used to set up the model. The data from these stations are used for specifying the incoming tidal elevations from the Pacific Ocean and Georgia Strait boundaries. The data from these stations are also used to compare with model results as part of the model validation exercise. Tide stations at Tatoosh Island and Blaine are used for specifying the tidal open boundary conditions, and four other stations are used for model validation. Figure 2-14 shows the time series of tidal elevations at Tatoosh Island and Blaine in November 2001. The figure shows clearly that as the tide propagates from the Pacific Ocean through the Strait of Juan de Fuca, the San Juan Islands, and towards Georgia Strait, tidal amplitude increases and the diurnal tide component becomes more dominant.

Wind data are required as a forcing input at the water surface in the model. Wind effect on surface currents and water surface elevation changes can be significant on the basin-wide scale. In this study, for simplicity, a spatially uniform wind field was specified based on observation data. NOAA's National Weather Service currently maintains several meteorological stations in the Puget Sound region. Paine Field Station in the city of Everett is located near the central region of Puget Sound. Therefore, wind data from this station were obtained and specified for the model input. Figure 2-15 shows a windstick plot for Paine Field wind data for November 2001. The data were available at 10-minute intervals. The average wind speed during the period of interest was about $3.5 \mathrm{~m} / \mathrm{s}$. The dominant wind direction was towards the northwest for the model simulation period of November 2001.

\subsection{Model Description}

The 3-D hydrodynamic model used in this study is the Finite Volume Coastal Ocean Model (FVCOM) developed by the University of Massachusetts at Dartmouth (Chen et al. 2003, 2004). FVCOM solves 3-D momentum, continuity, temperature, salinity, and density equations in an integral form by computing fluxes between non-overlapping horizontal triangular control volumes. This finitevolume approach combines the advantages of finite-element methods for flexibility in handling complex shorelines and the superior ability of finite difference methods for limiting numerical diffusion, handling simple discrete structures, and computation efficiency. A sigma-stretched coordinate system is used in 

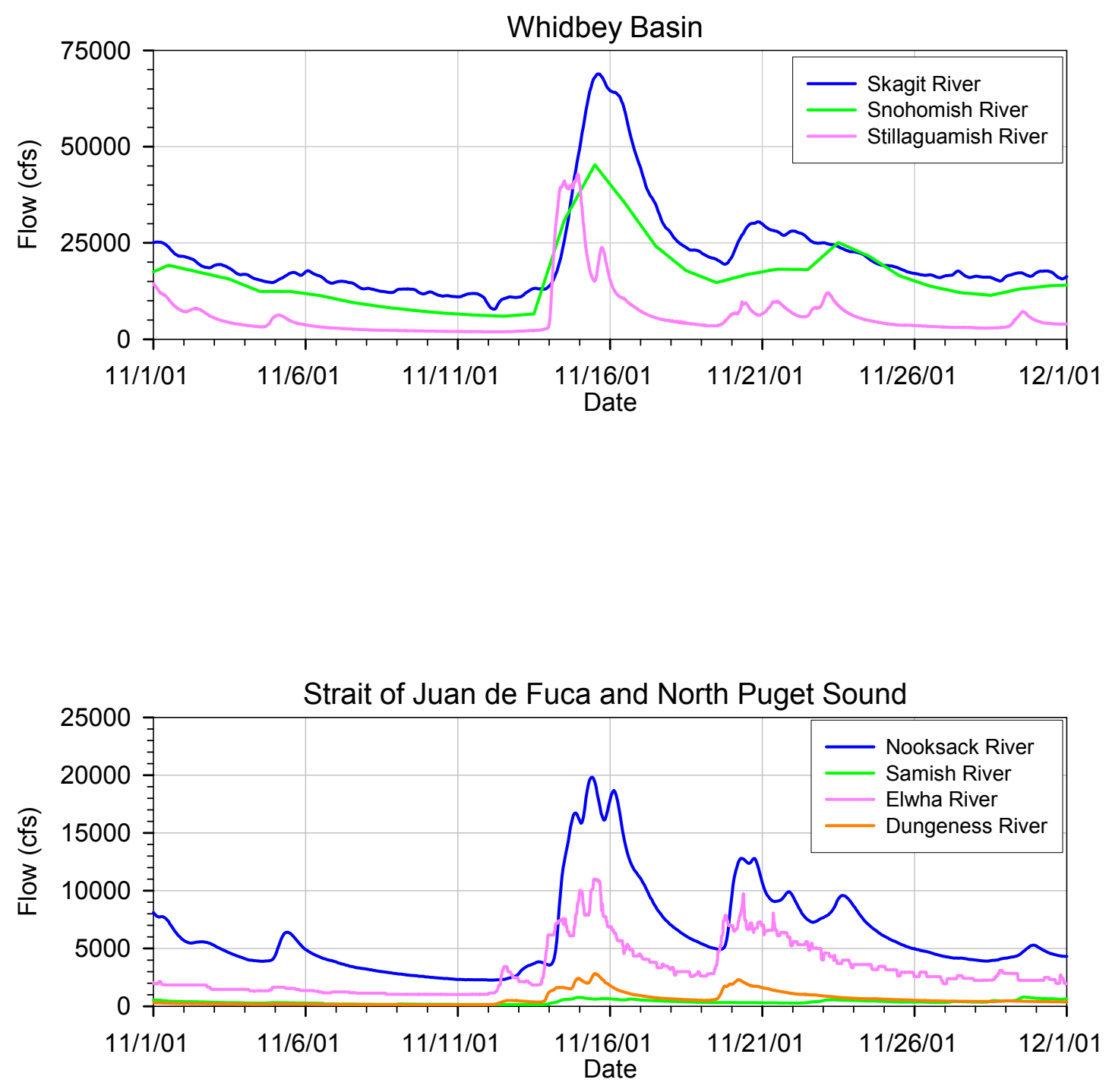

Note:

- Times are in Pacific Time Zone.

Battelle

The Business of Innovation

\section{FIGURE 2-12}

River Inflows in Whidbey Basin, North Sound, and Strait of Juan de Fuca

Northwest Straits Commission Mt. Vernon, Washington 


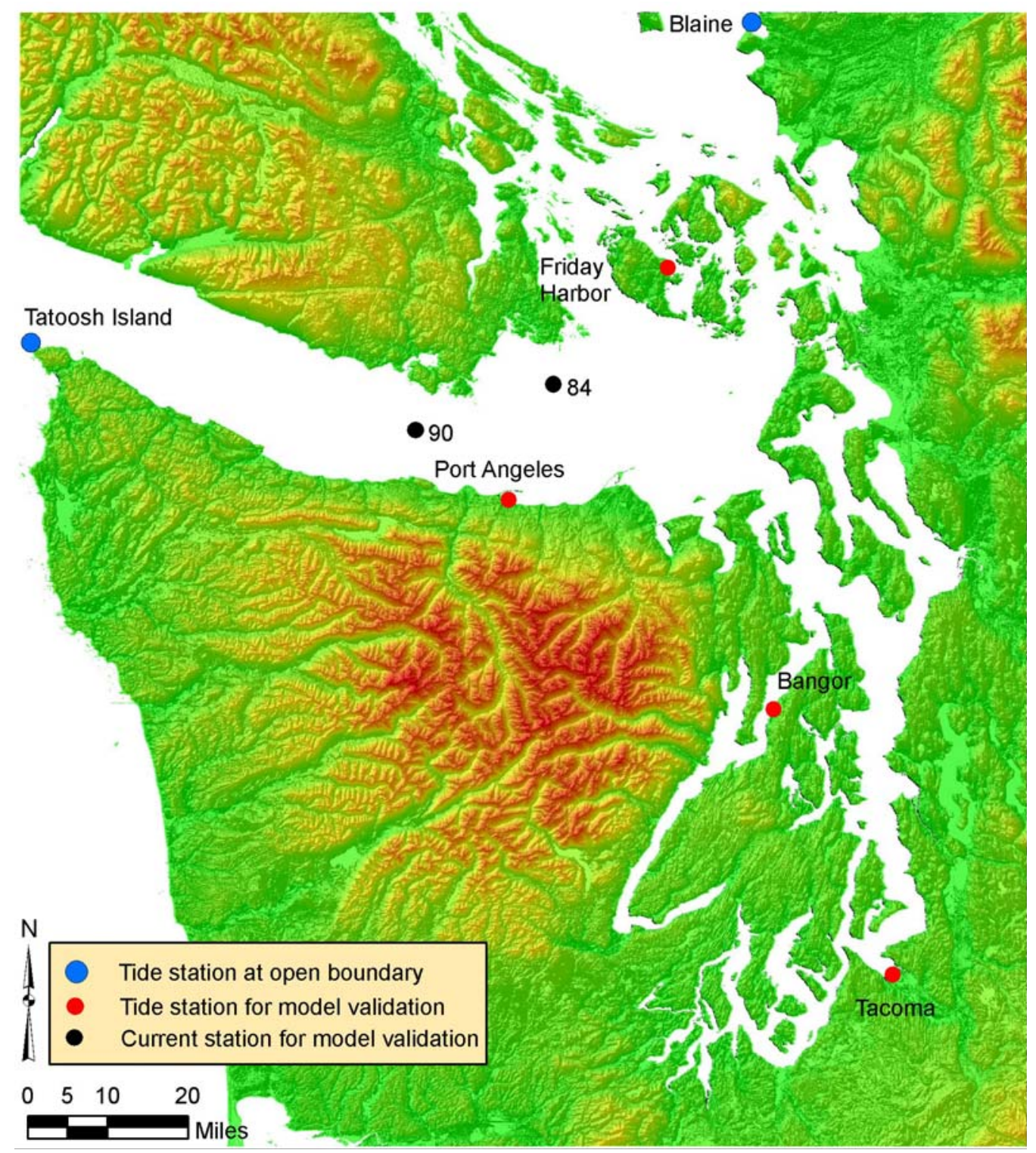

FIGURE 2-13

Tide Stations for Model Open Boundary Condition and Validation

Battelle

The Business of Innovation
Northwest Straits Commission

Mt. Vernon, Washington 

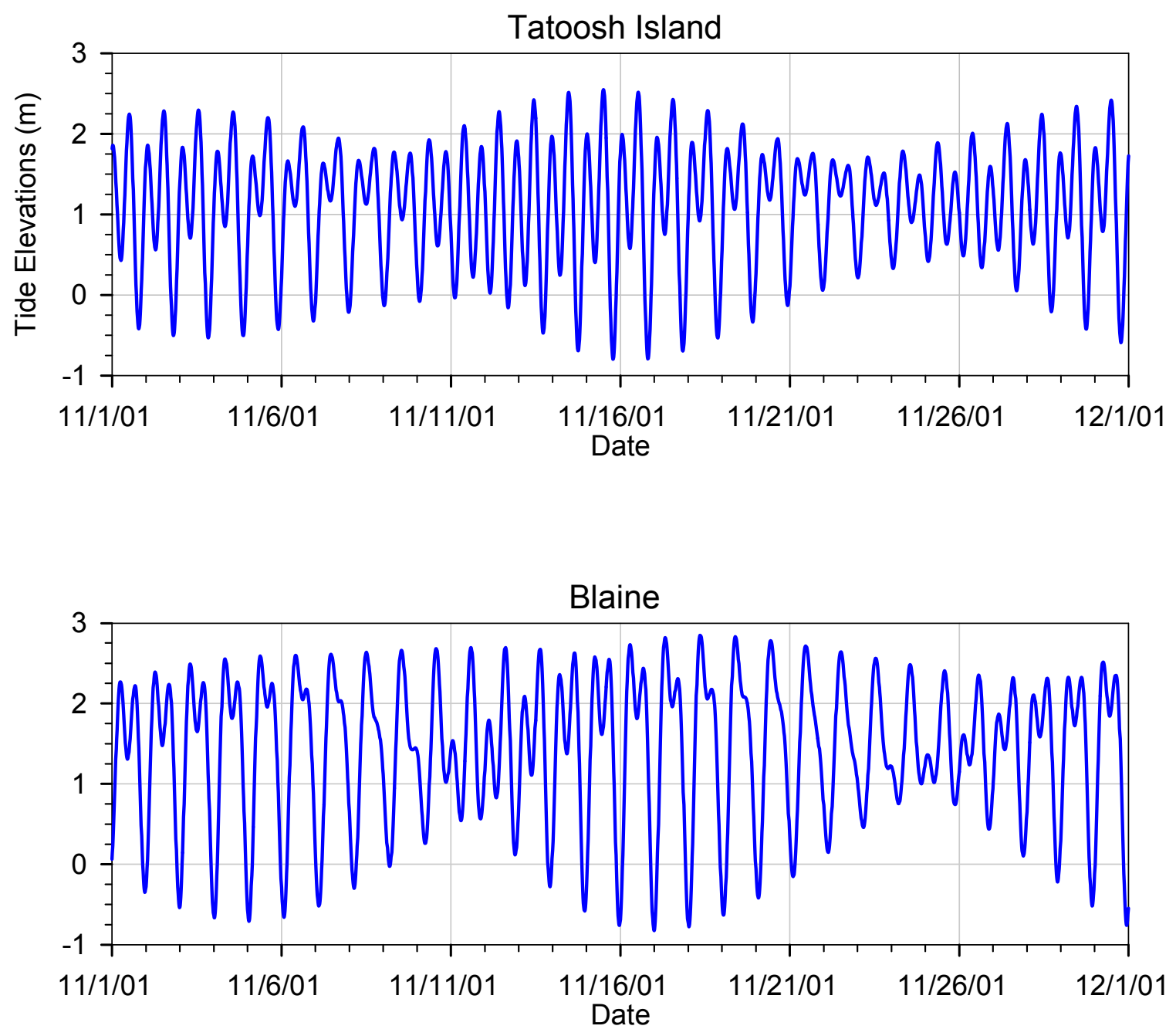

Note:

- Times are in Pacific Time zone.

- Elevations are with reference to NAVD 88 datum.

- $\quad$ Source: NOAA X-Tide predictor

\section{Battelle}

FIGURE 2-14

Predicted Tides at Model Open Boundaries

Northwest Straits Commission Mt. Vernon, Washington 


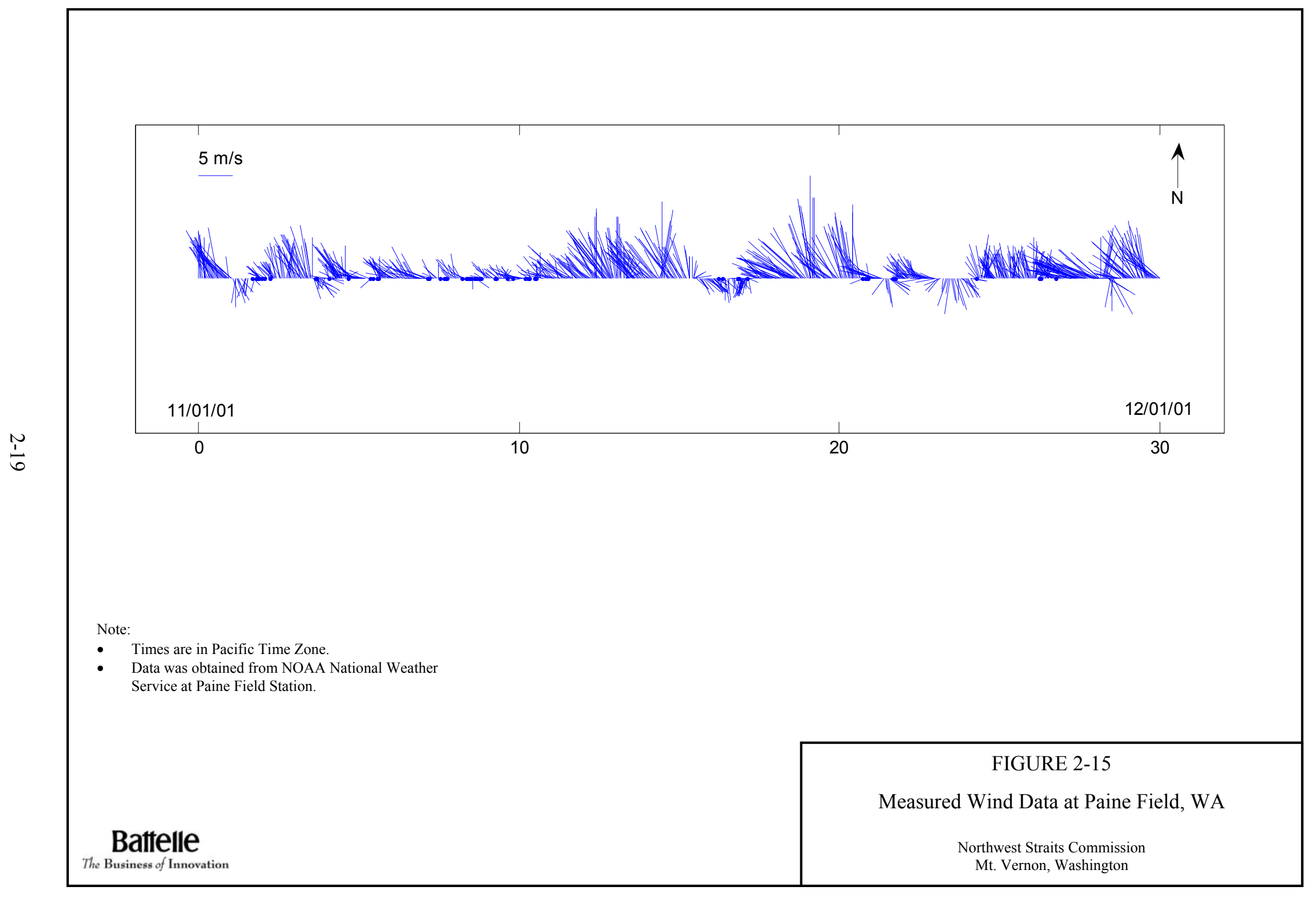


the vertical plane to better represent the irregular bottom topography. Unstructured triangular cells are used in the horizontal plan. The model employs the Mellor Yamada level 2.5 turbulent closure scheme for vertical mixing (Mellor and Yamada 1982) and the Smogarinsky scheme for horizontal mixing (Smogarinsky 1963). The model has been successfully applied to simulate hydrodynamics and transport processes in lakes and estuaries (Zheng et al. 2003; Chen et al. 2004), and restoration projects in Puget Sound (Yang et al. 2006; Yang Khangaonkar 2007).

\subsection{Model Setup}

Data needed for the hydrodynamic model setup were described in Section 2. The hydrodynamic model setup for Puget Sound consists of two procedures: 1) construction of an unstructured model grid in the study area and 2) specification of the model boundary conditions and forcing mechanisms. The model setup is described in the following subsections.

\subsubsection{Model Grid}

To simulate the tidal wave propagation properly into Puget Sound, the model open boundary must be specified far enough from the entrance of Admiralty Inlet to minimize the effects of the open boundary conditions on Puget Sound. The mouth of the Strait of Juan de Fuca was selected for the west open boundary. On the eastern boundary, because of the existence of the San Juan Islands, the open boundary line was specified farther north at the United States and Canadian border well north of the San Juan Island Passages.

For model efficiency, the model grid was generated in a way such that coarse grid resolution was used in the areas away from the shoreline, and a fine grid resolution was specified near the estuaries and nearshore regions. The model grid resolution gradually decreases away from the estuarine delta to the open boundaries to maintain the computational efficiency of the model. Model grid sizes vary from $2500 \mathrm{~m}$ at the open boundaries to as small as $10 \mathrm{~m}$ within the bays, estuaries, and river channels. The total number of nodes and triangular elements in the model are 114,590 and 208,452, respectively, in the horizontal plane. Twenty uniform vertical layers were specified in the water column in a sigma-stretched coordinate system. The model grid was set up in Universal Transverse Mercator North American Datum (NAD) 83 (Zone 10) coordinates in the horizontal plane with reference to NAVD 88 in the vertical direction. Figure 2-16 shows the final unstructured model grid for the entire Puget Sound. Close-ups of the model grids in the subbasins including southern Puget Sound, the Central Basin, Whidbey Basin, Hood Canal, the San Juan Passages, and North Sound are shown in Figures 2-17 to 2-21. Model bathymetry data are shown in Figure 2-22. The deepest regions in the model domains are Haro Strait, the entrance of the Strait of Juan de Fuca, and the Central Basin.

\subsubsection{Model Boundary Conditions}

Model open boundary conditions were specified with tidal elevations predicted using the XTIDE program based on National Oceanic Service algorithms. Tidal elevations were specified at the following two open boundaries: 1) the entrance of the Strait of Juan de Fuca (Tatoosh Island Station) and 2) the United States and Canada border at the south of Georgia Strait (Blaine Station) (Figure 2-14). There were no salinity data available along the open boundaries, and a constant value of $32 \mathrm{ppt}$ was specified over the entire water column. In the current study, temperature effect on the density-induced currents was not considered. At the water surface, wind stress was specified. Wind stress was applied uniformly across the entire model domain (see Figure 2-15). 


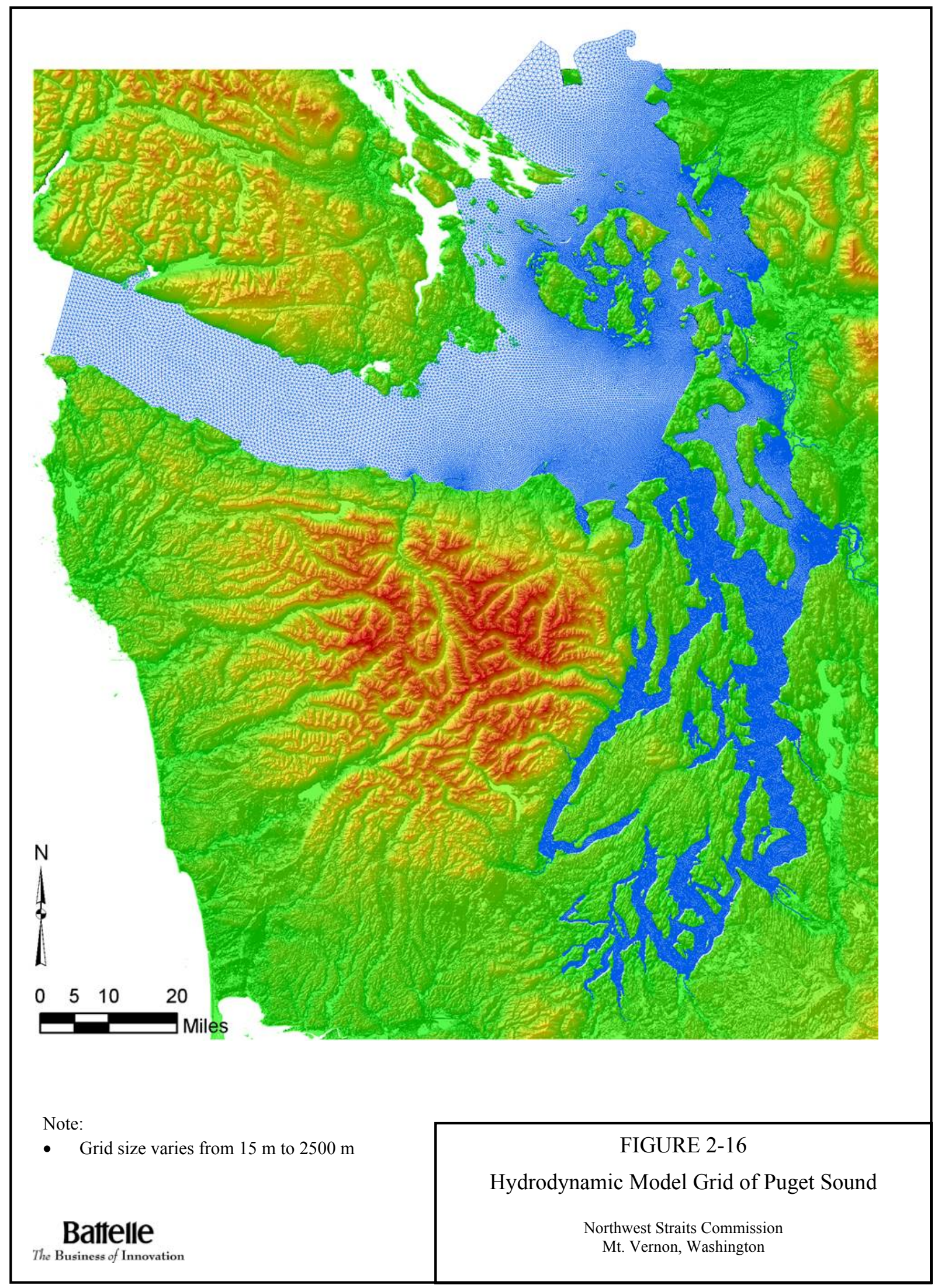




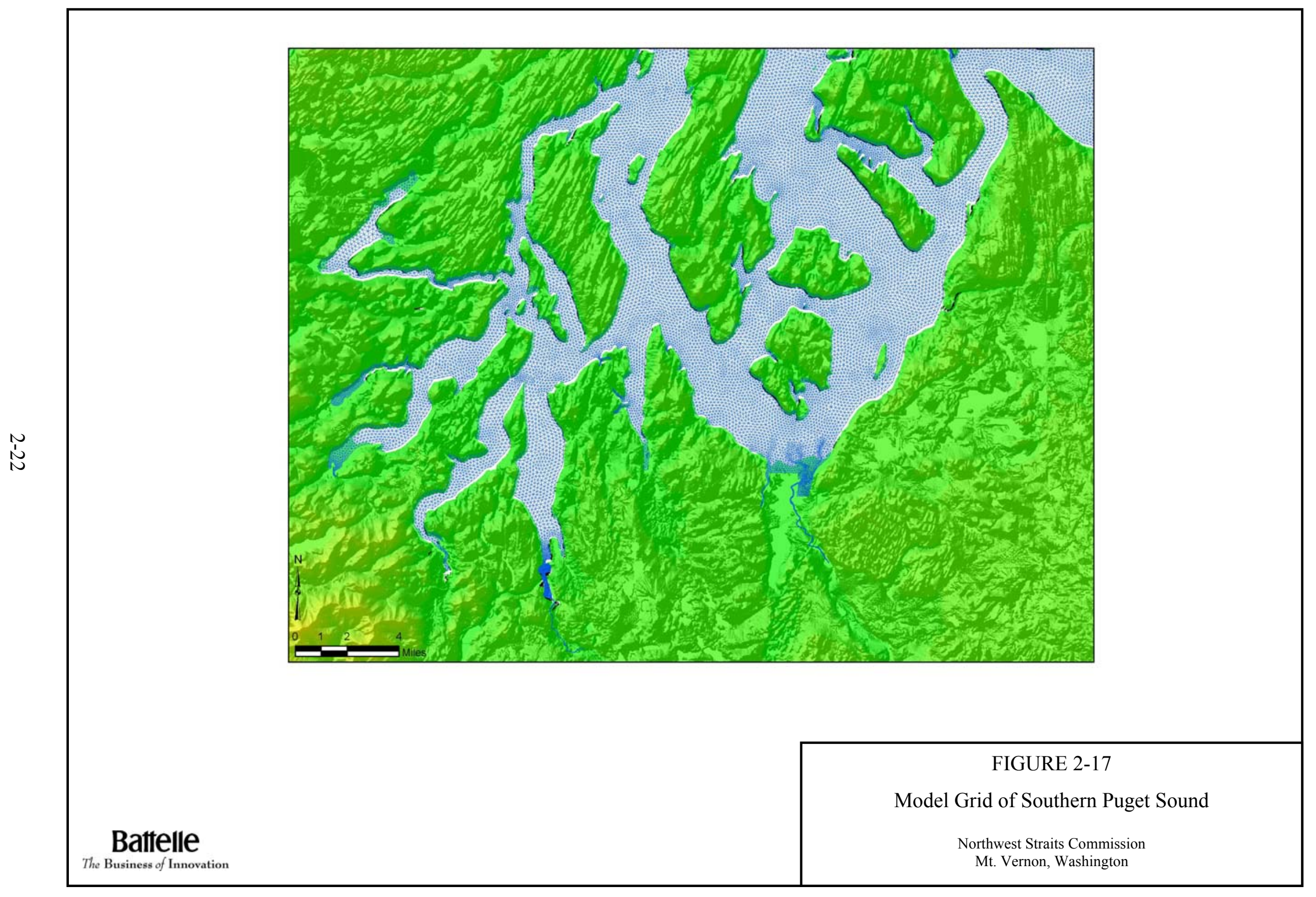




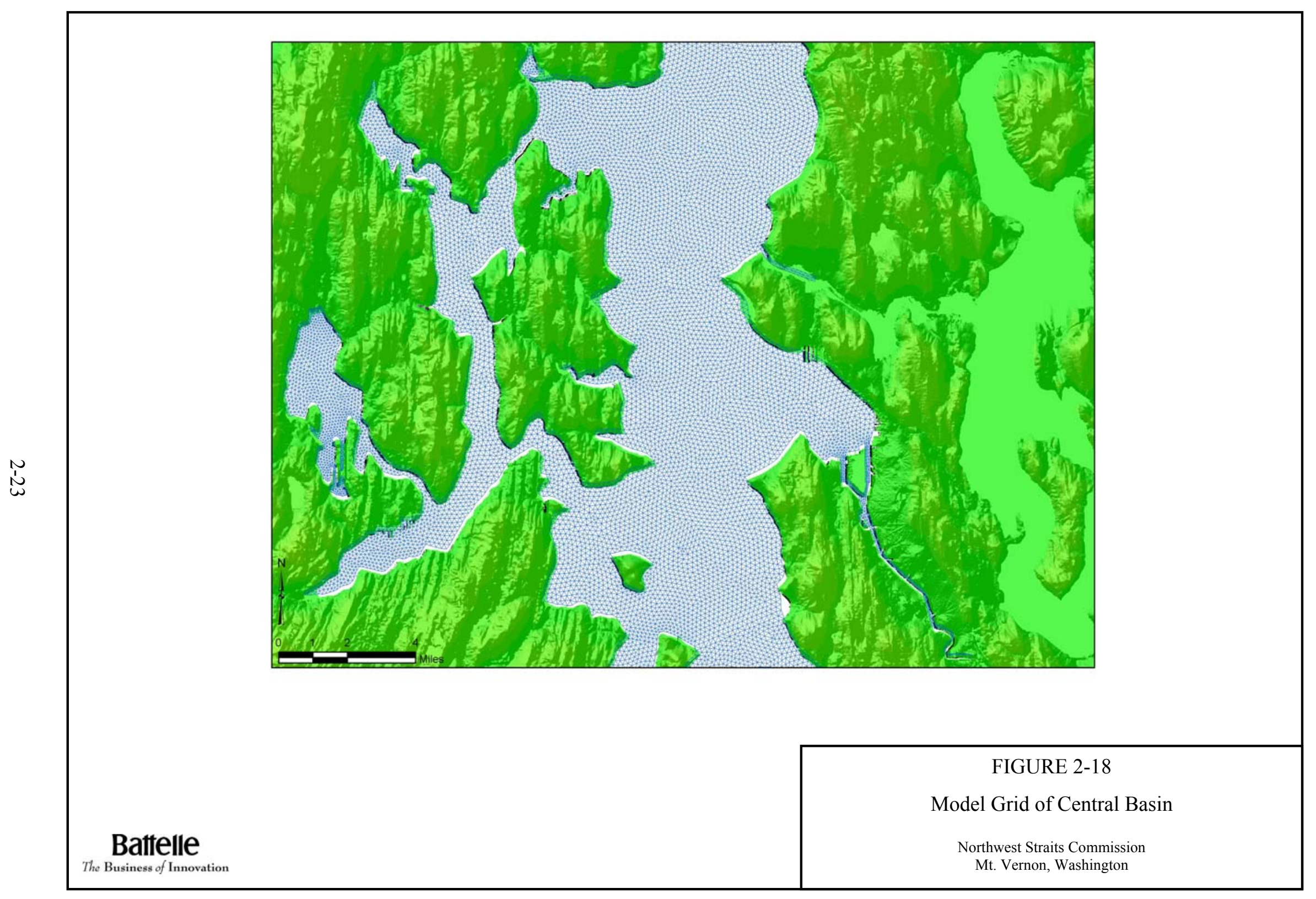




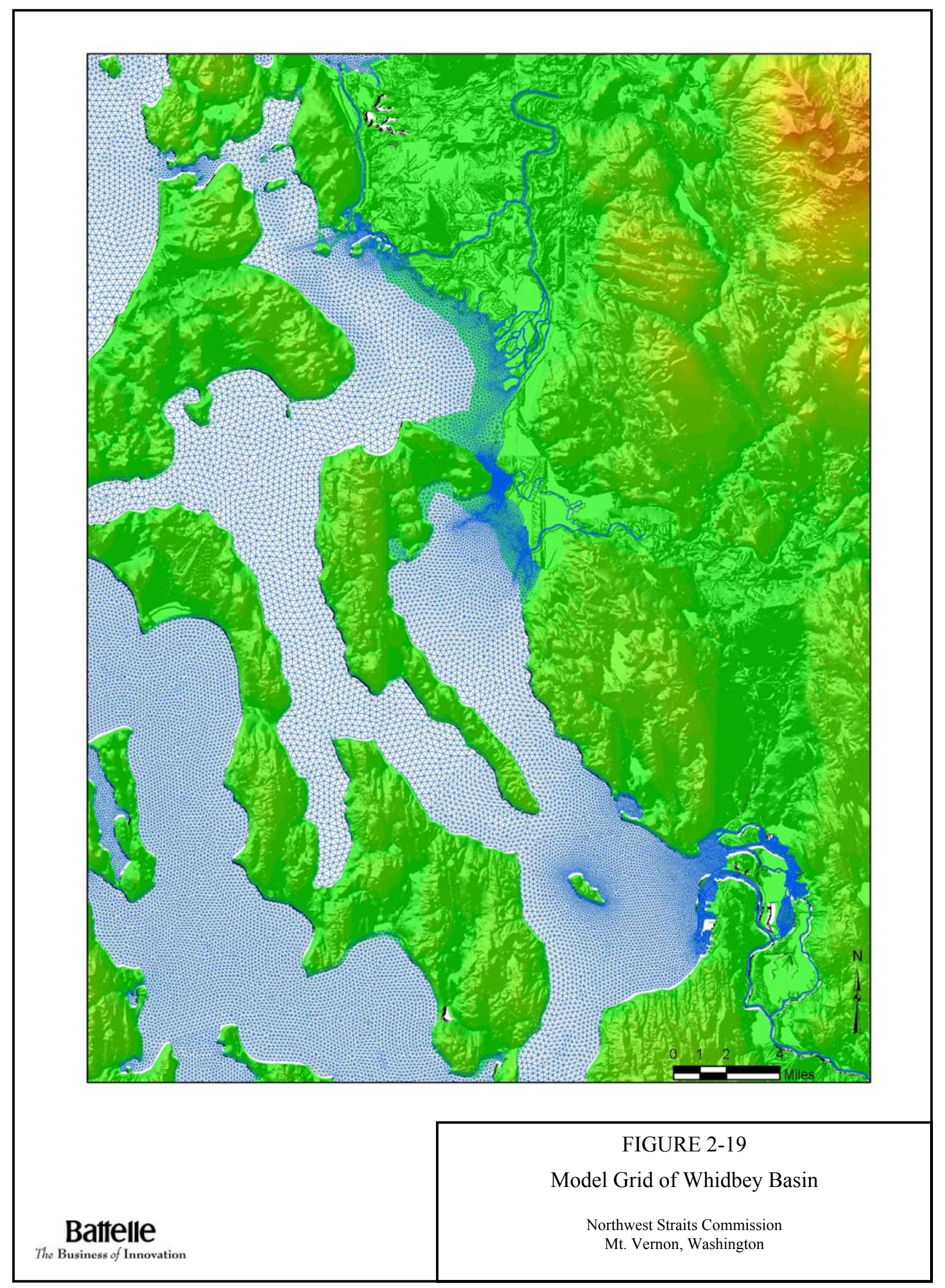




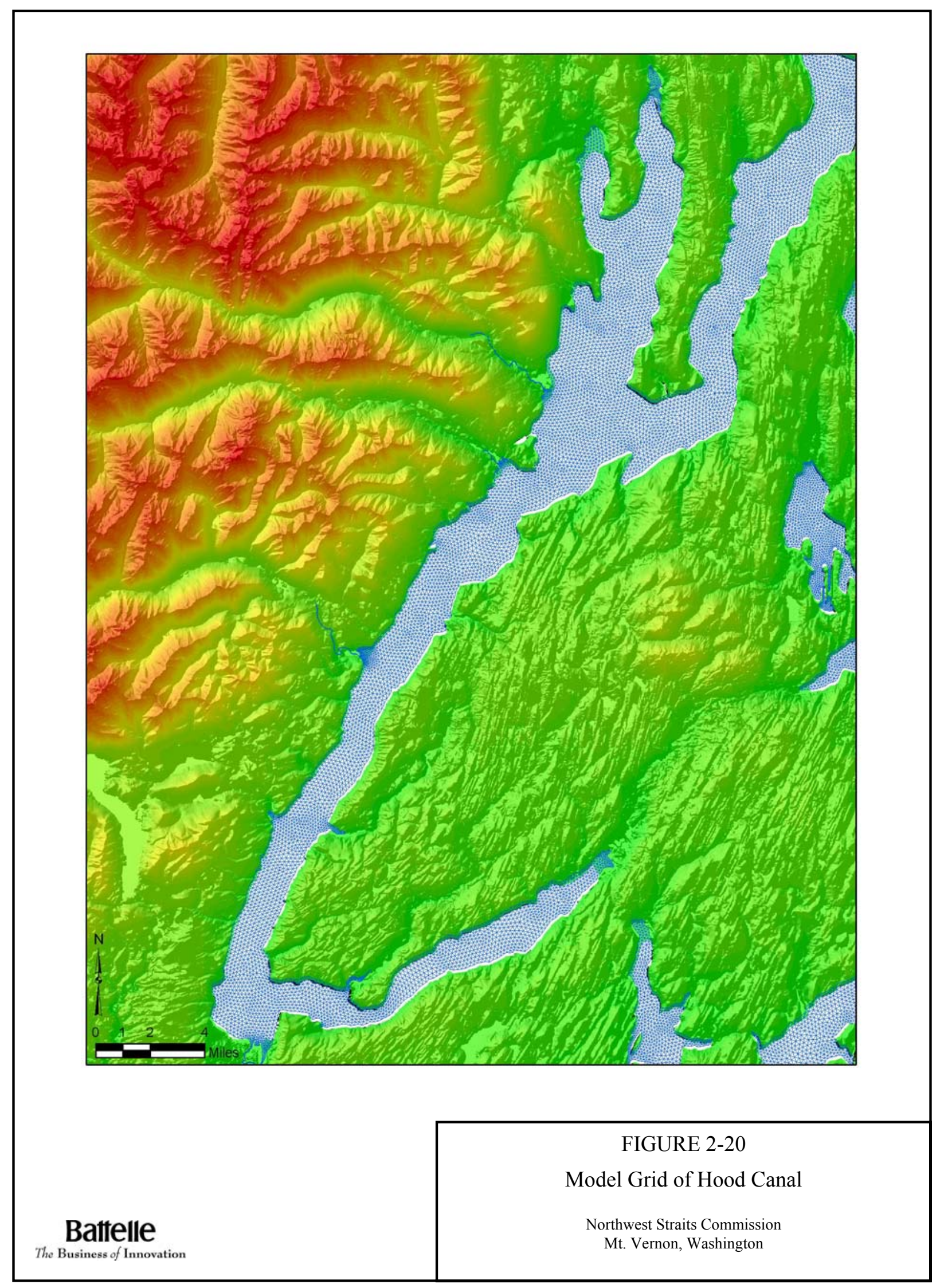




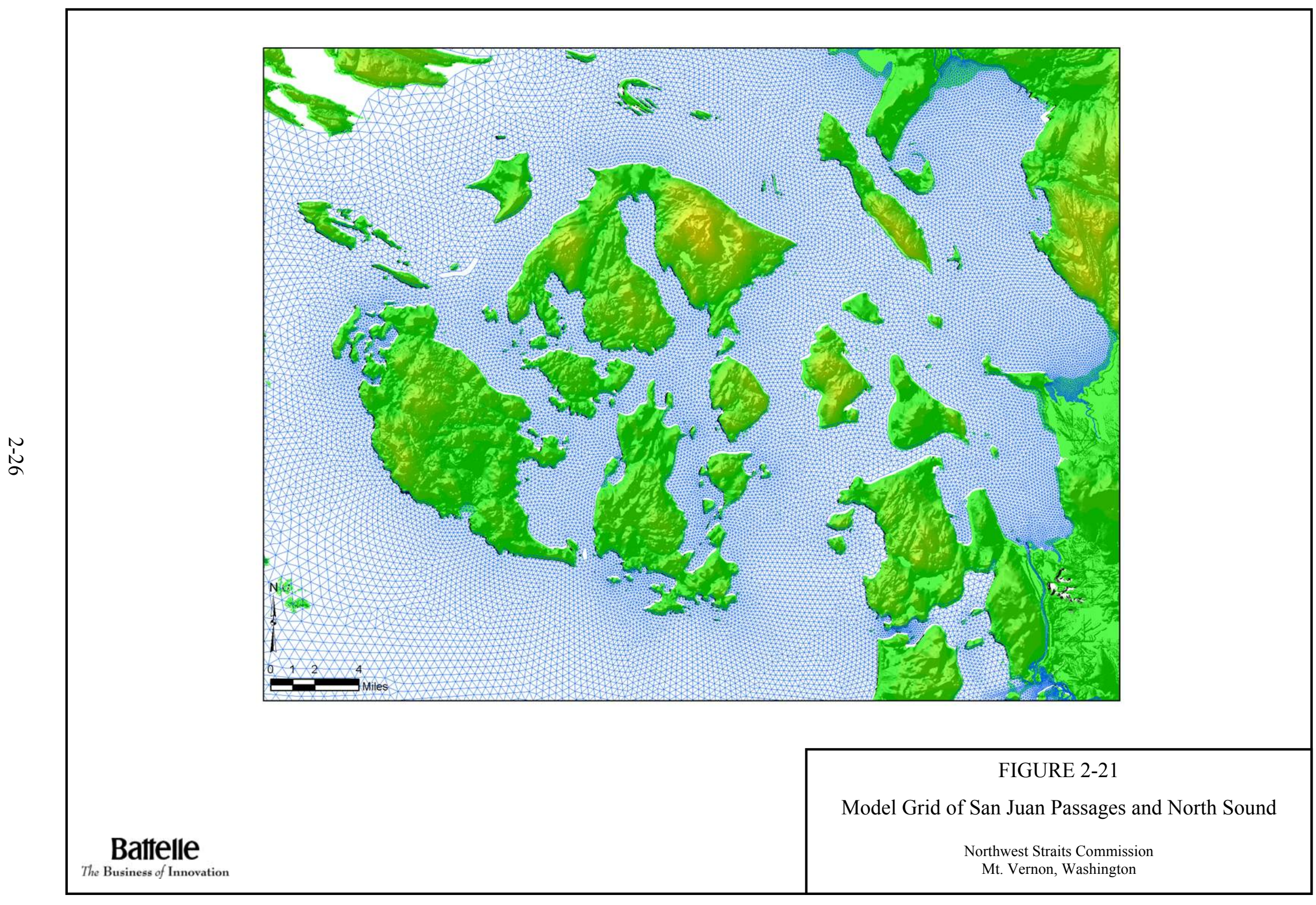




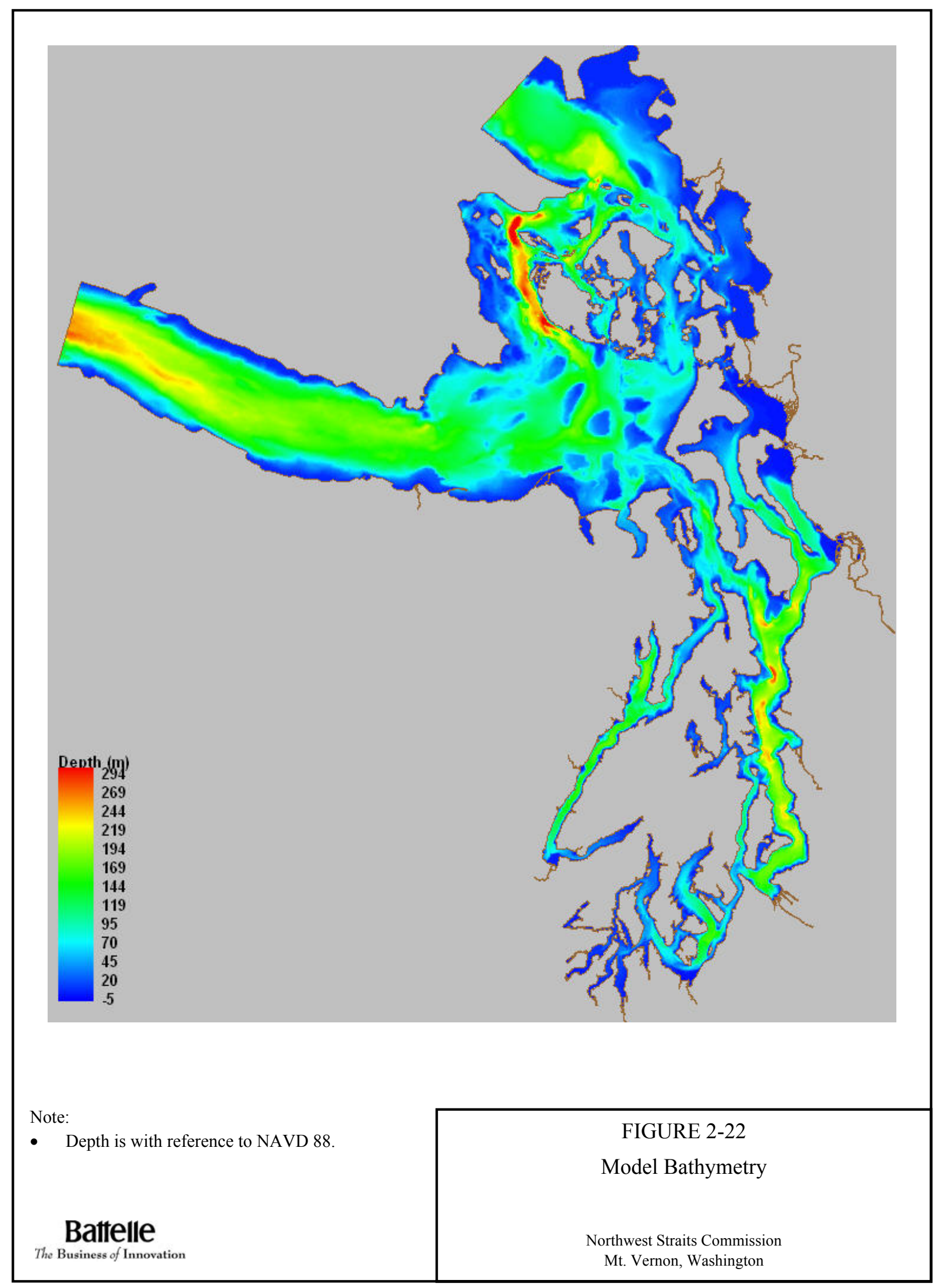




\subsection{Validation of Hydrodynamic Model of Puget Sound}

The model was validated for the period of November 2001. Because many intertidal mudflat areas exist near the mouths of estuaries, wetting and drying processes of the intertidal zone were included in the model. A water depth of $20 \mathrm{~cm}$ was used as the dry-cell criteria in the model (i.e., when the depth fell below $20 \mathrm{~cm}$, the model assumed that the element was dry). Model calibration and validation in general is a long-term and iterative process, especially for complex systems like Puget Sound. As a first step, model validation of Puget Sound focused on tide prediction in Puget Sound. Model validation was conducted primarily through matching model results to NOAA tide data by refining the model grid and adjusting bottom roughness and open boundary conditions.

Predicted water surface elevations at four selected stations in the straits and Puget Sound were compared to NOAA tide data. Figure 3-1 shows comparisons of predicted tidal elevations to the observed data at Port Angeles, Friday Harbor, Bangor, and Tacoma. Predicted water-surface elevations matched the observed data well in all the stations. The spring-neap tidal cycle and the diurnal inequality were reproduced well in the model. Predicted high and low tidal phases were also in good agreement with observed data. As tides propagate from the Strait of Juan de Fuca to Puget Sound, tidal amplitudes are amplified and semi-diurnal tides become more dominant. No current data were available in the Strait of Juan de Fuca for the model simulation period. Predicted velocities were qualitatively compared to velocity data collected by NOAA in 1975. Figure 3-2 shows the comparison of predicted velocities to the observed data at two stations in the eastern Strait of Juan de Fuca. Predicted velocities generally match the data in terms of magnitudes and phase variations.

Comparisons of model results to observed data described above indicate that the model of Puget Sound works properly in general. The model is able to reproduce the basic characteristics of tidal waves and currents in Puget Sound and adjacent water bodies. Further detail and comprehensive model calibration in each subbasin and estuary would require extensive observed data sets and level of effort, which is beyond the scope of work of this study.

To visualize the tide propagation and freshwater plumes in Puget Sound and the straits, predicted horizontal two-dimensional (2-D) tidal elevation, surface velocity, and salinity distributions are generated. Predicted tidal elevations during low tide and high tide with respect to Seattle are presented in Figure 3-3 $(a, b)$. Model results indicate that when water surface elevation is at high tide in Seattle, it is around low to mean tide at the entrance of the Strait of Juan de Fuca. When water surface elevation is at low tide at Seattle, it is around high to mean tide at the entrance of the Strait of Juan de Fuca.

Predicted surface current magnitudes during flood tide and ebb tide with respect to Seattle are shown in Figure 3-4 $(a, b)$. In general, currents are much stronger in the Strait of Juan de Fuca and San Juan Passages than those in Puget Sound. High currents are observed at the mouth of Admiralty Inlet, the Tacoma Narrows, and the entrance of Hood Canal, where shallow sills exit. Model results also show that tidal currents during ebb tide (Figure 3-4b) are generally stronger than those during flood tide (Figure 3-4a). Examples of velocity vector distribution are presented in the San Juan Passages and southern Puget Sound during flood tide and ebb tide (Figures 3-5 to 3-6). Figure 3-6 (a, b) shows that surface currents in the San Juan Passages are very complicated. Water exchange between the Strait of Juan de Fuca and Georgia Strait is mainly through Haro and Rosario straits. 

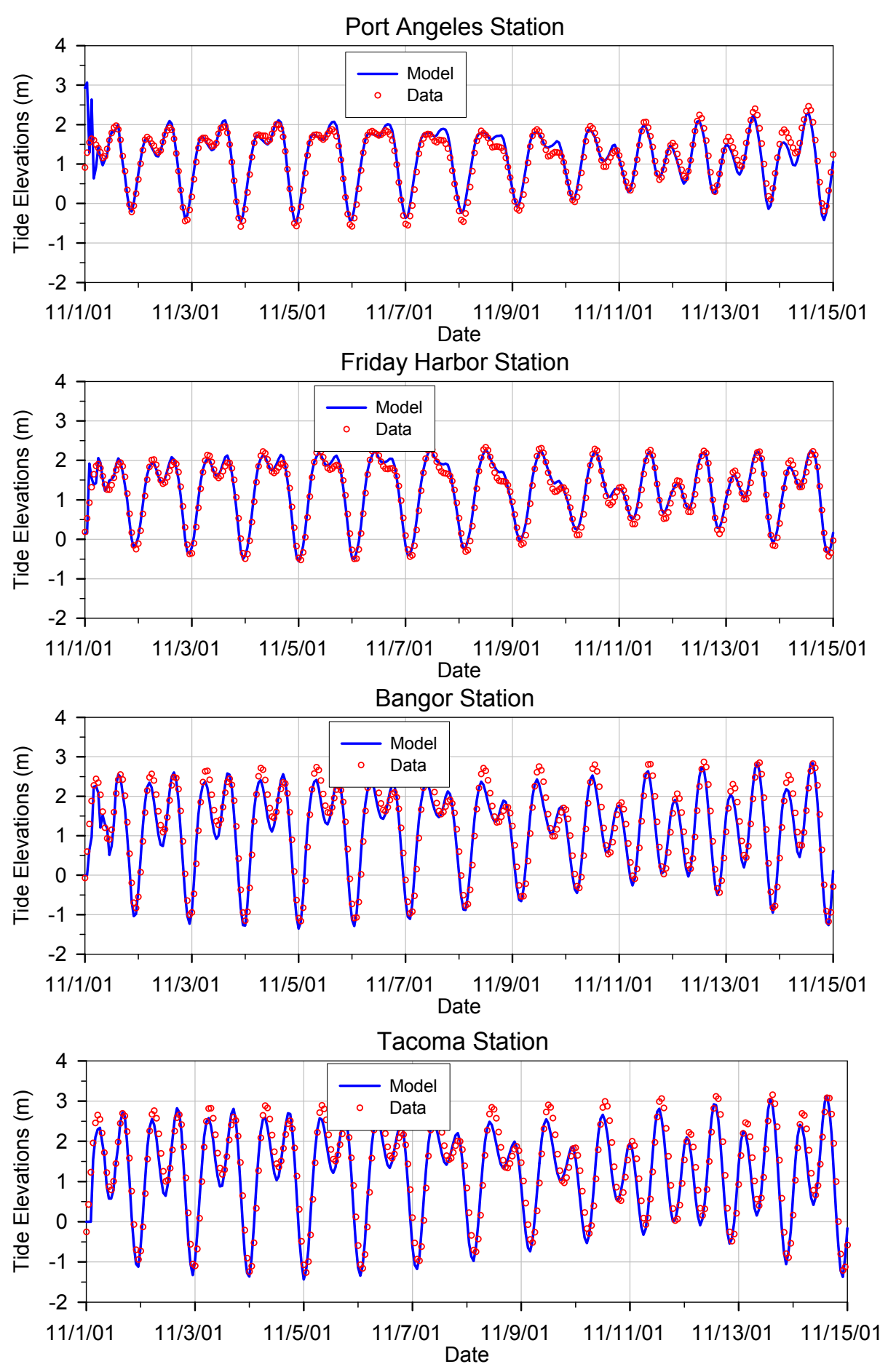

Note:

- Times are in Pacific Time Zone.

- $\quad$ Vertical datum is with reference to NAVD 88

\section{Battelle}

The Business of Innovation
FIGURE 3-1

Model Validations for Water Surface Elevations in Puget Sound

Northwest Straits Commission Mt. Vernon, Washington 


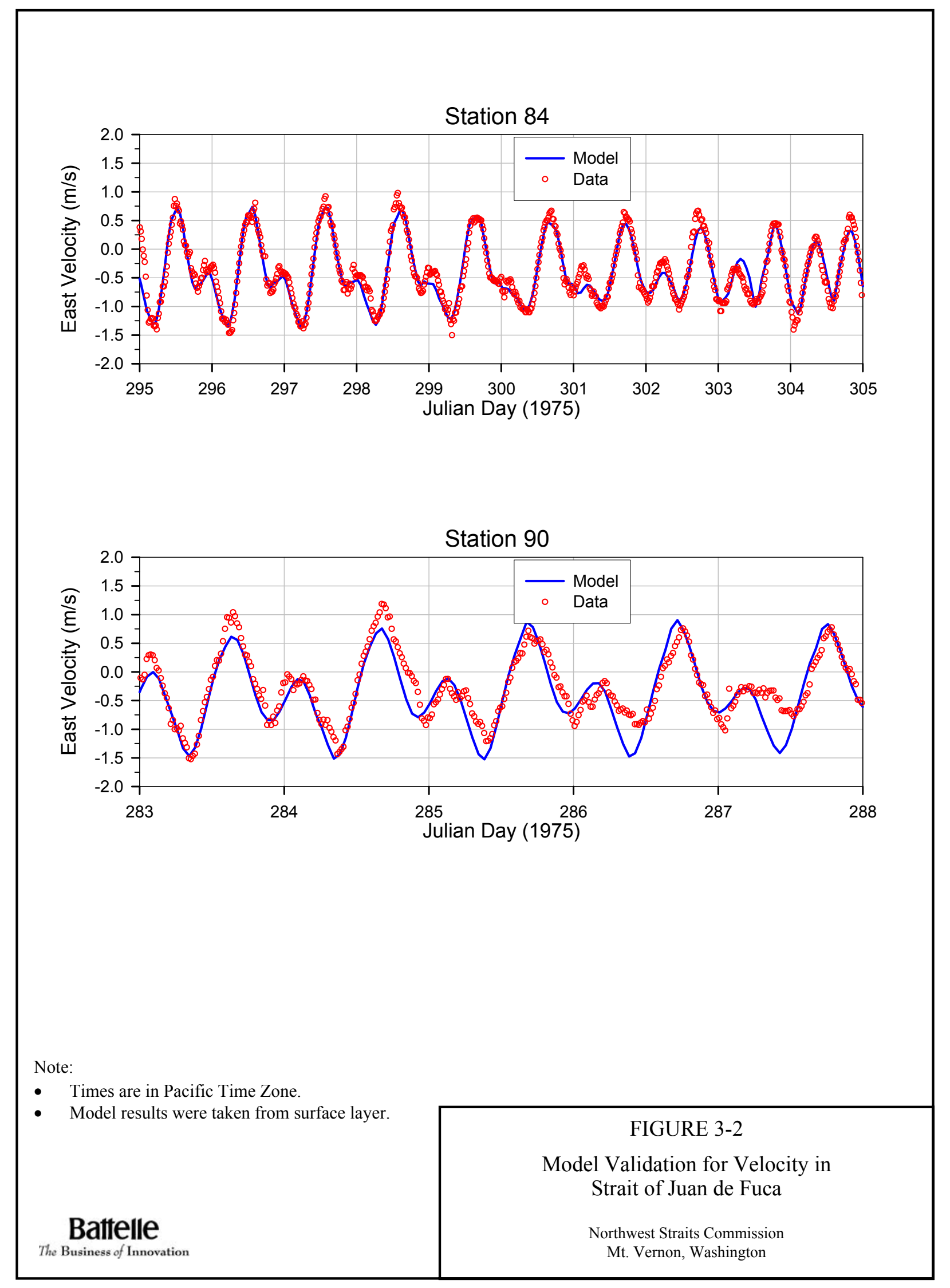




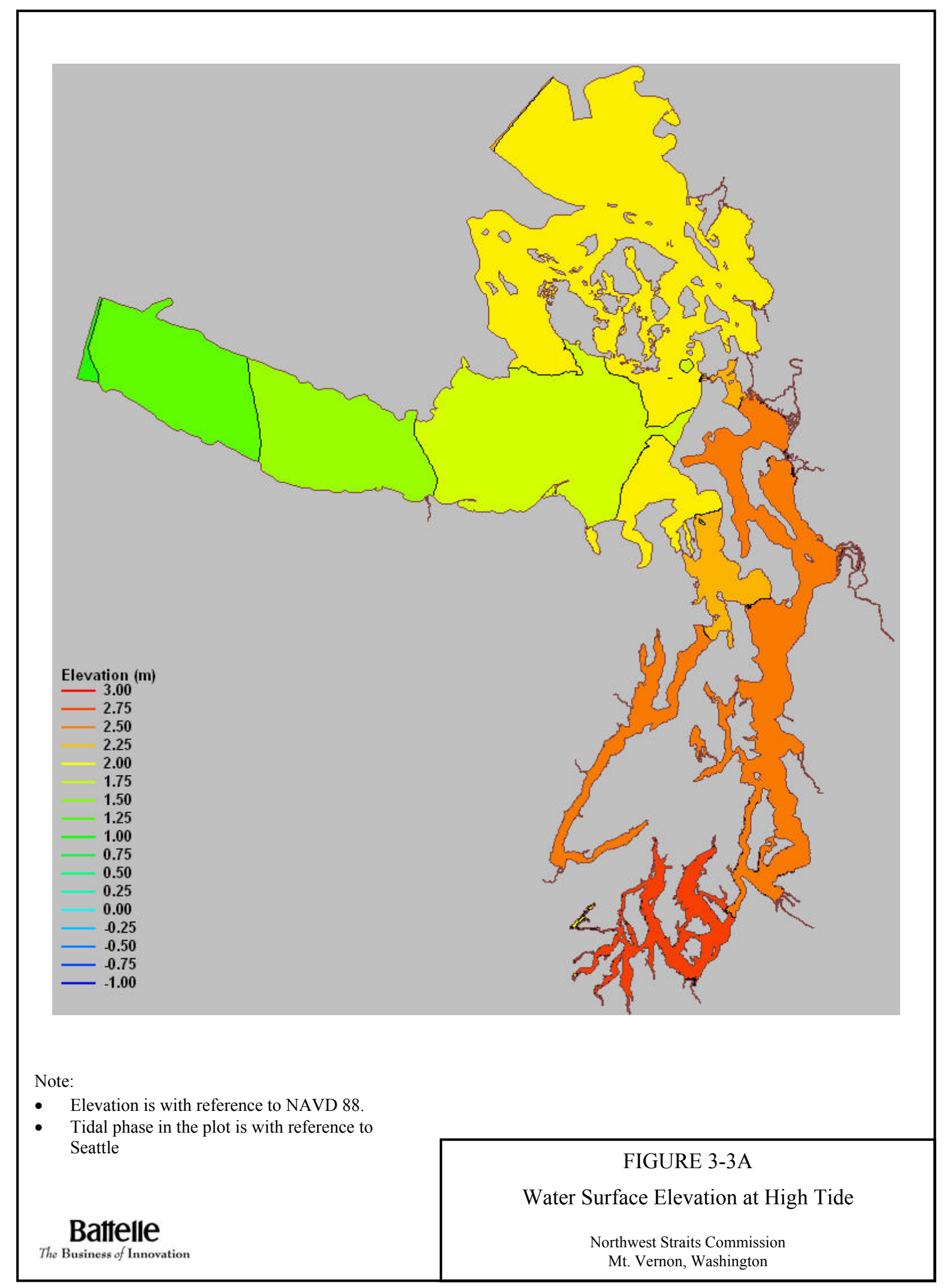




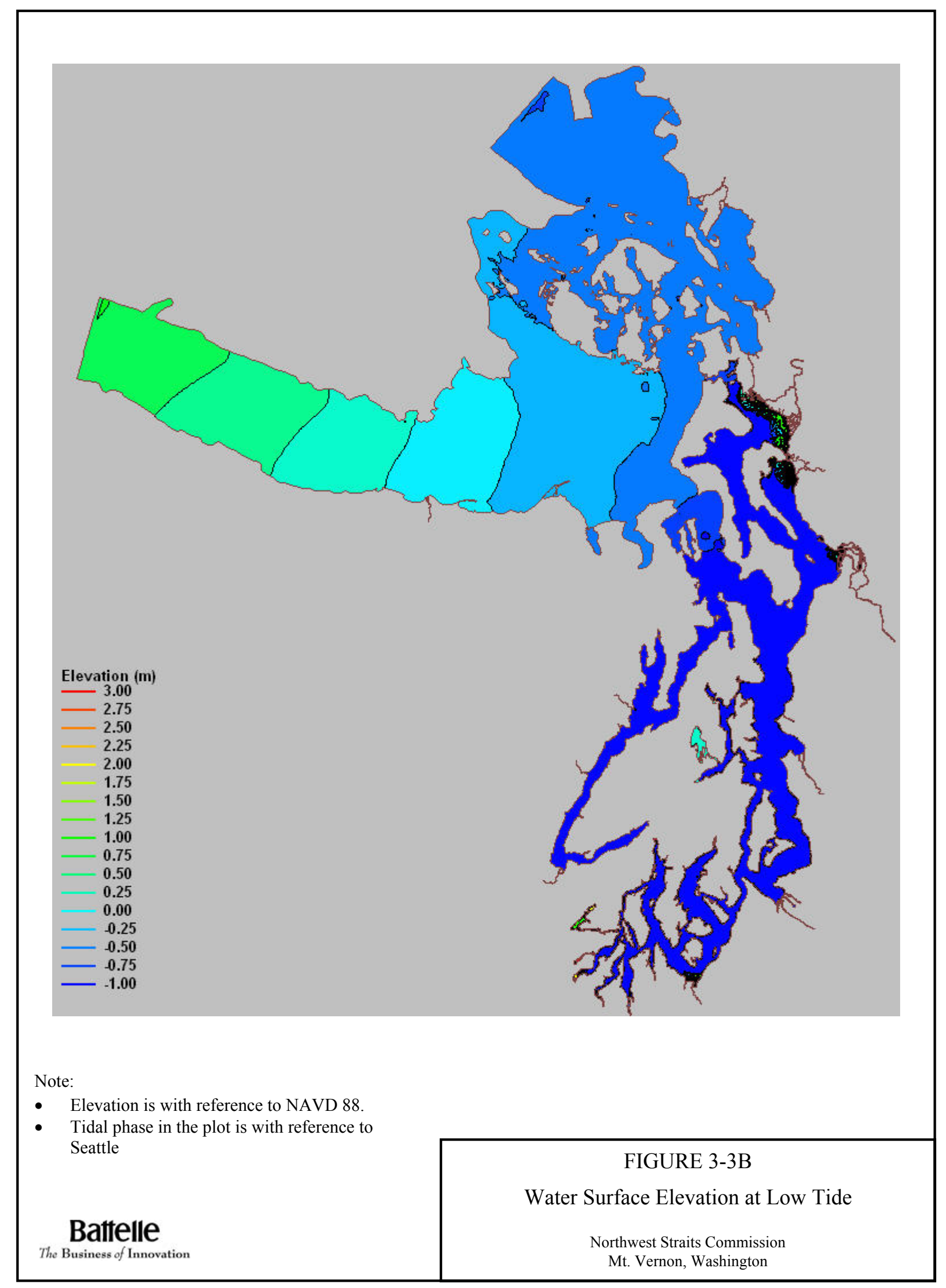




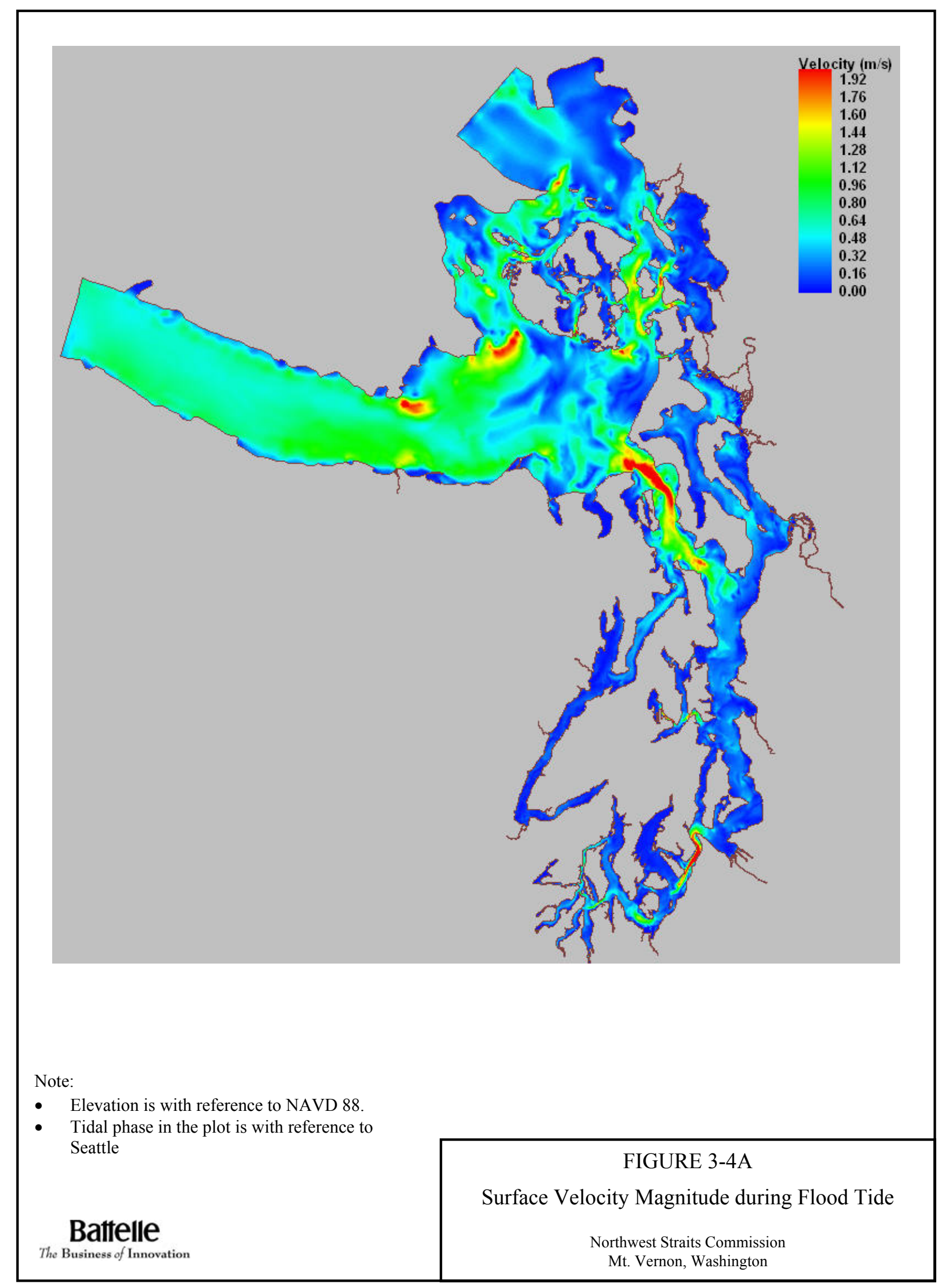




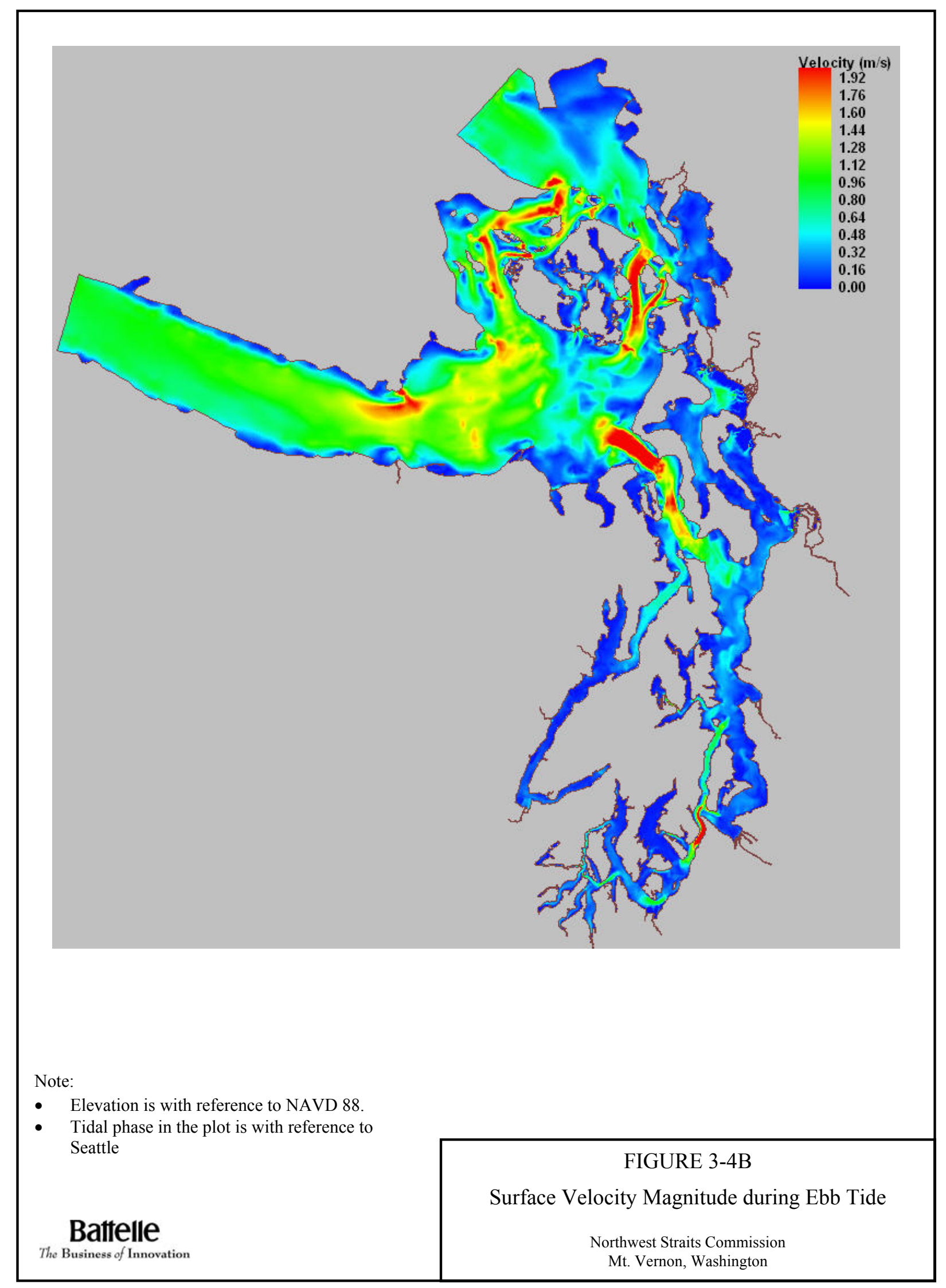




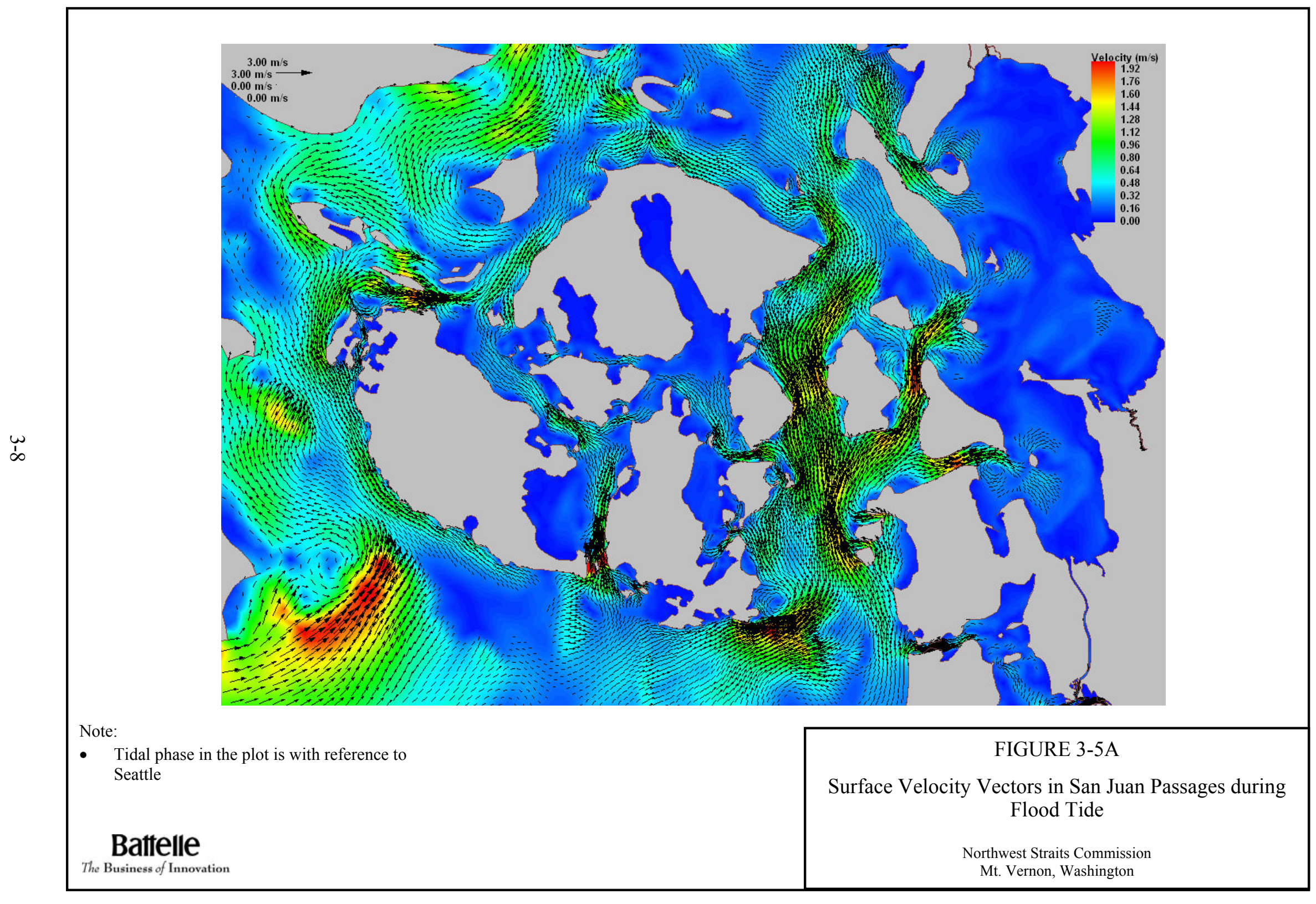




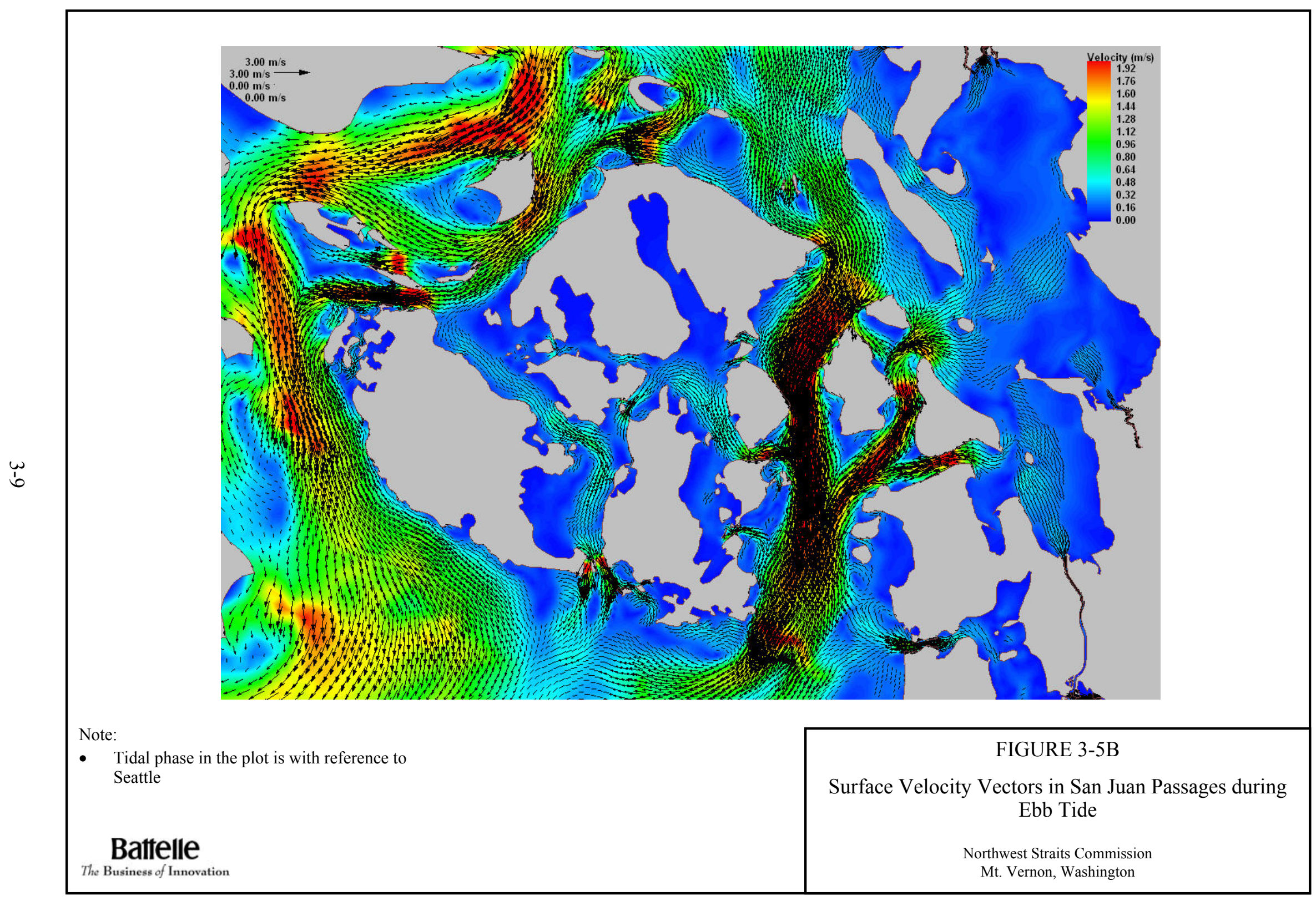




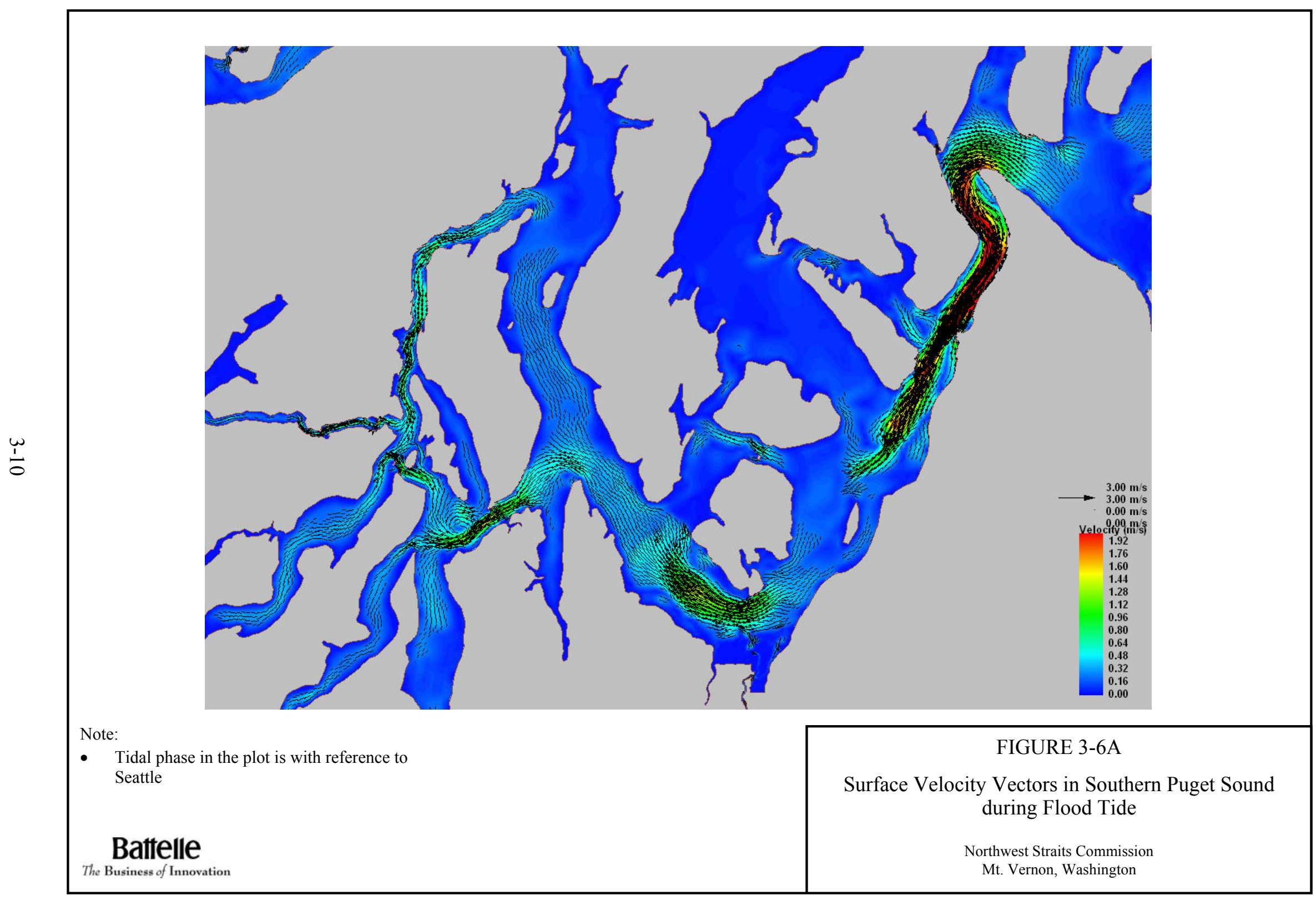




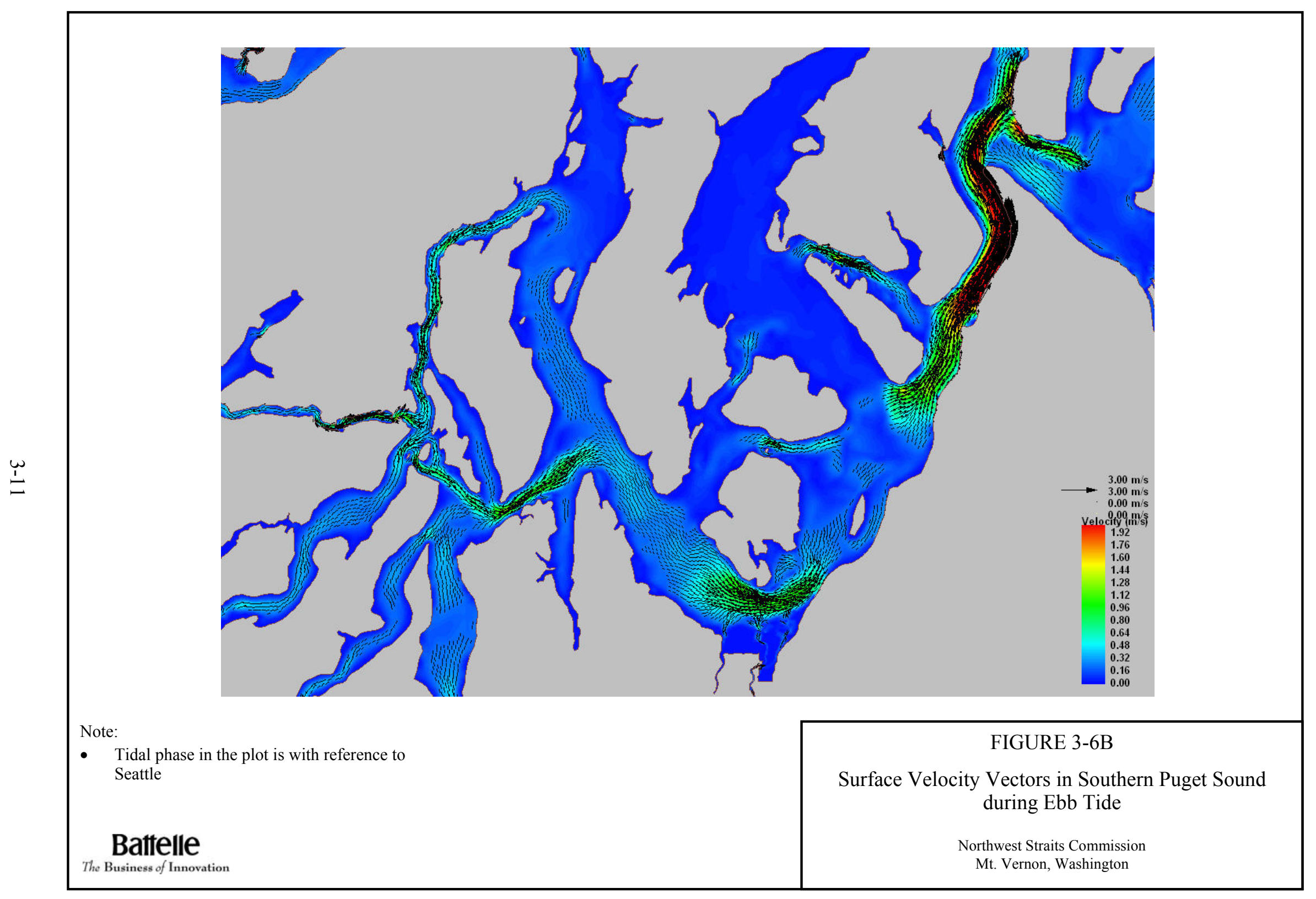


Velocities in the waterways between the islands and North Sound are generally small. In southern Puget Sound, tidal currents are small overall, except in the Tacoma Narrows and the mouth of the Nisqually River (Figure 3-6).

Salinity was simulated in the model with freshwater inputs from all the rivers around Puget Sound and the straits. Figure 3-7 (a, b) shows salinity distributions in Whidbey Basin at high tide and low tide. Strong freshwater plumes discharge from the Skagit River, Stillaguamish River, and Snohomish River. Large areas of tidal mudflats become dry during low tide (Figure 3-7b). Significant portion of freshwater from the Skagit River is trapped in the south Skagit Bay in the entire cycle. Because the Fraser River was not considered in this study, the Nooksack River was the largest river in the straits in the current model domain. Figure 3-8 $(a, b)$ shows salinity distribution in the North Sound. The Freshwater plum from the Nooksack River is quite weak because of relatively low freshwater input (Figure 2-12). The Freshwater plume of the Nooksack River tends to travel along the west shoreline of Bellingham Bay. 


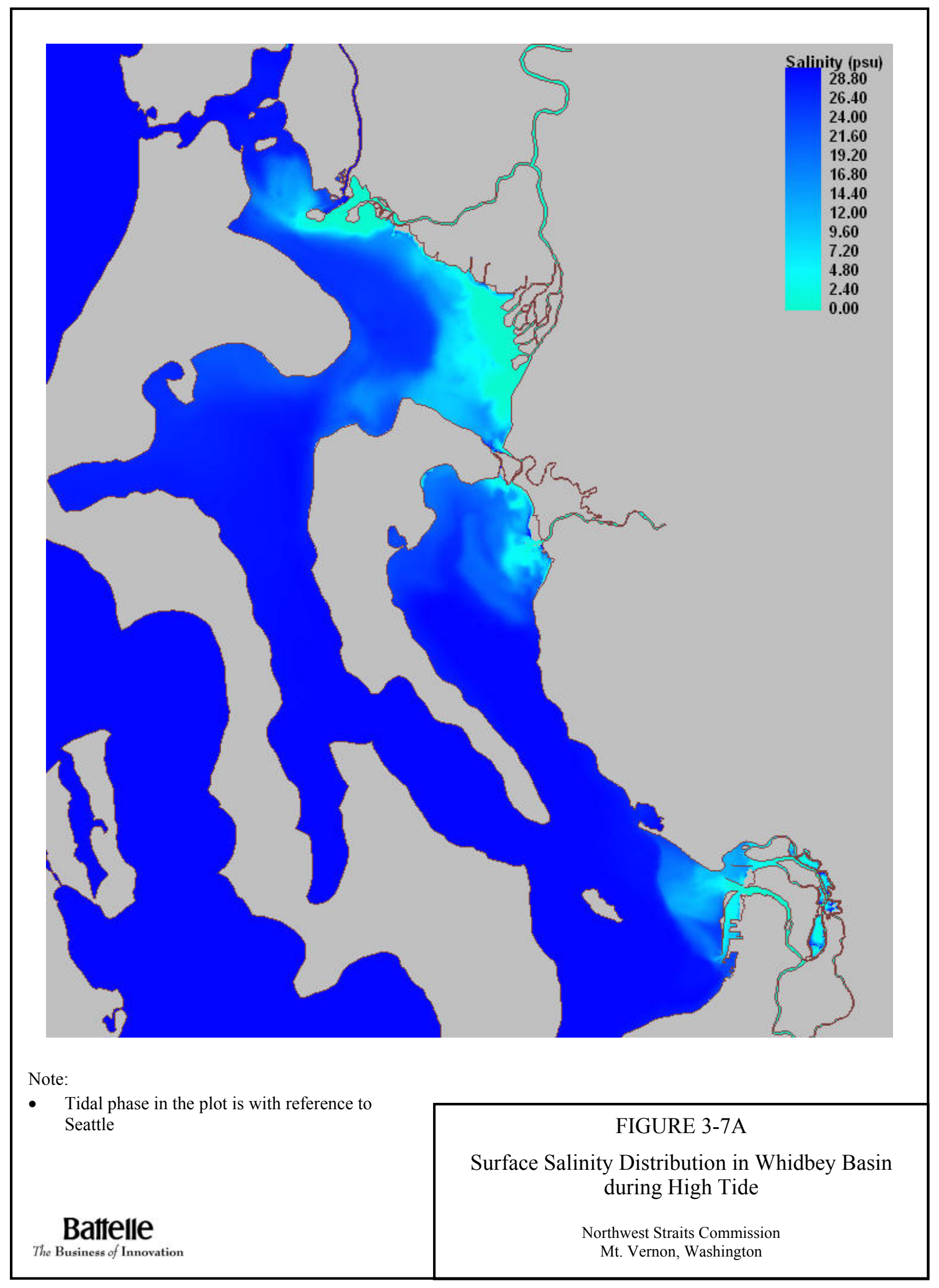




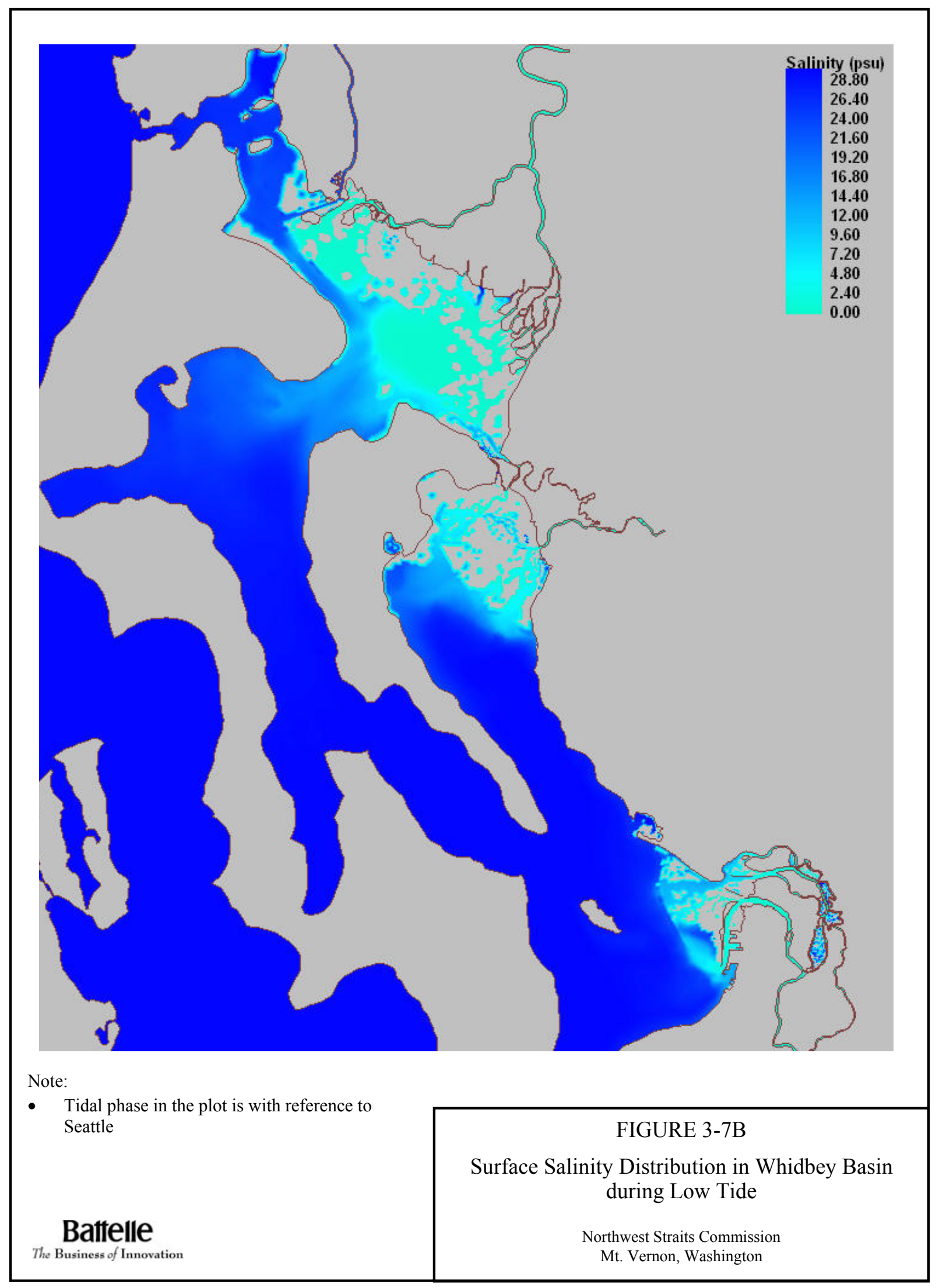




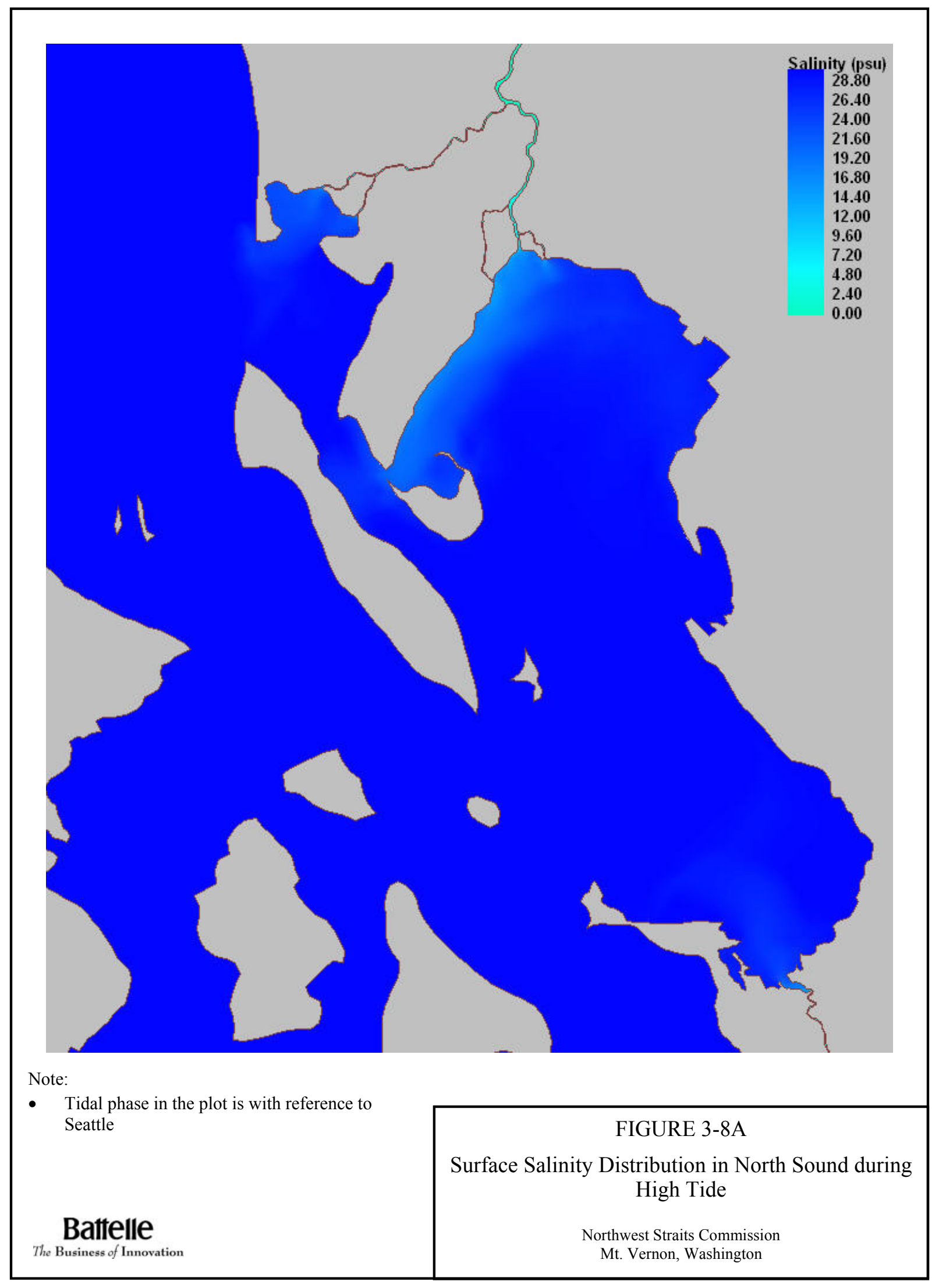




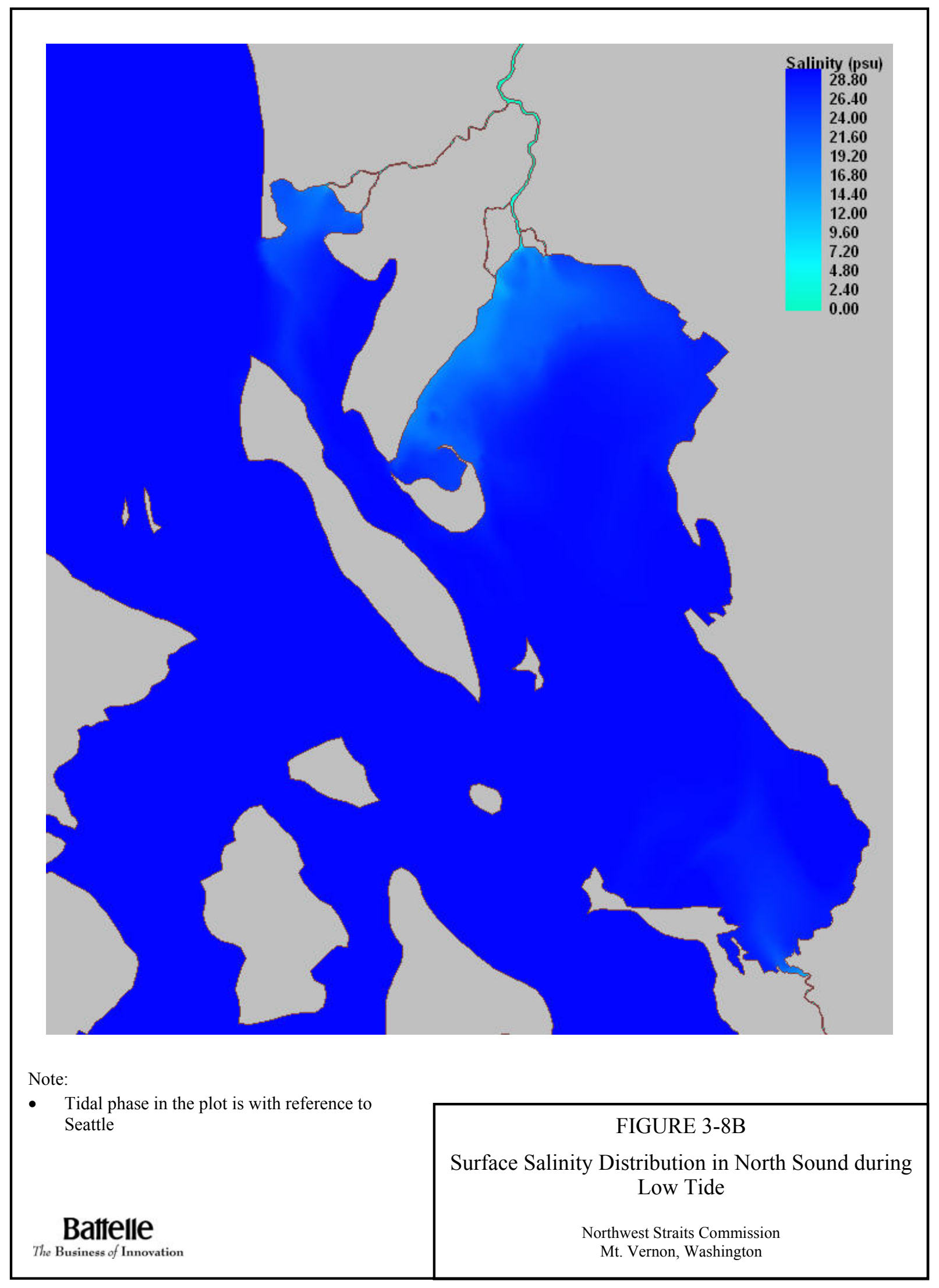




\subsection{Model Application for Water Movement in the Straits}

\subsection{Introduction}

After completion of preliminary model validation, the Puget Sound model was applied to simulate particle movement in the straits and Puget Sound with linkage to the GNOME model. The GNOME model was developed by the Emergency Response Division (formerly the Hazardous Materials Response Division [HAZMAT]) of NOAA's Office of Response and Restoration and is designed for predicting oil spill trajectory during an oil spill. In this study, particles were released as neutrally buoyant particles without specific oil properties.

Specifically, Puget Sound hydrodynamic model solutions were converted into the GNOME location file for the entire Puget Sound and the straits regions. The platform of GNOME with the Puget Sound location file is shown in Figure 4-1. GNOME was applied to simulate particle trajectories in the following six selected locations in Puget Sound and the straits:

- Southern Puget Sound

- Central Basin

- Hood Canal

- Haro Strait

- Rosario Strait

- Strait of Juan de Fuca.

The first three locations are located within Puget Sound, and the last three locations are in the northwest straits. The GNOME model results are presented and discussed in the next subsection.

\subsection{Model Application -Simulations of Particle Trajectories Using GNOME}

\subsubsection{Particle Trajectory Simulation in Puget Sound}

Because the release locations in Puget Sound are far apart from each other, model results for them are presented together in this section. The initial release location in the Central Basin was specified at the mouth of Elliott Bay because it receives extensive shipping traffic to the Port of Seattle. The initial release location in southern Puget Sound was specified in the channel of the Tacoma Narrows because it is the only entrance to southern Puget Sound. The initial release location in Hood Canal was specified at the junction area of Dabob Bay and the northern and southern Hood Canal basins. Particles were released at 11/02/2001, 00:00 a.m. (indicated by the + symbol in the figures). Simulated particle trajectories at intervals of every 4 hours (i.e., 4:00 a.m., 8:00 a.m., 12:00 p.m., 4:00 p.m., 8:00 p.m., and 12:00 a.m.) are presented in Figures 4-2 to 4-7. It is seen that after one day, particles released in the Tacoma Narrows traveled relatively long distances both north and south in and out of the southern Puget Sound. Particles traveled to the Central Basin mainly through Colvos Passage around Vashon Island instead of via the East Passage. Particles released in Hood Canal and Elliott Bay did not travel as long a distance as those in the Tacoma Narrows due to smaller velocity magnitudes (Figure 3-4). Particles released in Hood Canal tended to spread in both directions, in and out of Hood Canal, while most particles released in Elliott Bay tended to travel north along the eastern shoreline. 


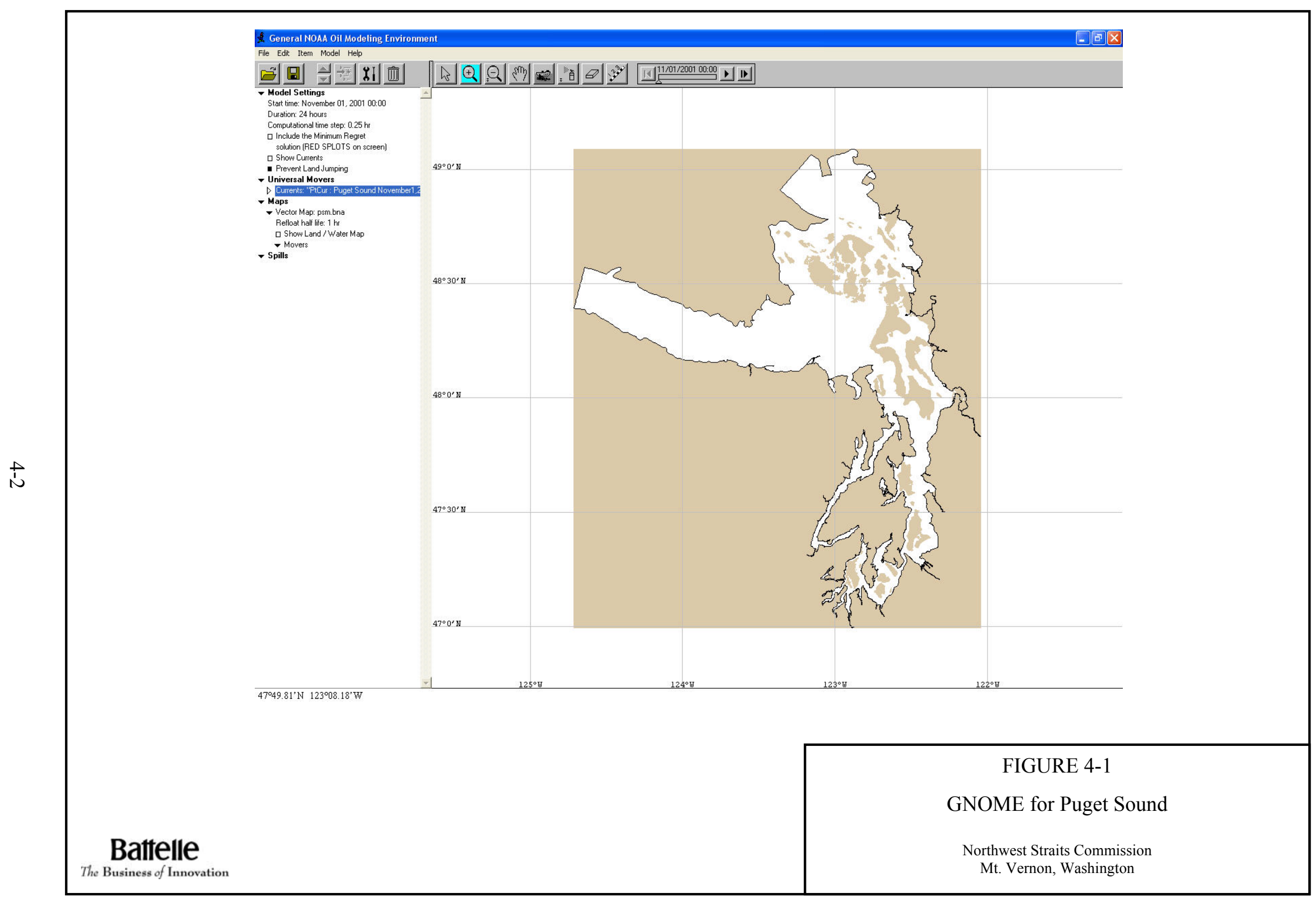




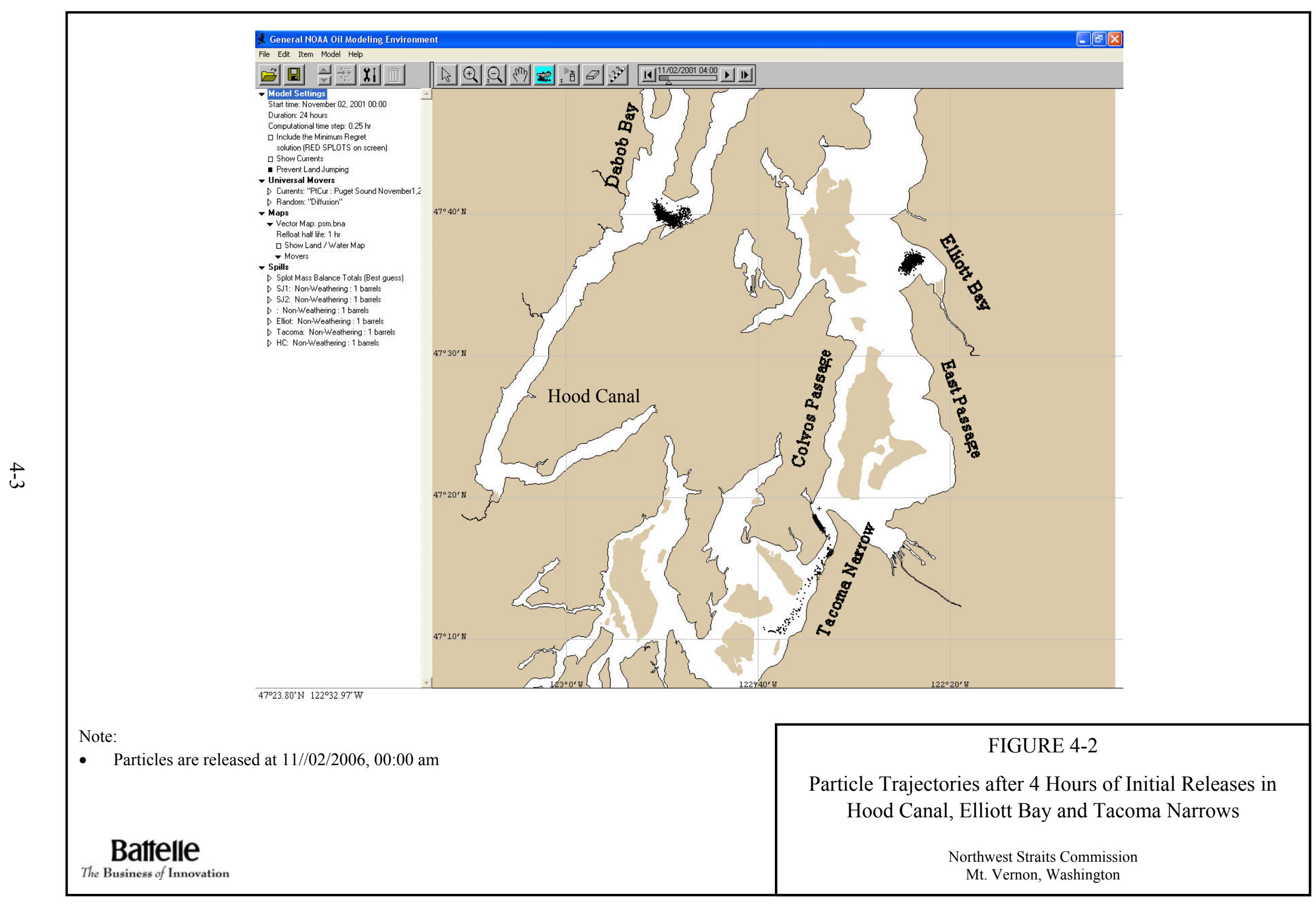




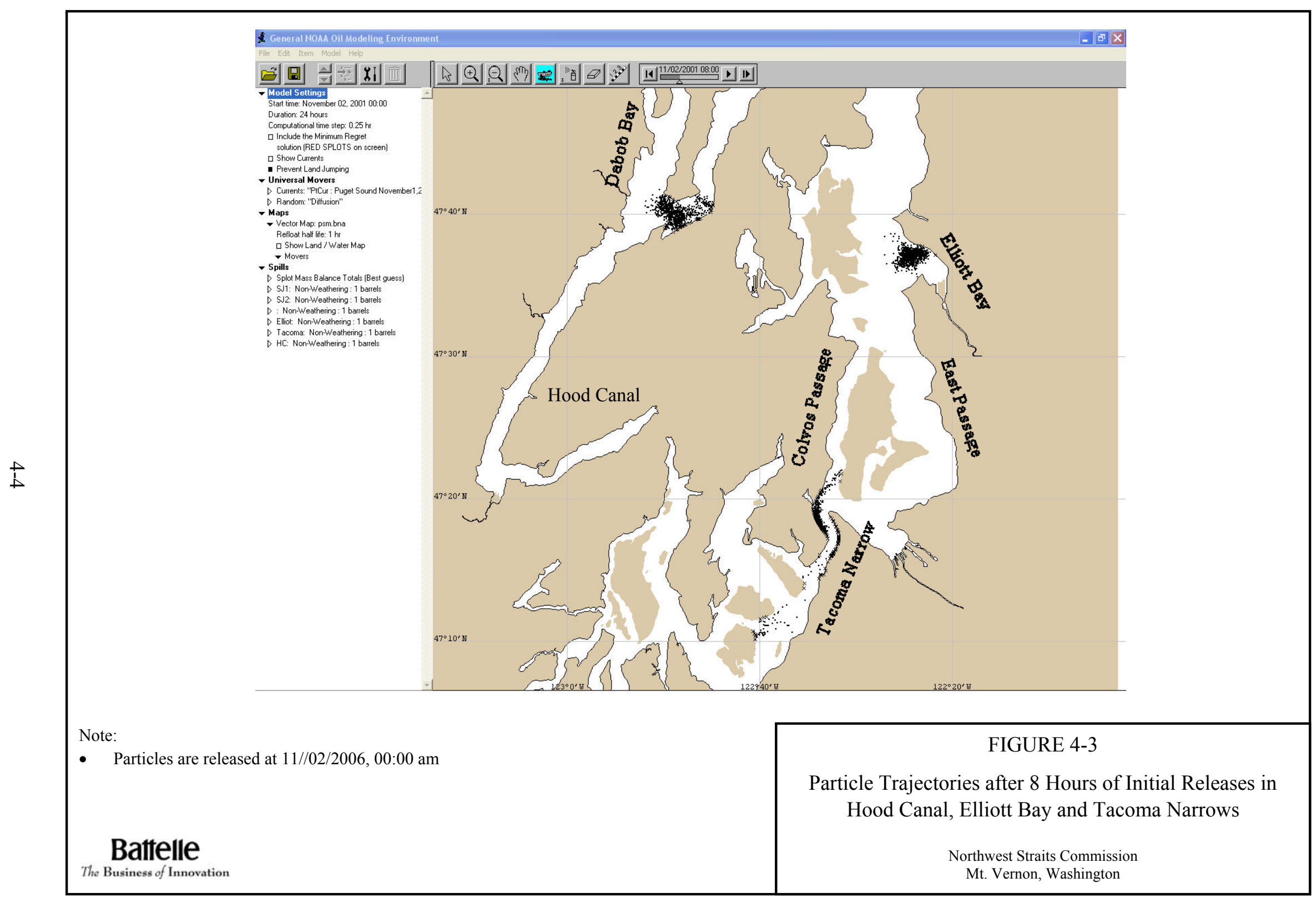




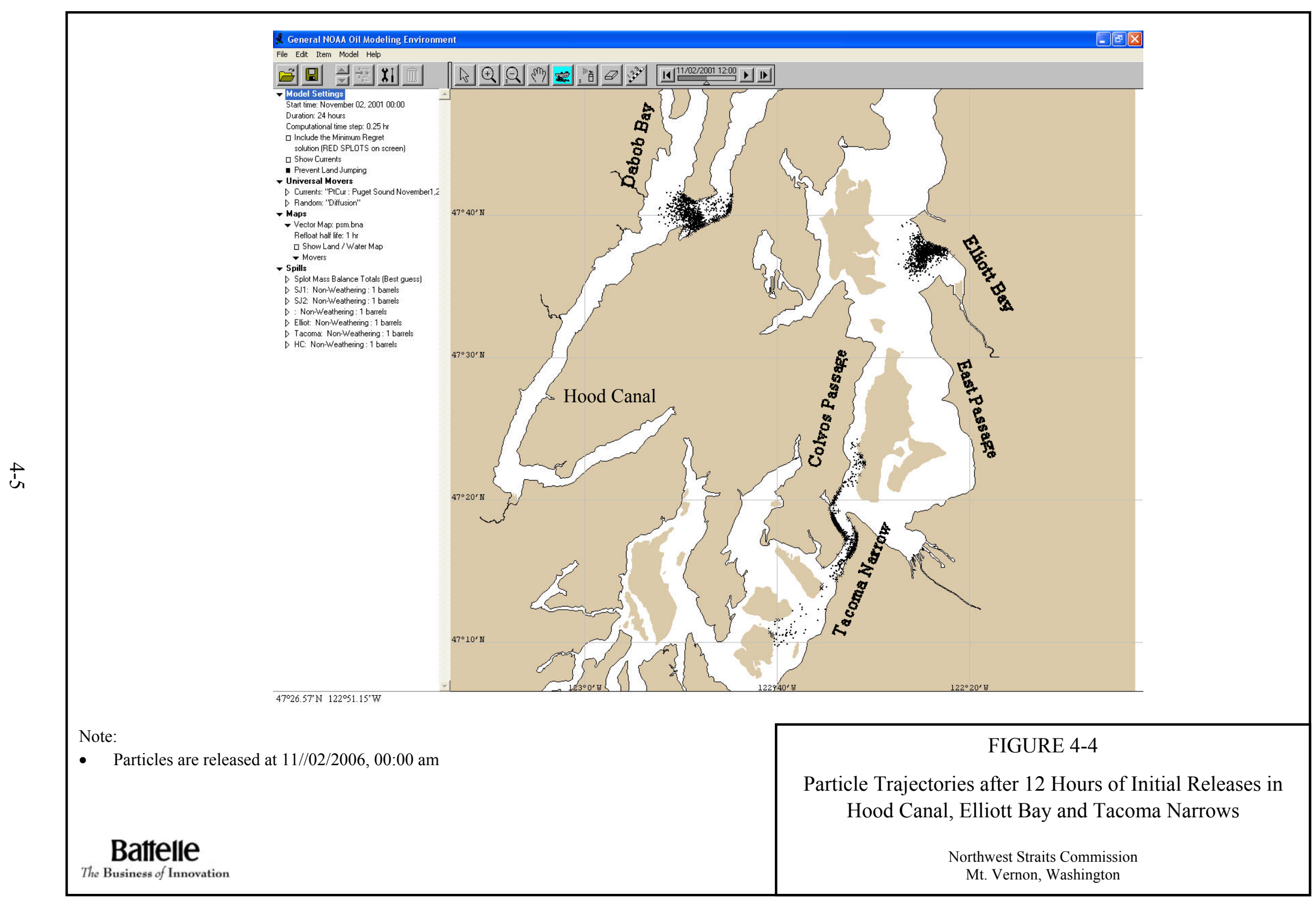




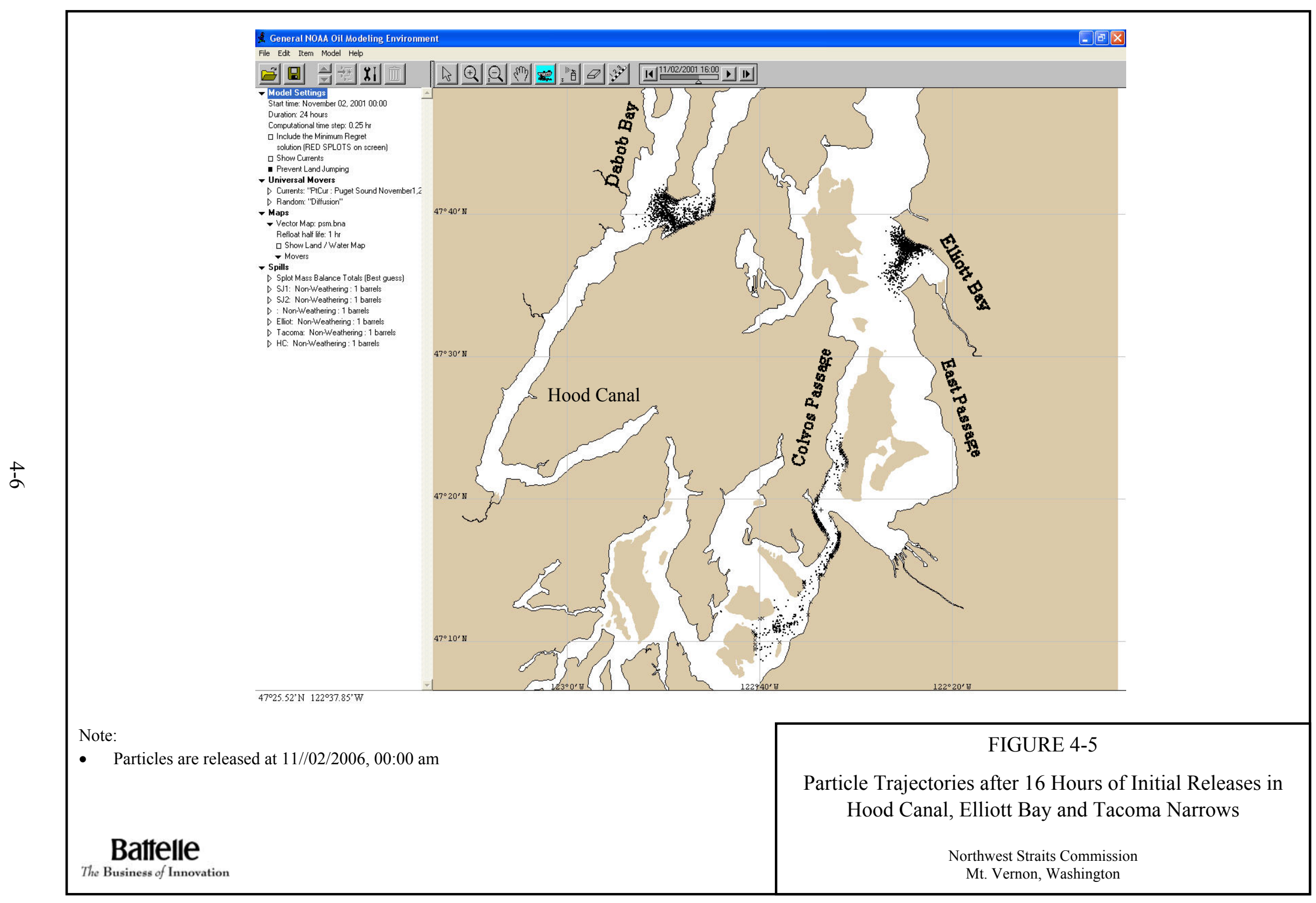




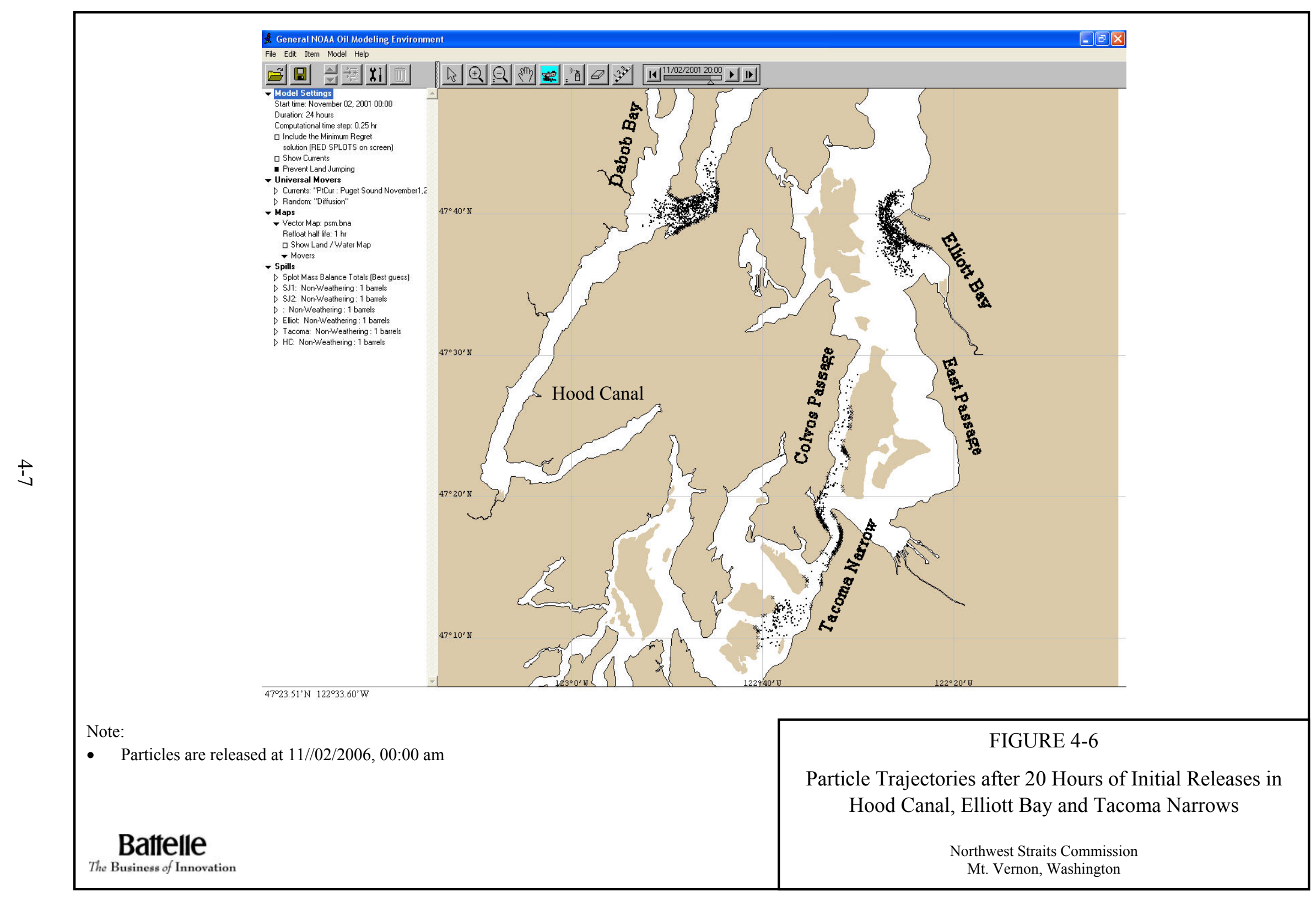




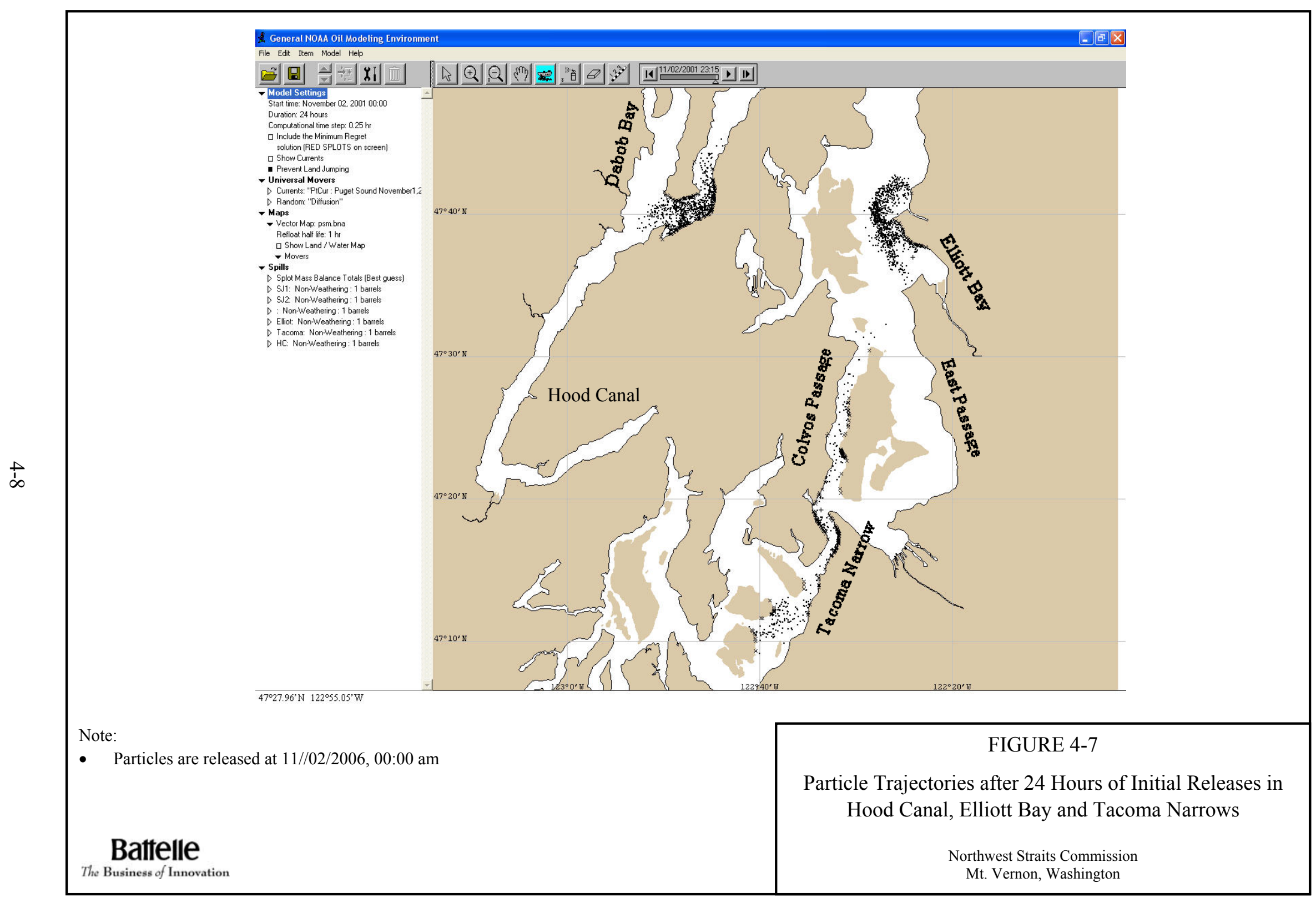




\subsubsection{Particle Trajectory Simulation in Northwest Straits}

Particle trajectories in the Northwest Straits region were simulated at the three locations: 1) Haro Strait, 2) Rosario Strait, and 3) the Strait of Juan de Fuca. Haro Strait and Rosario Strait were selected because they are the main water exchange pathways between the Strait of Juan de Fuca and Georgia Strait. Initial particle release locations were specified in the middle of Haro Strait and Rosario Strait. Initial particle release location in the Strait of Juan de Fuca was specified near the coast between Port Angeles and Dungeness Spit. Initial particles were released at 11/02/2001, 00:00 a.m. at the same time for all three locations (indicated by the + symbol in the figures). Simulated particle trajectories in the Northwest Straits at intervals of every 4 hours (i.e., 4:00 a.m., 8:00 a.m., 12:00 p.m., 4:00 p.m., 8:00 p.m., and 12:00 a.m.) are presented in Figures 4-8 to 4-13. Particles released at Haro Strait tended to travel south to the Strait of Juan de Fuca and continued westward to the ocean along the coastline of Vancouver Island. Particles released in Rosario Strait tended to move both north and south along the waterway, but the majority of the particles moved to the south to the Strait of Juan de Fuca. Particles released near Port Angeles and the Dungeness Spit traveled to the west to the Pacific Ocean in the Strait of Juan de Fuca. 


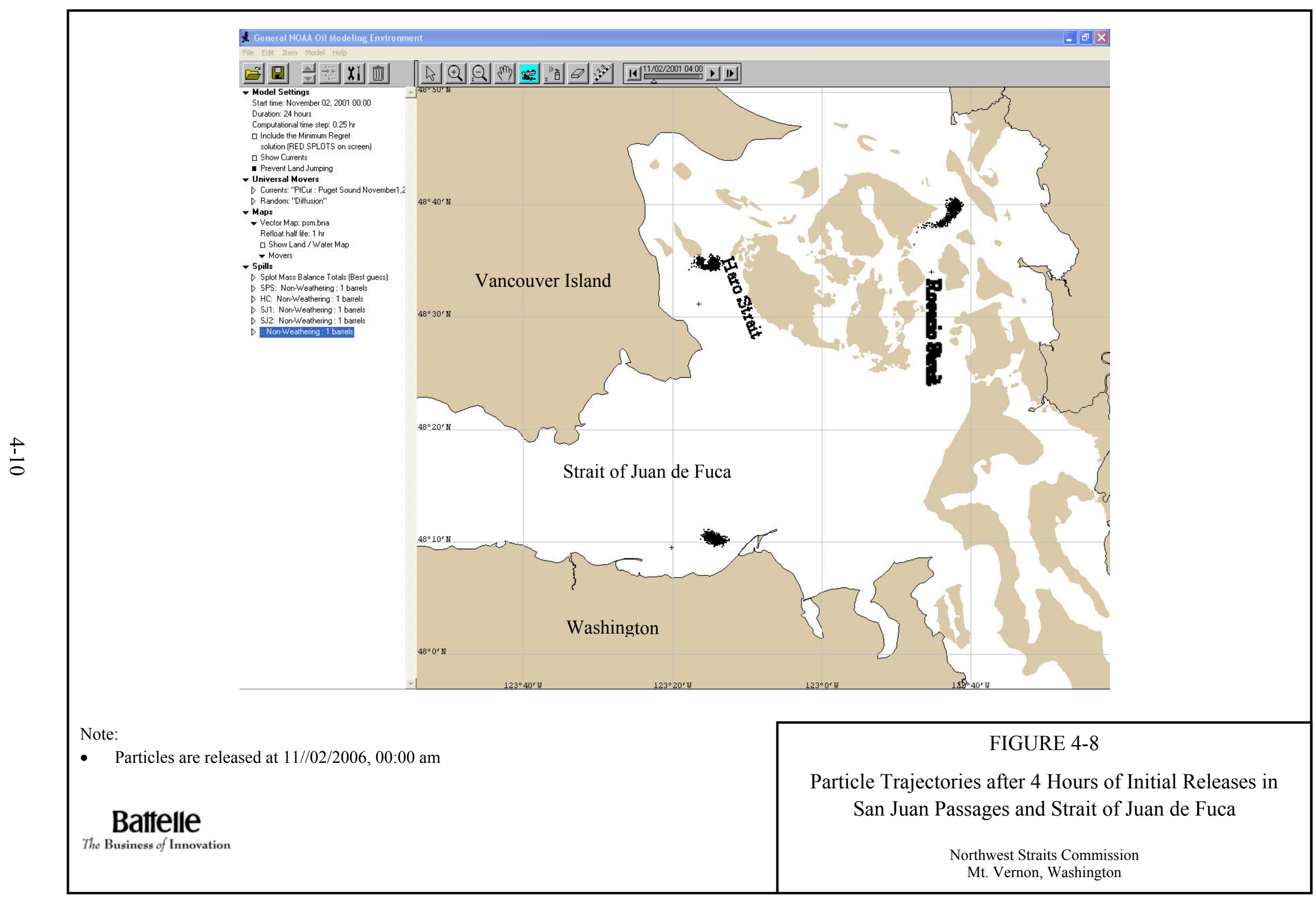




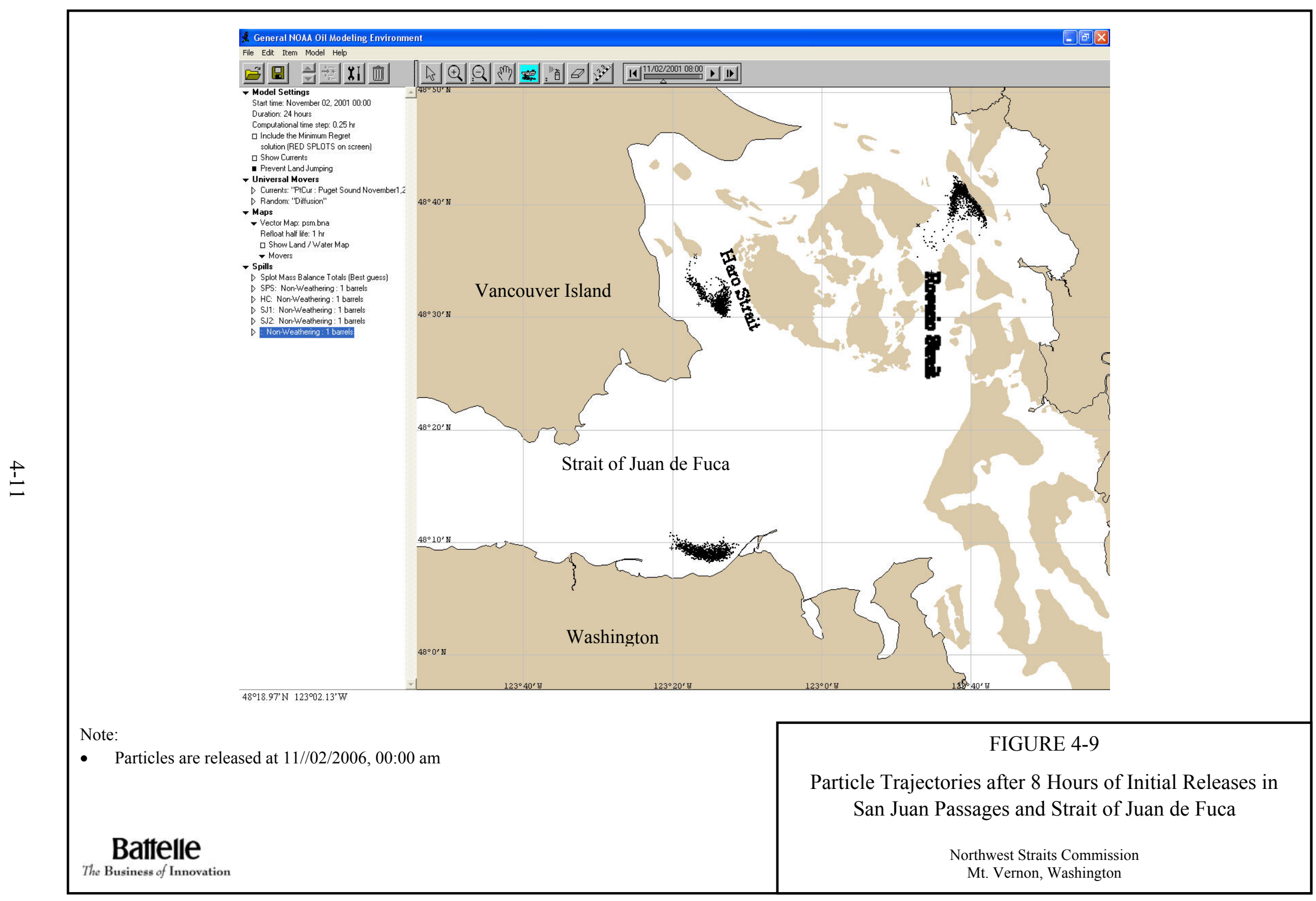




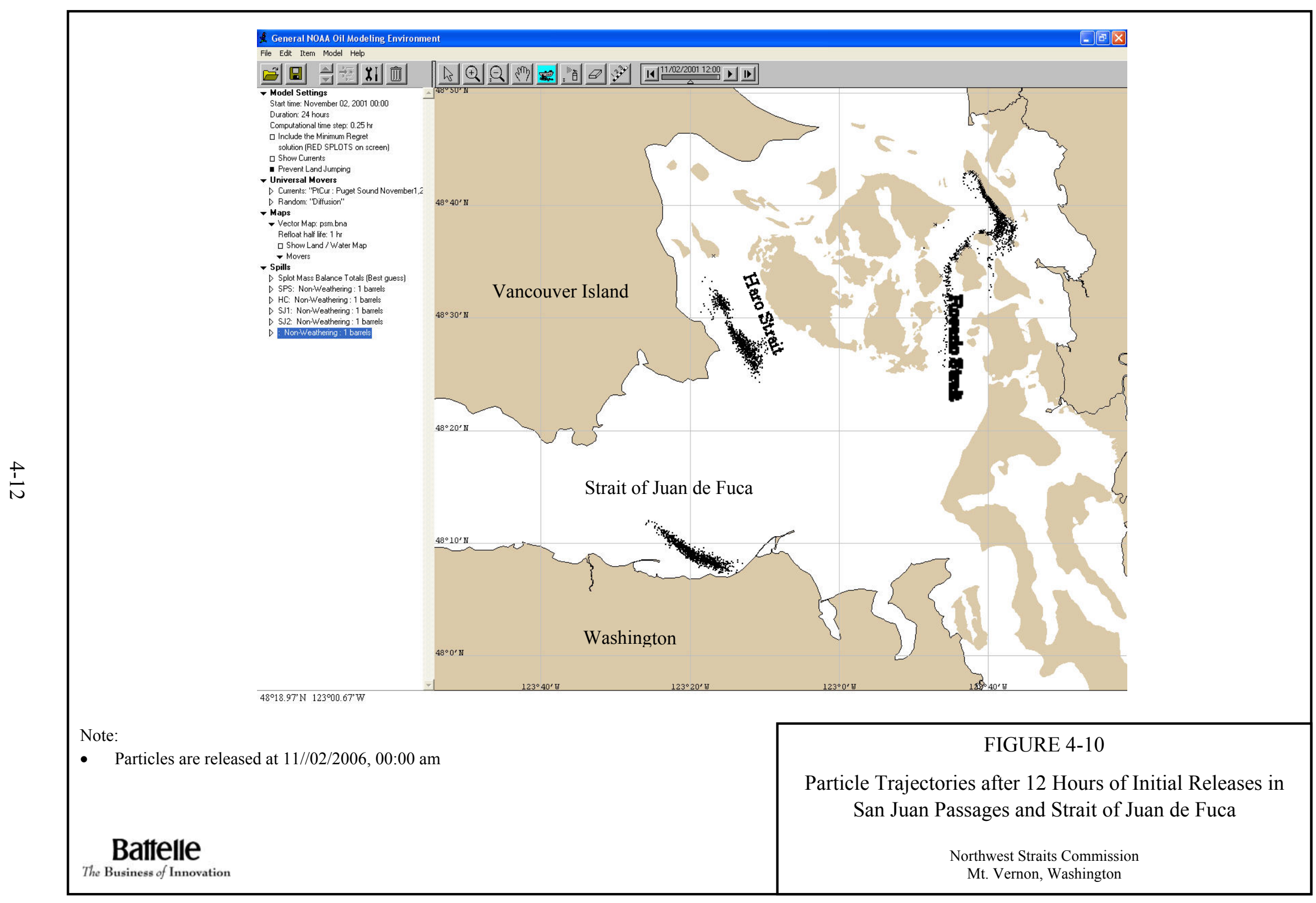




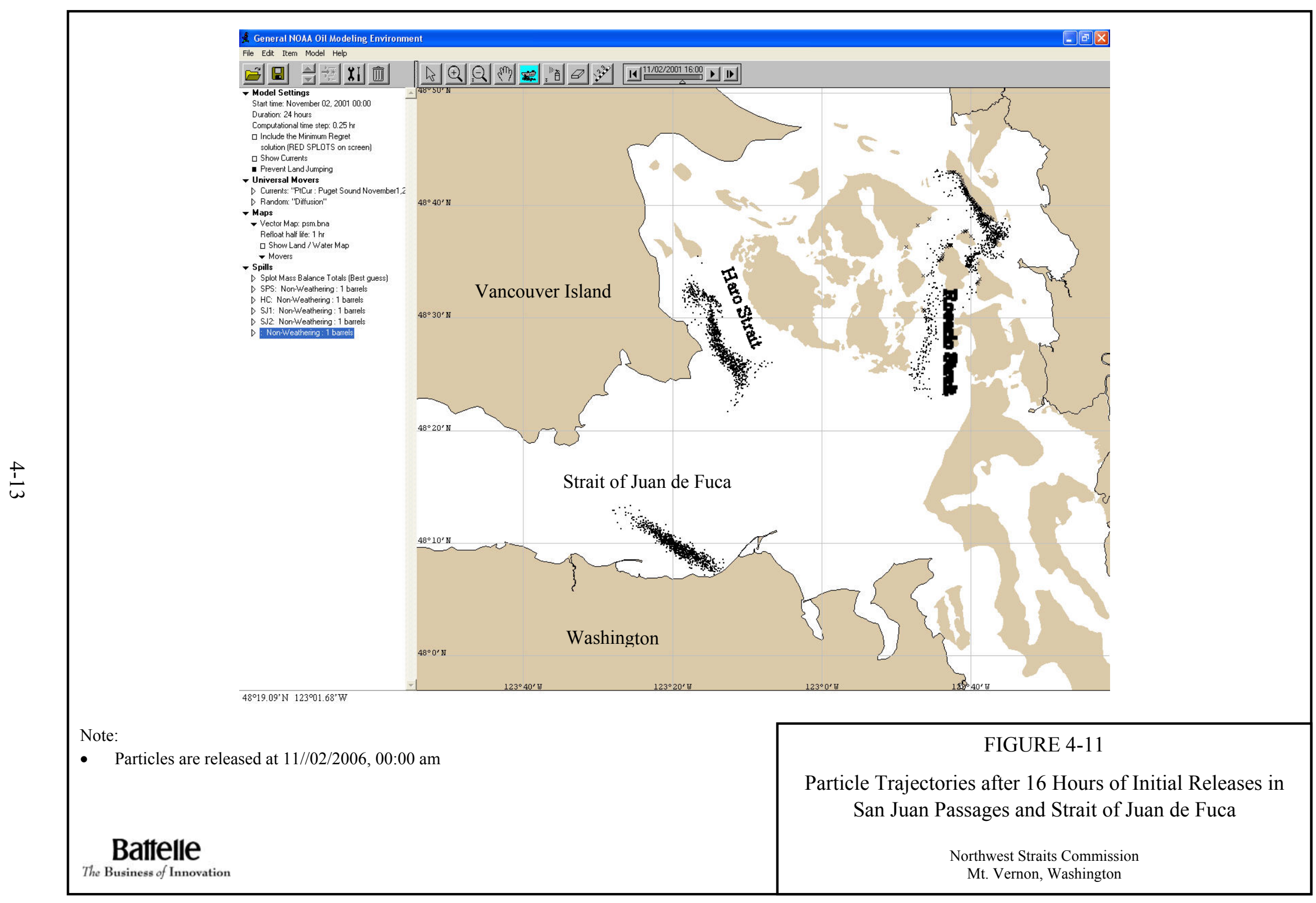




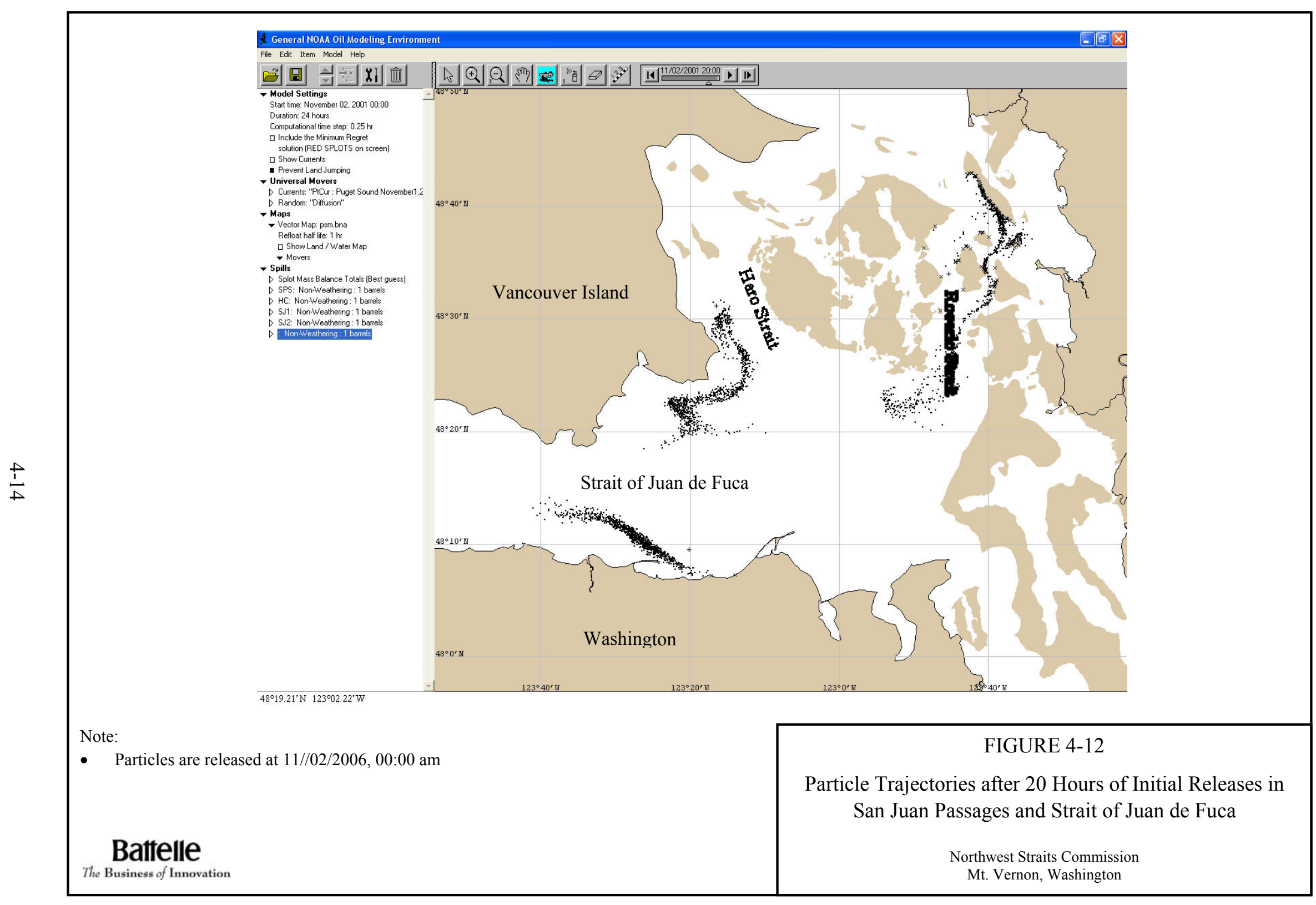




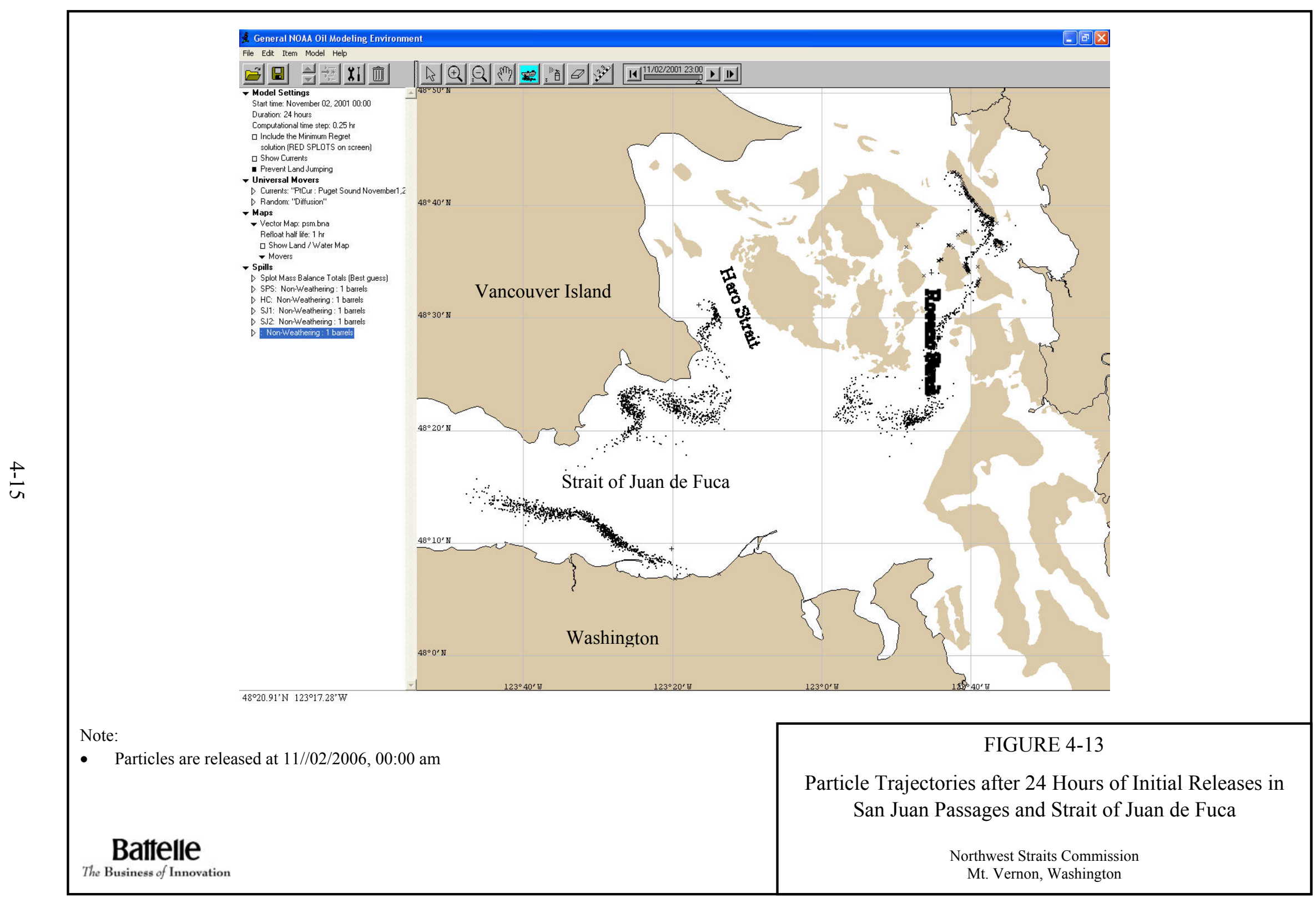




\subsection{Summary and Conclusions}

In this study, a 3-D hydrodynamic model for Puget Sound and the straits was developed to support NWSC's mission of protecting and restoring marine resources in Puget Sound and the straits. The hydrodynamic model used in this study is the Finite Volume Coastal Ocean Model (FVCOM) developed by the University of Massachusetts at Dartmouth. The unstructured grid and finite volume framework, as well as the capability of wetting/drying simulation and baroclinic simulation, makes FVCOM a good fit to the modeling needs for nearshore restoration in Puget Sound. The model domain covers the entire Puget Sound, Strait of Juan de Fuca, San Juan Island and San Juan Passages up north to the United StatesCanada Border. The model consists of high-resolution near shore regions developed specifically to guide near shore restoration actions. The model was driven by tides, freshwater discharge, and surface wind. Model simulation was conducted for a two-week period in November 2001. Preliminary model validation was conducted for tides at various locations in the straits and Puget Sound based on NOAA tide data. The hydrodynamic model was successfully linked to the NOAA oil spill model GNOME to predict particle trajectories at various locations in Puget Sound. The Puget Sound GNOME model is a powerful tool that can be used to provide first-hand information for emergency response such as oil spills and to assess impacts to fish migration pathways. The specific model results are summarized below:

- A near shore high-resolution 3-D hydrodynamic model for the entire Puget Sound, Strait of Juan de Fuca, San Juan Islands, and Southern Georgia Strait was developed for prediction of circulations driven by tides, winds, and density gradients.

- Model prediction for tides matched the NOAA tide data well at various locations in the straits and Puget Sound.

- The model reproduced tidal wave characteristics such as phase difference, amplitude amplification, diurnal inequality, and Coriolis effect reasonably well in the entire model domain.

- The model successfully simulated freshwater plume dispersion and transport in many estuaries and bays in Puget Sound and the straits.

- The model was successfully linked to the NOAA oil spill model GNOME for particle trajectory simulations in Puget Sound and the straits. GNOME was applied to simulate particle trajectories in six selected locations in Puget Sound and the straits.

While the Puget Sound model was successfully developed and preliminary model validation was conducted, considerable effort is still needed before the model can achieve operational status and forecasting capabilities. Further improvement of the model is necessary in several areas and is being pursued as part of ongoing PNNL Puget Sound model development efforts. Specific model limitations and improvements are listed below.

- Further calibration/validation of the model is necessary at every estuary, bay, and subbasin and will be conducted as part of future site-specific studies and as sufficient measured data become available. 
- In the current model setup, the northern model open boundary was specified along the United States-Canada border, and the Fraser River was not considered due to the lack of bathymetry data on the Canada side. To simulate the effect of the Fraser River on Puget Sound, it is important to include the Fraser River and extend the model domain to the entire Georgia Strait.

- Wind may play an important role in circulation in some shallow water regions in Puget Sound. Spatial uniform wind stress was applied in the current model configuration. To simulate wind effect accurately, spatial varied wind force should be considered, either based on multiple meteorological observation stations around Puget Sound or on predicted wind field from the meteorological model.

- The entire model domain covering the Strait of Juan de Fuca, Puget Sound, and Georgia Strait is generally considered as a large, complex estuarine system. Initial conditions of salinity and temperature fields are important for accurate simulation of long-term, subtidal circulations in Puget Sound. Initial conditions can be improved based on climatology data. 


\subsection{References}

Chen C, H Liu, and RC Beardsley. 2003. "An Unstructured, Finite-Volume, Three-Dimensional, Primitive Equation Ocean Model: Application to Coastal Ocean and Estuaries." J. Atm. \& Oceanic Tech. 20:159-186.

Chen C, J Zhu, L Zheng, E Ralph, and JW Budd. 2004. "A Non-Orthogonal Primitive Equation Coastal Ocean Circulation Model: Application to Lake Superior.” J. Great Lakes Res. 30(Supplement 1):41-54.

Mellor, G.L. and T. Yamada (1982), "Development of a Turbulence Closure Model for Geophysical Fluid Problems,” Rev. Geophys. Space Phys. 20: pp 851-875.

Smogarinsky, J. (1963), "General Circulation Experiments with the Primitive Equations. I. The Basic Experiment," Mon. Weather Rev. 91: pp. 99-164.

Yang Z, H Liu, T Khangaonkar, and B Perkowski. 2006. "Development of a Hydrodynamic Model for Skagit River Estuary for Estuarine Restoration Feasibility Assessment." In: Proceedings of the $9^{\text {th }}$ International Conference, ML Spaulding et al. (eds.). American Society of Civil Engineers, Charleston, SC, pp. 752-767.

Yang Z and T Khangaonkar. 2007. "Modeling of Salt Intrusion, Intertidal Mixing, and Circulation in a Braided Estuary." J. Coastal Research. (Submitted)

Zheng L, C Chen, and H Liu. 2003. “A Modeling Study of the Satilla River Estuary, Georgia. Part I: Flooding/Drying Process and Water Exchange Over the Salt Marsh-Estuary-Shelf Complex." Estuaries 26(3):651-669. 